DANIEL BROOKE PEIG

\title{
MODELO PARA OTIMIZAÇÃO DO PROJETO DE SISTEMAS DE ULTRAFILTRAÇÃO
}

\author{
Dissertação apresentada à Escola \\ Politécnica da Universidade de São Paulo \\ para a obtenção do título de Mestre pelo \\ departamento de Engenharia Hidráulica e \\ Ambiental, em Saneamento Ambiental. \\ Área de concentração: \\ Engenharia Hidráulica \\ Orientador: \\ Prof. Dr. José Carlos Mierzwa
}


DANIEL BROOKE PEIG

\title{
MODELO PARA OTIMIZAÇÃO DO PROJETO DE SISTEMAS DE ULTRAFILTRAÇÃO
}

\author{
Dissertação apresentada à Escola \\ Politécnica da Universidade de São Paulo \\ para a obtenção do título de Mestre pelo \\ departamento de Engenharia Hidráulica e \\ Ambiental, em Saneamento Ambiental. \\ Área de concentração: \\ Engenharia Hidráulica \\ Orientador: \\ Prof. Dr. José Carlos Mierzwa
}


Este exemplar foi revisado e alterado em relação à versão original, sob responsabilidade única do autor e com a anuência de seu orientador.

São Paulo, 20 de maio de 2011.

Assinatura do autor

Assinatura do orientador

FICHA CATALOGRÁFICA

Peig, Daniel Brooke

Modelo para otimização do projeto de sistemas de ultrafiltração / D.B. Peig. -- ed.rev. -- São Paulo, 2011.

$117 \mathrm{p}$.

Dissertação (Mestrado) - Escola Politécnica da Universidade de São Paulo. Departamento de Engenharia Hidráulica e Ambiental.

1.Engenharia sanitária e ambiental 2.Tratamento de água 3.Ultrafiltração (Sistemas) 4.Otimização matemática I.Universidade de São Paulo. Escola Politécnica. Departamento de Engenharia Hidráulica e Ambiental II.t. 


\section{AGRADECIMENTOS}

Aos meus pais, irmãos e à Simone Jesus pela paciência e incentivo ao longo dos anos de pós-graduação.

Ao Engenheiro José Roberto Ramos pelo suporte ao meu desenvolvimento profissional desde o início da minha carreira na área de tratamento de água e efluentes.

Ao professor José Carlos Mierzwa pela orientação e pela tranqüilidade transmitida ao longo de todo o curso.

À Perenne Equipamentos e Sistemas de Água S/A pelas informações técnicas cedidas, pelas horas investidas na capacitação de seus colaboradores e por todo o suporte dado aos institutos de pesquisa e iniciativas de desenvolvimento tecnológico no Brasil. 


\section{RESUMO}

A proposta deste trabalho foi a concepção de um modelo para o dimensionamento otimizado de sistemas para tratamento de água baseados na tecnologia de Ultrafiltração com membranas de fibra-oca pressurizadas. O modelo relaciona o comportamento das membranas com a qualidade da água bruta através de resultados de ensaios em unidade piloto ou de bancada e equações de bloqueio de poros. A validação desta relação foi realizada através da análise dos dados de uma planta piloto operada em dois períodos distintos em regimes de fluxo variando de 60 a $70 \mathrm{~L} / \mathrm{m}^{2}$.h e alimentada com água bruta proveniente de um manancial de superfície. Os resultados apontaram para a predominância do mecanismo de obstrução através da formação de torta e indicaram uma boa aderência das equações do modelo físico à realidade observada. Variáveis econômicas foram incorporadas ao modelo de forma a permitir a otimização através da busca do mínimo custo total de propriedade. Uma análise de sensibilidade demonstrou que os parâmetros de projeto mais impactantes no custo total, quantidade de membranas, duração do ciclo de filtração e duração do ciclo de contralavagem, podem variar seu peso em diferentes regiões do mundo influenciando o dimensionamento. Outras variáveis de projeto como a vazão de ar de limpeza demonstraram ser pouco significantes para a redução do custo total. A otimização do modelo foi realizada através de um algoritmo de busca numérica para as variáveis de duração do ciclo de filtração e quantidade de membranas, os resultados a partir das informações colhidas na planta piloto levaram a um projeto arrojado, porém dentro das recomendações gerais dos fabricantes de membranas. Como conclusão é possível afirmar que o modelo de dimensionamento do projeto é capaz de reduzir os custos totais de uma estação de tratamento de água baseada na tecnologia de ultrafiltração além de demonstrar potencial para a otimização dinâmica de plantas já instaladas.

Palavras-chave: Tratamento de água. Ultrafiltração. Otimização. Projeto. 


\begin{abstract}
The goal of this work was the development of an optimal design model for water treatment plants based in the pressurized hollow-fiber ultrafiltration membrane technology. The model uses operational data from pilot plants or bench scale units as input and pore blocking equations to predict the behavior of the membranes. The correlation between the fouling model adopted and the pilot plant results was evaluated using a pilot plant operated in two different time frames with flux rates from $60 \mathrm{~L} / \mathrm{m}^{2} \mathrm{~h}$ to $70 \mathrm{~L} / \mathrm{m}^{2} \mathrm{~h}$ and fed with raw water from a lake. The results from this validation have shown that the major fouling mechanism is the cake filtration and the theoretical curves had a good fitting with the operational data. To allow the cost optimization, economic variables were added to the model. A sensitivity analysis demonstrated that the most significant design parameters on the overall cost were the membrane area, the duration of the filtration cycle and the duration of the backwash cycle. According to the analysis, since the costs of the commodities and membranes are different from a region to the other, the optimal system design will also be different. Other design parameters like the membrane aeration rate have shown almost no impact on the total operating cost. The model optimization for the membrane quantity and the filtration cycle duration was based on bi-dimensional discrete numeric algorithm. The results from the optimization using the pilot plant data were compatible with the typical ranges and limits proposed by the membrane manufacturers. The design model proposed was able to reduce the total costs of new plants and demonstrated a good potential for the dynamic optimization of existing plants.
\end{abstract}

Keywords: Water treatment. Ultrafiltration. Optimization. Design. 


\section{LISTA DE FIGURAS}

Figura 3.1 Diagrama dos módulos de membranas de fibra oca disponíveis no mercado.

Figura 3.2 Fluxograma de sistemas com membranas pressurizadas de fluxo tangencial.

Figura 3.3 Fluxograma de sistemas com múltiplos estágios e recirculação.

Figura 3.4 Fluxograma de sistema de múltiplos estágios sem recirculação parcial.

Figura 3.5 Fluxograma de sistema com membranas submersas.

Figura 3.6 Fluxograma de sistemas com membranas pressurizadas e filtração convencional.

Figura 3.7 Representação simulada do comportamento teórico da resistência em sistemas de filtração dead-end em função do acúmulo de sólidos ao longo do tempo.

Figura 3.8 Similaridades físicas entre os módulos de membranas de diferentes fabricantes.

Figura 3.9 Efeito da pressão sobre membranas de ultrafiltração e a formação da camada gel.

Figura 3.10

Bloqueio completo de poros.

Figura 3.11

Bloqueio padrão de poros.

Figura 3.12 Bloqueio intermediário de poros. 29

Figura 3.13 Filtração em torta. 30

Figura 3.14 Comportamento da resistência em função do volume filtrado para cada mecanismo de retenção de partículas.

$\begin{array}{lll}\text { Figura } 4.1 & \text { Fluxograma de trabalho. } & 44\end{array}$

Figura 4.2 Fluxograma do processo genérico de ultrafiltração. 46

Figura 4.3 Processo de dimensionamento econômico. 53

Figura 4.4 Unidade de ultrafiltração e módulo instalado. 60

Figura 4.5 Fluxograma simplificado do processo de tratamento e da Unidade Piloto.

Figura 4.6 Localização da captação, descarte de permeado/concentrado e planta piloto na Raia Olímpica da USP.

Figura 4.7 Matriz de origem contendo todas as possíveis combinações de resultados para a função $F(x, y)$.

Figura 4.8 Matriz de resultados com todas as ocorrências do valor mínimo 
para a função objetivo.

Figura 4.9 Composição do modelo de dimensionamento na forma de planilha de cálculo.

Figura 5.1 Atuação do coeficiente K1 sobre o perfil de resistência das membranas.

Figura 5.2 Equacionamento e encadeamento lógico do modelo físico.

Figura 5.3 Equacionamento e encadeamento lógico do modelo econômico.

Figura 5.4 Contribuição dos fatores econômicos no TCO de um sistema instalado no Brasil com a cobrança pelo uso da água e lançamento de efluentes instaurada.

Figura 5.5 Contribuição dos fatores econômicos no TCO de um sistema instalado no Brasil sem a cobrança pelo uso da água e lançamento de efluentes instaurada.

Figura 5.6 Contribuição dos fatores econômicos no TCO de um sistema instalado na Holanda.

Figura 5.7 Variação da turbidez da alimentação e do permeado ao longo do primeiro período de operação do piloto.

Figura 5.8 Turbidez da alimentação e do permeado no segundo período de operação do piloto.

Figura 5.9 Resistência ao longo da operação do sistema com água pura.

Figura 5.10 Sobreposição de curvas de pressão em função da duração do ciclo.

Figura 5.11 Variação da resistência das membranas ao longo do ciclo de filtração.

Figura 5.12 Formação de depósitos ao longo da operação.

Figura 5.13 Variação da resistência ao longo das fases do segundo período de operação da planta.

Figura 5.14 Determinação do coeficiente C e m nas fases III, IV e V.

Figura 5.15 Determinação do coeficiente C e m nas fases VI a IX.

Figura 5.16 Linearização das curvas da resistência $(R)$ em função do volume filtrado para as fases III a $\mathrm{V}$.

Figura 5.17 Linearização das curvas da resistência (R) em função do volume filtrado para as fases VI a IX.

Figura 5.18 Representação do comportamento do custo total de operação em função da duração do ciclo para um caso genérico a partir do 
modelo proposto.

Figura 5.19 Representação do comportamento do custo total de operação em função da quantidade de membranas para um caso genérico a partir do modelo proposto.

Figura 5.20 Algoritmo de otimização da quantidade de membranas e duração do ciclo. 


\section{LISTA DE TABELAS}

Tabela 3.1 Tecnologias para a remoção de sólidos na água.

Tabela 3.2 Comparativo entre membranas para saneamento

Tabela 3.3 Etapas de operação de sistemas de membranas.

Tabela 3.4 Equações de Hermia para a resistência da membrana.

Tabela 3.5 Composição dos custos operacionais segundo a literatura.

Tabela 4.1 Correlação entre os parâmetros de projeto e variáveis de entrada necessárias ao cálculo.

Tabela 4.2 Fases de operação da unidade piloto de Ultrafiltração.

Tabela 4.3 Condições da contralavagem.

Tabela 4.4 Freqüência e dados coletados ao longo da operação.

Tabela 5.1 Componentes do CAPEX influenciados pelas características do processo.

Tabela 5.2 Componentes do OPEX influenciados pelas características do processo.

Tabela 5.3 Escala das variáveis aperfeiçoáveis na análise de sensibilidade.

Tabela 5.4 Custos unitários para calibração do modelo de dimensionamento tendo como referência de fornecimento um consumidor industrial instalado região do Vale do Paraíba.

Tabela 5.5 Custos dos insumos na Holanda convertidos.

Tabela 5.6 Análise de sensibilidade para sistema instalado no Brasil COM COBRANÇA pela captação da água e lançamento de efluentes.

Tabela 5.7 Análise de sensibilidade para sistema instalado no Brasil SEM COBRANÇA pela captação da água e pelo lançamento de efluentes.

Tabela 5.8 Análise de sensibilidade para sistema instalado na Holanda.

Tabela 5.9 Resultados da regressão linear e exponencial dos dados operacionais.

Tabela 5.10 Coeficientes obtidos nas diferentes fases de operação da unidade piloto.

Tabela 5.11 Resultado da otimização com variação do coeficiente K1.

Tabela 5.12 Resultados da otimização dentro dos limites dos fabricantes para dois cenários econômicos. 


\section{LISTA DE ABREVIATURAS E SÍMBOLOS}

\begin{tabular}{|c|c|}
\hline$\Delta \mathrm{P}$ & Diferencial de pressão (Pa) \\
\hline$\Delta \mathrm{P}_{0}$ & Diferencial de pressão na membrana limpa (Pa) \\
\hline$\Delta \mathrm{P}_{\text {máx }}$ & Diferencial de pressão máximo admitido pela membrana (Pa) \\
\hline$\mu$ & Viscosidade dinâmica da água (Pa.s) \\
\hline A & Área total de membranas instaladas ( $\left.\mathrm{m}^{2}\right)$ \\
\hline$A_{m}$ & Área do elemento individual de membranas $\left(\mathrm{m}^{2}\right)$ \\
\hline C & Fator de formação de depósitos (metro(“m”-2) \\
\hline $\mathrm{C}_{\mathrm{aa}}$ & Custo anual da água captada (\$/ano) \\
\hline CAPEX & Custos de capital $(\$)$ \\
\hline $\mathrm{C}_{\mathrm{da}}$ & Custo anual da disposição de efluentes (\$/ano) \\
\hline $\mathrm{C}_{\mathrm{e}}$ & Custo unitário da energia elétrica (\$/kWh) \\
\hline $\mathrm{C}_{\mathrm{ea}}$ & Custos de energia anuais (\$/ano) \\
\hline $\mathrm{C}_{\mathrm{m}}$ & Custo unitário das membranas (\$/membrana) \\
\hline $\mathrm{C}_{\mathrm{ma}}$ & Custo anual das membranas de reposição (\$/ano) \\
\hline $\mathrm{C}_{\mathrm{qa}}$ & Custo anual dos produtos químicos (\$/ano) \\
\hline $\mathrm{D}_{\mathrm{cg}}$ & Dosagem de coagulante (mg/L) \\
\hline $\mathrm{D}_{\mathrm{cl}}$ & Dosagem de cloro contínua (mg/L) \\
\hline$D_{\text {clb }}$ & Dosagem de cloro na contralavagem (mg/L) \\
\hline$E$ & Consumo energético do ciclo de filtração $(\mathrm{J})$ \\
\hline e & Valor da elasticidade na análise de sensibilidade (adimensional) \\
\hline $\mathrm{E}_{\mathrm{a}}$ & Consumo energético do soprador de ar $(\mathrm{J})$ \\
\hline $\mathrm{E}_{\mathrm{b}}$ & Consumo energético da bomba de contralavagem (J) \\
\hline i & Taxa de juros anual \\
\hline I & Índice de fouling para o cálculo do $\mathrm{MFI}\left(\mathrm{m}^{-2}\right)$ \\
\hline $\mathrm{Im}$ & Intervalo entre limpezas químicas de manutenção (dias) \\
\hline $\mathrm{J}$ & Fluxo de água através da membrana (m³/m².s) \\
\hline $\mathrm{J}_{0}$ & Fluxo de água através da membrana limpa (m³/m².s) \\
\hline $\mathrm{J}_{\mathrm{b}}$ & Fluxo de contralavagem $\left(\mathrm{m}^{3} / \mathrm{m}^{2} . \mathrm{s}\right)$ \\
\hline $\mathrm{K}_{0}$ & Constante de formação de depósitos $\left(\mathrm{s}^{-1}\right)$ \\
\hline
\end{tabular}


$\mathrm{K}_{1} \quad$ Coeficiente de aumento de resistência ao fim da vida útil

m Mecanismo de acúmulo de sólidos predominante

$\mathrm{M}_{\mathrm{cg}} \quad$ Consumo de coagulante $(\mathrm{kg} / \mathrm{h})$

$\mathrm{M}_{\mathrm{cl}} \quad$ Consumo de cloro $(\mathrm{kg} / \mathrm{h})$

$\mathrm{MFI} \quad$ Índice de Fouling Modificado $\left(\mathrm{s} / \mathrm{L}^{2}\right)$

N Quantidade de elementos de membranas instalados

$\mathrm{Pa}_{\mathrm{a}} \quad$ Pressão do ar na saída do soprador $(\mathrm{Pa})$

$\mathrm{P}_{\mathrm{atm}} \quad$ Pressão atmosférica $(\mathrm{Pa})$

Q Vazão de permeado de projeto $\left(\mathrm{m}^{3} / \mathrm{s}\right)$

Qae Vazão de ar específica por módulo $\left(\mathrm{Nm}^{3} / \mathrm{h}\right)$

$\mathrm{Q}_{\mathrm{b}} \quad$ Vazão de contralavagem $\left(\mathrm{m}^{3} / \mathrm{s}\right)$

$\mathrm{Q}_{\mathrm{f}} \quad$ Vazão de alimentação $\left(\mathrm{m}^{3} / \mathrm{s}\right)$

$\mathrm{Q}_{\mathrm{p}} \quad$ Vazão de permeado desejada $\left(\mathrm{m}^{3} / \mathrm{s}\right)$

Qreqd Vazão de produto desejada ( $\left.\mathrm{m}^{3} / \mathrm{s}\right)$

$\mathrm{R} \quad$ Resistência à passagem da água $\left(\mathrm{m}^{-1}\right)$

$\mathrm{R}_{0} \quad$ Resistência da membrana $\left(\mathrm{m}^{-1}\right)$

$\mathrm{R}_{\mathrm{a}} \quad$ Resistência dos depósitos adsorvidos $\left(\mathrm{m}^{-1}\right)$

$\mathrm{R}_{\mathrm{c}} \quad$ Resistência da camada de torta $\left(\mathrm{m}^{-1}\right)$

$\mathrm{S} \quad$ Modo de operação do processo

SI $\quad$ Valor do índice de sensibilidade (\$)

Duração da etapa de filtração (s)

$\mathrm{t}_{\mathrm{a}} \quad$ Duração da etapa de aeração (s)

$\mathrm{T}_{\mathrm{a}} \quad$ Temperatura do ar na alimentação do soprador $\left({ }^{\circ} \mathrm{C}\right)$

$t_{b} \quad$ Duração da etapa de contralavagem (s)

$t_{d} \quad$ Duração da etapa de drenagem (s)

$t_{f} \quad$ Duração do período de enxágue/pré-operação (s)

$\mathrm{t}_{\mathrm{m}} \quad$ Duração da limpeza química de manutenção (s)

$\mathrm{t}_{\mathrm{t}} \quad$ Duração total do ciclo (s)

U Vida útil do equipamento (anos)

$U_{\mathrm{m}} \quad$ Vida útil das membranas (anos)

$\checkmark \quad$ Volume de água produzida durante o ciclo de filtração $\left(\mathrm{m}^{3}\right)$

$V_{b} \quad$ Volume de água consumida na operação de contralavagem $\left(\mathrm{m}^{3}\right)$

$V_{d} \quad$ Volume de água consumida durante a drenagem das membranas $\left(m^{3}\right)$ 
VPU Fator de valor presente uniforme

W Consumo energético médio da planta $(\mathrm{kW})$

$X \quad$ Valor da variável de entrada na análise de sensibilidade (unidade)

Y Recuperação de água (\%)

Y Valor da função objetivo na análise de sensibilidade (\$)

$\eta \quad$ Rendimento do conjunto bomba/motor

$\eta_{\mathrm{a}} \quad$ Rendimento global do soprador de ar (mecânico + elétrico)

$\omega \quad$ Volume específico de água permeada $\left(\mathrm{m}^{3} / \mathrm{m}^{2}\right)$

$\gamma \quad$ Trajetória da formação de depósitos na membrana 


\section{SUMÁRIO}

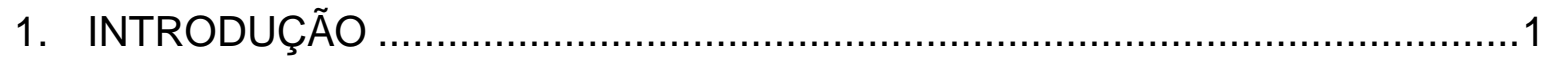

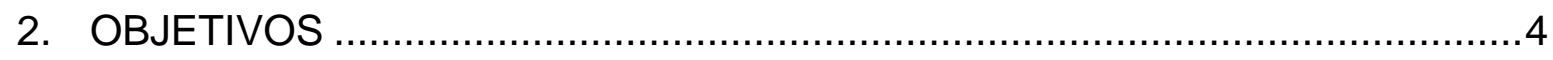

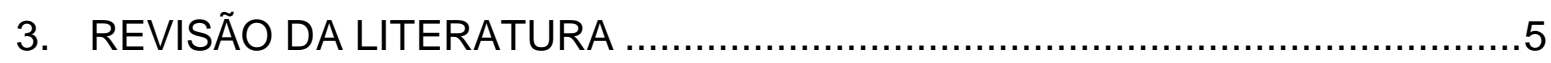

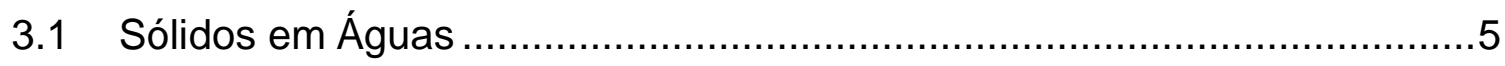

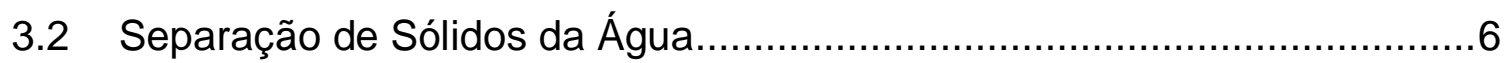

3.3 Processos de separação por membranas.......................................... 8

3.4 Membranas de Micro e Ultrafiltração .................................................11

3.5 Configuração dos sistemas de ultrafiltração ......................................14

3.6 Princípios de operação das membranas..........................................24

3.7 Dimensionamento econômico de sistemas de ultrafiltração .....................34

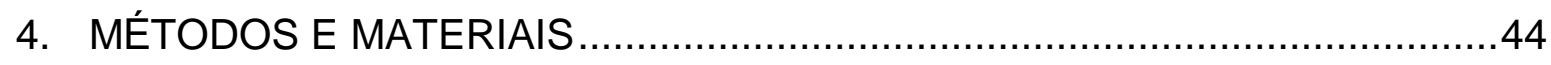

4.1 Metodologia de desenvolvimento.............................................44

4.2 Definição do processo de ultrafiltração genérico a ser modelado .............45

4.3 Considerações para a concepção do modelo de dimensionamento .........48

4.4 Métodos utilizados para a análise de sensibilidade .............................54

4.5 Metodologia utilizada para a determinação dos parâmetros de

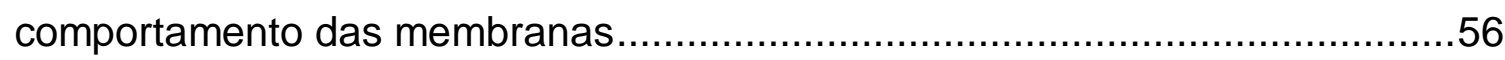

4.6 Unidade piloto de ultrafiltração................................................ 58

4.7 Método para a otimização discreta da função custo ................................64

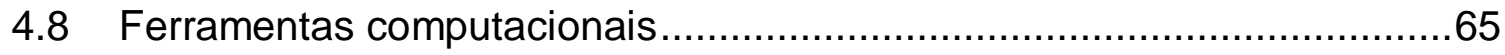

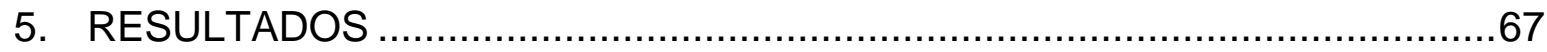

5.1 Concepção do Modelo Físico.................................................67

5.2 Concepção do Modelo Econômico: Custos de Capital ..............................76

5.3 Concepção do Modelo Econômico: Custos Operacionais ......................78

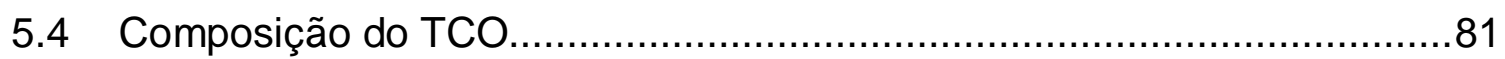

5.5 Equacionamento completo do modelo ...................................... 81

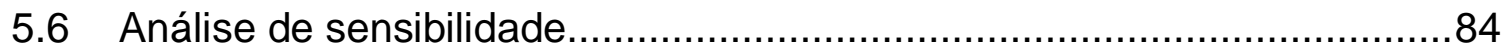

5.7 Análise de consistência do modelo físico.......................................91

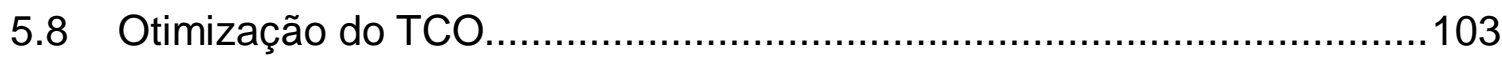




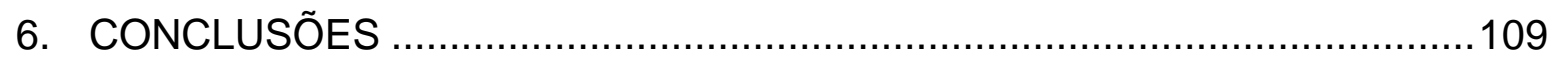

7. RECOMENDAÇÕES PARA ESTUDOS FUTUROS .....................................112

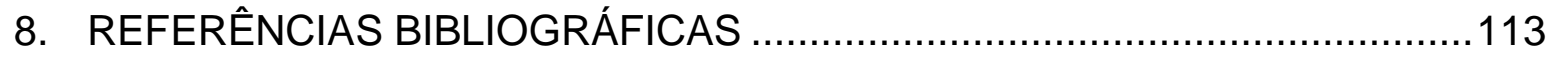




\section{INTRODUÇÃO}

A crescente demanda por água e o problema da poluição dos mananciais têm continuamente fomentado a busca por tecnologias capazes de remover os contaminantes de forma segura com custos e impactos ambientais aceitáveis.

$\mathrm{Na}$ área de saneamento ambiental, a crescente preocupação com a remoção de patógenos (MWH, 2004) e a presença de micropoluentes em mananciais poluídos (MIERZWA, 2009) levou à busca por processos alternativos de tratamento de águas.

Neste contexto, foram introduzidos os processos baseados em membranas de ultrafiltração. Esta tecnologia, utilizada desde a década de 1950 em processos industriais (MILLIPORE, 2010) passou, na década de 1980, a ser estudada como alternativa para o tratamento de água de abastecimento em substituição aos sistemas físico-químicos convencionais, nos dias atuais vem cada vez mais sendo adotada em estações de tratamento públicas e industriais (AWWA, 1999).

Para abastecimento público, os sistemas de membranas apresentam diversas vantagens em relação aos processos convencionais de tratamento, principalmente quanto à qualidade do produto final permitindo atender aos requisitos mais restritivos das novas regulamentações referentes ao tratamento de água (AWWA, 1999; EPA 2001).

Apesar da qualidade superior do produto final, sistemas baseados em membranas ainda contam com custos de implantação elevados se comparados aos processos convencionais. Em um estudo recente Mierzwa (2008) estimou e comparou os custos do tratamento no Brasil de um processo convencional ao de membranas obtendo uma diferença de 100\% no valor da água justificando a adoção da tecnologia apenas em casos aonde é necessária uma maior eficiência na remoção de contaminantes. A diferença entre os valores refere-se principalmente ao elevado grau de automação e ao custo das membranas, importadas. 
A peça tecnológica chave dos processos de ultrafiltração ou microfiltração é a membrana, uma estrutura sintética construída usualmente com base em polímeros que tem como característica principal os poros de diâmetro uniforme, da ordem de centésimos de micrômetros. As membranas de micro e de ultrafiltração são baseadas em tecnologias proprietárias e, até o momento, não há normas que padronizam estes componentes. Desta forma, poucas empresas ao redor do mundo dominam as técnicas de síntese de membranas em escala industrial e cada uma conta com a sua própria linha de produtos com características exclusivas e funcionamento distinto (PEARCE, 2007). Os equipamentos de tratamento são projetados em função das membranas que utilizarão.

Considerando o elevado valor das membranas, tanto para a implantação quanto na ocasião da reposição, a definição da quantidade de membranas pode impactar no custo do tratamento ao longo da vida útil da planta. As boas práticas de projeto recomendam a realização de estudos em escala piloto com duração adequada para a definição dos parâmetros de dimensionamento e da quantidade de elementos. Contudo, em função dos prazos envolvidos para implantação dos sistemas, esta prática dificilmente é adotada pelas empresas de engenharia, que preferem basear os seus projetos nos dados de manuais fornecidos pelos fabricantes de membranas ou em experiências próprias de instalações e projetos anteriormente realizados.

A arbitrariedade nos projetos é intensificada pela ampla gama de opções de membranas e tecnologias existentes no mercado e pelas próprias orientações dos fabricantes sobre os produtos e a sua respectiva aplicação, muitas vezes mantidas sob sigilo industrial ou de difícil acesso, até mesmo por aqueles que participam do projeto das unidades. Quando há disponibilidade de informações e recomendações para o dimensionamento de seus produtos, fornecedores de membranas utilizam em seus manuais de projeto limites conservadores buscando assim garantir a eficácia dos componentes em condições gerais, considerando que, ainda, não é possível prever ou generalizar precisamente todas as condições ambientais dos mananciais aos quais seus produtos serão expostos. 
Por outro lado, mesmo considerando a diversidade do mercado e das tecnologias disponíveis, observa-se que algumas das categorias de equipamentos e processos utilizados no tratamento de água como um todo são muito semelhantes. As pressões de operação estão na mesma escala assim como a área de membranas, permeabilidade dos elementos, operações de limpeza e outras condições de trabalho. Uma das hipóteses para justificar estas semelhanças seria a de que os novos fornecedores de membranas, ao introduzir seus produtos no mercado, baseiam-se em concorrentes já estabelecidos com processos consagrados e aceitos pelos usuários, buscando assim conquistar expansões e a reposição de membranas em plantas já existentes.

Este trabalho parte do princípio de que a identificação de características comuns entre diferentes sistemas e fornecedores de membranas permite estabelecer um modelo físico único, genérico, que poderá ser aplicado no projeto de qualquer sistema baseado no mesmo grupo de configurações. A partir deste modelo físico é possível obter, de uma forma racional, parâmetros para o projeto de unidades de tratamento de água baseadas na tecnologia de ultrafiltração.

A tecnologia dos fabricantes distintos pode ser incorporada no modelo genérico através dos estudos de curta duração e baixos custos, para a avaliação do comportamento da membrana perante a amostra de água do manancial, realizados em unidades piloto ou em células de fluxo. Os limites indicados nos manuais passam a ser condições de contorno e limitantes para os algoritmos de busca da combinação ótima.

O uso de variáveis econômicas locais também possibilita o equilíbrio do dimensionamento aos custos locais. Em regiões em que o custo de água é significativo, como na bacia do Vale do Paraíba do Sul, SP, na qual está instaurada a cobrança pelo uso, o projeto pode privilegiar a recuperação de água, ou seja, minimizar a produção de efluentes. Em regiões afastadas como é o caso dos estados do noroeste e norte do país, a disponibilidade da água é alta, neste caso, a logística de produtos químicos torna estes insumos custosos. O projeto pode então privilegiar o tempo de contralavagem das membranas em detrimento do uso de químicos para a limpeza. 


\section{OBJETIVOS}

Este trabalho tem como objetivo o desenvolvimento de um modelo prático unificado para a otimização do projeto de sistemas de ultrafiltração para tratamento de água e efluentes, passível de adaptação a elementos de diferentes fornecedores.

O modelo unificado deve permitir o dimensionamento ótimo a partir de resultados provenientes de ensaios em piloto ou em células de fluxo, dados fornecidos nos catálogos e manuais das membranas e custos de materiais e insumos para a operação.

De forma a obter um modelo consistente e compatível com o propósito deste trabalho, as seguintes metas foram fixadas:

- Concepção do modelo de dimensionamento;

- Análise de sensibilidade e significância das variáveis envolvidas;

- Validação das equações do modelo através da análise de dados obtidos em plantas reais ou piloto;

- Concepção de um algoritmo para otimização dos parâmetros de projeto de sistemas de Ultrafiltração;

- Avaliação do algoritmo de otimização através da comparação dos resultados com recomendações dos manuais de projeto de sistemas de Ultrafiltração. 


\section{REVISÃO DA LITERATURA}

\subsection{Sólidos em Águas}

Uma das mais importantes características de qualidade das águas, sob o aspecto de tratamento por membranas é o teor de sólidos. Dentro da categoria de sólidos é possível enquadrar desde partículas inorgânicas como areia, argilas, óxidos metálicos e sais até orgânicas como substâncias químicas, bactérias e vírus. As diferentes frações de sólidos na água são usualmente classificadas em função do tamanho das partículas.

O AWWA Standard Methods (1998) divide os sólidos em dois grandes grupos, Sólidos Dissolvidos e Sólidos Suspensos. Ambos são determinados gravimetricamente. Os sólidos suspensos referem-se à fração que fica retida em um

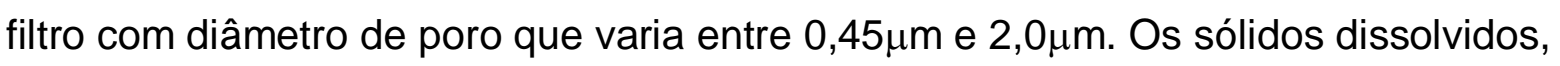
por sua vez, são aqueles que passam pelo filtro. A fração dissolvida, determinada através do método proposto pelo Standard Methods contempla não apenas partículas em solução verdadeira, ou seja, que formam um sistema homogêneo com a água, estão inclusas também as partículas coloidais, de tamanhos entre $10^{-3} \mu \mathrm{m} \mathrm{e}$ $1 \mu \mathrm{m}$ (METCALF \& EDDY, 2003).

Bactérias e protozoários como o Cryptosporidium oocysts encontram-se na faixa das partículas coloidais e sólidos em suspensão. A capacidade dos processos de membranas de micro e ultrafiltração de reter esta categoria de contaminantes foi um dos fatores que mais impulsionou o uso deste tipo de processo no saneamento (MWH, 2004; EPA, 2001). 


\subsection{Separação de Sólidos da Água}

No tratamento de água e efluentes, é possível destacar um grupo de operações unitárias que tem como função a separação de sólidos da água. Dentro desta classe de processos, aplicados em escala industrial, estão: flotação, sedimentação, precipitação, troca iônica, adsorção, absorção e a filtração em meio granular e membranas (MWH, 2004). Outra operação, não mencionada por MWH, porém utilizada na área de saneamento é a evaporação/destilação. Dentre estes processos, resumidamente caracterizados na seqüência, existem operações amplamente utilizadas e conhecidas por engenheiros e projetistas da área de saneamento e outras ainda em fase de expansão. As membranas podem ser utilizadas, a princípio, para a substituição parcial ou total de qualquer uma das tecnologias de separação de sólidos conforme ilustra a tabela 3.1.

Tabela 3.1 - Resumo das tecnologias para a remoção de sólidos na água.

\begin{tabular}{|c|c|c|}
\hline Processo & Ions e metais & $\begin{array}{c}\text { Sólidos Suspensos e } \\
\text { Coloidais }\end{array}$ \\
\hline Flotação & & $\mathrm{X}$ \\
\hline Sedimentação & & $\mathrm{x}$ \\
\hline Precipitação química & $x$ & \\
\hline Troca lônica & $\mathrm{x}$ & \\
\hline Filtração em meio granular & & $x$ \\
\hline Adsorção & $x$ & \\
\hline Evaporação & $x$ & $x$ \\
\hline $\begin{array}{c}\text { Membranas - Osmose Reversa } \\
\text { e Nanofiltração }\end{array}$ & $x$ & \\
\hline $\begin{array}{c}\text { Membranas - Microfiltração e } \\
\text { Ultrafiltração }\end{array}$ & & $x$ \\
\hline
\end{tabular}

Fontes: AWWA 1999, MWH 2004, METCALF \& EDDY 2003, DESSOUKY e ETTOUNEY 2002, BAKER 2004.

A flotação e a sedimentação são baseadas nas diferenças de densidade das partículas sólidas e da água (AWWA, 1999). A utilização destas técnicas é viável, do ponto de vista prático, quando existe um elevado teor de sólidos de densidades significativamente distintas da água. Esta diferença de densidade pode ser uma característica do poluente, como grãos de areia em suspensão que possuem uma elevada densidade ou artificialmente induzida, como na flotação em que bolhas de 
ar são agregadas aos flocos de modo a permitir a sua elevação até a superfície da água.

A precipitação é uma técnica para a remoção de sólidos dissolvidos utilizando como base os limites de solubilidade dos poluentes. Usualmente, em estações de tratamento de água e efluentes, a precipitação é alcançada através da adição de produtos químicos que se combinam com o poluente ou que alteram a sua solubilidade na água. Formam-se então sólidos de dimensões maiores, passíveis de serem removidos por técnicas de sedimentação ou filtração.

A troca iônica é um processo de separação para sólidos dissolvidos. Materiais naturais ou sintéticos com sítios carregados atraem os compostos iônicos dissolvidos na água, liberando outros íons pelos quais possuem menor afinidade. No saneamento, os materiais de troca iônica apresentam-se na forma granular e são utilizados como enchimento de filtros. As principais aplicações são o abrandamento (remoção da dureza), remoção de nitratos, cromo e outros compostos tóxicos como arsênio, fluoretos e percloratos e a desmineralização (AWWA 1999; MWH, 2004). A capacidade de troca dos materiais utilizados neste processo de separação é limitada, ao se esgotar, é necessário descartar o enchimento dos filtros ou, se possível, regenerá-lo através do uso de soluções químicas. Esta característica, inerente do processo, está associada a custos e à geração de resíduos.

A adsorção pode ser definida como a acumulação de substâncias, que estão em solução, em uma interface. Trata-se de uma operação de transferência de massa da fase líquida (água) para a fase sólida (adsorvente). (METCALF \& EDDY, 2003) No tratamento de água, convencionalmente utiliza-se o carvão ativado, que possui uma elevada área superficial, como adsorvente para a remoção de compostos orgânicos ou para a remoção de cloro livre através de reações de óxido-redução.

A evaporação tem sido adotada como uma alternativa para a dessalinização de água do mar ou em aplicações que requerem água com alto grau de pureza, como na indústria farmacêutica. Através de processos de evaporação em múltiplos estágios ou evaporação parcial (flash) seguida de condensação do vapor, é possível 
obter água com teores de sólidos dissolvidos inferiores a 10 mg/L (DESSOUKY; ETTOUNEY, 2002).

Dentre os processos mais utilizados para a remoção de sólidos em estações de tratamento de água, complementando processos anteriores de sedimentação ou flotação está a filtração em meio granular. Os filtros são tanques ou vasos preenchidos com material granular, usualmente areia e carvão antracito. Os sólidos, ao passarem através do meio são retidos por diferentes mecanismos como o efeito de coar, aderência aos grãos do meio filtrante e degradação biológica (filtros lentos). Os filtros de areia são uma forma eficiente e consagrada para a remoção de sólidos suspensos e material coloidal. BAKER (2004) situa a capacidade de retenção dos processos de filtração convencionais em meio granular entre 10 e 100 micrômetros.

\subsection{Processos de separação por membranas}

Pela definição apresentada em MWH (2004) "Os processos de membranas são técnicas modernas de separação físico-química que utilizam diferenças de permeabilidade (dos constituintes da água) como mecanismo de separação". A IUPAC (1996) apresenta as membranas como "estruturas que possuem dimensões laterais muito superiores à espessura através das quais ocorre o transporte de massa sob diversos tipos de força motriz".

As membranas têm sido utilizadas no tratamento de água e efluentes desde a década de 1960. As primeiras plantas de grande porte, para o abastecimento urbano eram baseadas na tecnologia de Osmose Reversa para a dessalinização de água do mar e de poços. Atualmente as membranas são utilizadas para a separação de sólidos em suspensão e sólidos dissolvidos da água. (METCALF \& EDDY, 2003).

Existem quatro processos desenvolvidos em escala industrial para a separação através de membranas, a microfiltração, a ultrafiltração, a osmose reversa/nanofiltração e a eletrodiálise. Os três primeiros processos baseiam-se em gradiente de pressão como força motriz. A eletrodiálise baseia-se na diferença de 
potencial elétrico. Todos estes processos são bem estabelecidos e o mercado é servido por diversos fabricantes. (BAKER, 2004).

As membranas de micro e ultrafiltração são amplamente aplicadas na indústria, em processos de tratamento de efluentes ou concentração de compostos de interesse (como vinho, sucos, pigmentos ou soro de leite). No saneamento, por sua capacidade de retenção de microorganismos e clarificação, são utilizadas como alternativa ao tratamento físico químico convencional para águas de abastecimento e no tratamento de efluentes (EPA,2001). Estas membranas são tidas como a "melhor tecnologia disponível" em países cuja legislação restritiva impede ou encarece os processos convencionais como é o caso dos EUA. Alguns autores classificam estes processos como processos de "baixa pressão" (DOW, 2004; EPA 2001).

As membranas de micro e ultrafiltração são as que possuem a maior diversidade de configurações, materiais, arranjos e aplicações. Ainda não há consenso sobre o tamanho de poro exato que distingue as membranas de micro e ultrafiltração. Diferentes fornecedores apresentam produtos de micro e ultrafiltração dentro de uma mesma faixa de diâmetros de corte. Em geral, as membranas de microfiltração são capazes de reter partículas com diâmetros superiores a 0,1 micrômetros, as membranas de ultrafiltração, por sua vez, têm um diâmetro de corte da ordem de 0,1 micrômetros até 2nm (IUPAC, 1996) e permitem remover, além de bactérias, alguns tipos de vírus e moléculas orgânicas com massa molecular elevada (EPA,2001). Como a metodologia de projeto é similar, bem como as configurações, arranjos e mecanismos de separação (BAKER, 2004), é possível enquadrar a ultrafiltração e a microfiltração em uma mesma categoria, a de filtração em meios porosos.

De forma a simplificar a interpretação deste texto, em alguns trechos apenas o termo "ultrafiltração" será utilizado. Toda a metodologia, todavia, também é aplicável á membranas de microfiltração em virtude da similaridade entre os dois processos.

As membranas de nanofiltração e osmose reversa são utilizadas para a remoção de compostos de baixo peso molecular e íons das águas. Em saneamento servem à aplicação de dessalinização de poços com águas salobras, dessalinização de água 
do mar, remoção de dureza, nitratos, flúor, metais e outros compostos tóxicos. As membranas de Osmose Reversa permitem a remoção de até 99,5\% do Cloreto de Sódio presente na água e foi nomeada pela associação americana de proteção ao meio ambiente (EPA) como uma das melhores tecnologias disponível para remover compostos orgânicos diversos da água (EPA, 2001).

A separação por Osmose Reversa ou Nanofiltração recebe segundo alguns autores, a definição de processo de "alta pressão" em decorrência da elevada pressão de alimentação necessária para a produção de permeado, entre 6 e 80 bar. Outra classificação utilizada para este grupo de membranas é a de filtração em meio não poroso ou membranas densas. Os fenômenos que regem este tipo de separação são explicados pelo modelo de transporte em solução-difusão. (CHERYAN, 1998).

Embora possuam a mesma composição, formato e padrões, as membranas de Osmose Reversa diferenciam-se das de Nanofiltração, pois são capazes de reter com maior eficiência os íons monovalentes das águas (Cloreto, Sódio, etc..) enquanto que as membranas de Nanofiltração rejeitam íons bivalentes e de maior massa molecular (Cálcio, Magnésio, Ferro, etc..). O dimensionamento econômico e a aplicação das membranas de Osmose Reversa e Nanofiltração são muito bem definidos e desenvolvidos. Cada fabricante disponibiliza programas computacionais próprios para o cálculo da quantidade de membranas e previsão das condições de operação, em função da composição iônica da água que alimenta o sistema, sendo que alguns possibilitam obter a estimativa do custo de tratamento. Cabe ressaltar que estes modelos ainda não são capazes de prever as possíveis interações físicoquímicas entre compostos presentes na água e o os materiais da membrana e tampouco o crescimento microbiano que pode afetar negativamente a operação.

A eletrodiálise é um processo de separação de íons da água que utiliza como força motriz a diferença de potencial elétrico entre dois eletrodos e membranas carregadas positivamente ou negativamente como meio de separação. Os íons presentes na água tendem a migrar para os eletrodos de carga oposta, as membranas seletivas permitem apenas a passagem de íons com cargas opostas à da membrana. A eletrodiálise tem sido utilizada em unidades de grande porte para a dessalinização de água salobra. Trata-se de uma alternativa econômica à Osmose 
Reversa em situações em que se tem um baixo teor de sais na água de alimentação ou em que não é necessária uma rejeição elevada já que a eficiência deste processo na separação do Cloreto de Sódio varia entre 85\% e 95\% (DOW, 2004).

\subsection{Membranas de Micro e Ultrafiltração}

As membranas de micro e ultrafiltração estão disponíveis em inúmeras formas, estruturas porosas e materiais. Metcalf e Eddy (2003) apresenta uma extensa coletânea das características que definem estas membranas. Para fins de projeto e dimensionamento de equipamentos, a classificação por arranjo físico das membranas é importante. Atualmente existem quatro configurações principais de membranas de baixa pressão para a aplicação no tratamento de água e efluentes: Tubulares, Fibra Oca, Placas planas e em Espiral (METCALF E EDDY, 2003) sendo que a IUPAC (1996) divide os módulos em apenas três categorias: Fibras Ocas, Placas planas e em Espiral.

Estudos mais complexos sobre estas configurações são raros no meio científico uma vez que o desenvolvimento dos módulos costuma ser protegido por patentes, ainda assim, Howe et al. (2007) realizaram um comparativo entre membranas de fibra oca e em folhas planas e identificou diferenças significativas entre o desempenho dos dois formatos quanto ao comportamento mediante o acúmulo de sólidos na superfície e eficácia da lavagem.

As membranas tubulares apresentam-se na forma de cilindros com diâmetros de alguns milímetros até 1 polegada (AWWA, 2005). A água bruta alimenta o tubo em uma das extremidades e o permeado é coletado externamente. Trata-se da configuração de membranas de ultrafiltração mais antiga, amplamente aplicada na indústria alimentícia e na recuperação de pigmentos e metais, através delas é possível tratar líquidos com elevadas concentrações de sólidos suspensos. No interior dos tubos, elevadas velocidades impedem acúmulo de sólidos na superfície das membranas. Esta configuração possui uma baixa densidade de empacotamento uma vez que a relação área de membranas / volume do equipamento está entre 140 e $310 \mathrm{~m}^{2} / \mathrm{m}^{3}$ (MWH, 2004). 
As membranas de fibra oca são compostas por um feixe de pequenos tubos, com um diâmetro interno de 0,4 a 1,5 mm (AWWA, 2005). Em geral o fluxo de água ocorre da parte externa das fibras para a parte interna ou no sentido inverso, conforme ilustra a Figura 3.1. Esta é a configuração mais comum em sistemas de tratamento de água (EPA, 2001). A alta densidade de empacotamento, de $1200 \mathrm{a}$ $1700 \mathrm{~m}^{2} / \mathrm{m}^{3}$ (MWH, 2004) permite o uso de sistemas compactos.
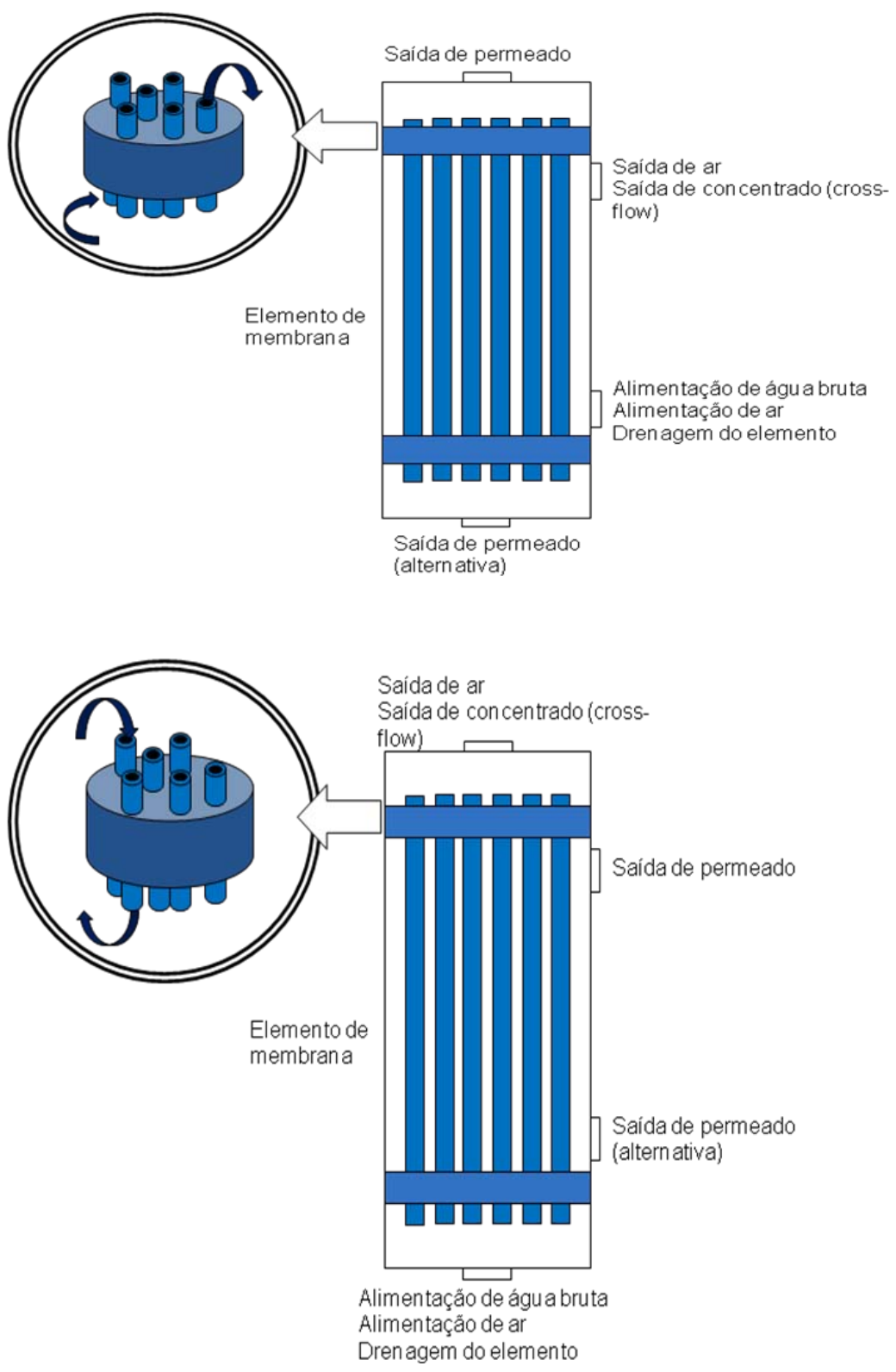

Figura 3.1 - Diagrama dos módulos de membranas de fibra oca disponíveis no mercado (ilustrações do próprio autor) 
Os elementos de membranas em placas planas, com duas folhas de membranas coladas sobre as faces de um suporte polimérico rígido, têm sido amplamente utilizados no tratamento de efluentes, em especial em processos que combinam o tratamento biológico com as técnicas de separação em membranas (Biorreatores de Membranas), pois apresentam uma elevada resistência mecânica e construção relativamente simples. A densidade de empacotamento desta opção, todavia, é muito menor que no caso dos sistemas de fibras ocas.

Os elementos de membranas em espiral são montados a partir do enrolamento de folhas planas de membranas em um tubo. A água alimenta os elementos tangencialmente e é coletada no tubo central, a circulação da água previne o acúmulo de sólido nas telas que separam as folhas. Permitem uma densidade de empacotamento superior aos conjuntos de placas planas, entre 700 e $1000 \mathrm{~m}^{2} / \mathrm{m}^{3}$. Esta configuração é típica nos elementos de Nanofiltração e Osmose Reversa, comercialmente disponíveis. 


\subsection{Configuração dos sistemas de ultrafiltração}

O arranjo dos sistemas de ultrafiltração (e microfiltração) industriais é variado, todavia, as configurações de processo a seguir tem sido as mais usuais para sistemas baseados em membranas espirais e de fibra oca.

\subsubsection{Membranas pressurizadas com fluxo tangencial (cross-flow) e com recirculação}

Nesta configuração, a membrana permeia apenas uma pequena porcentagem da água que alimenta o elemento. Parte do concentrado é descartada para garantir o balanço de massa de sólidos no sistema (operação contínua). A outra parte do concentrado, maior vazão, entra em um circuito de recirculação em alta velocidade. O objetivo desta condição de recirculação é a remoção de sólidos acumulados na superfície da membrana através da turbulência e forças de cisalhamento.

Este tipo de arranjo é utilizado em sistemas com membranas tubulares ou em espiral. A necessidade de recirculação em altas velocidades é a responsável pela maior parte do consumo energético deste processo, uma forma de reduzir este consumo é a utilização de duas bombas, uma de baixa vazão e maior carga, para a alimentação do circuito de recirculação e fornecimento da pressão para a filtração e outra bomba de baixa carga e alta vazão para o circuito de recirculação, conforme ilustra a Figura 3.2. 


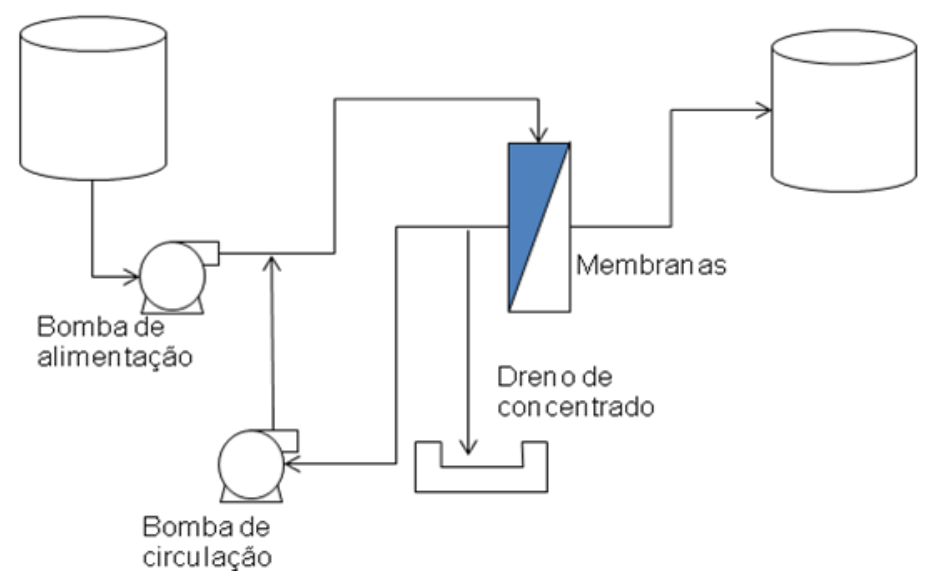

Figura 3.2 - Fluxograma de sistemas com membranas pressurizadas de fluxo tangencial (ilustração do próprio autor)

\subsubsection{Membranas pressurizadas com fluxo tangencial (cross-flow) com recirculação e múltiplos estágios}

Esta configuração pouco utilizada em sistemas de tratamento de água e efluentes em função de sua complexidade, porém é aplicada em larga escala em processos industriais. Consiste em acoplar mais de um circuito de membranas pressurizadas do tipo cross-flow com recirculação em série (Figura 3.3). BAKER (2004) apresenta como vantagens deste arranjo a possibilidade reduzir a área total de membranas do sistema.

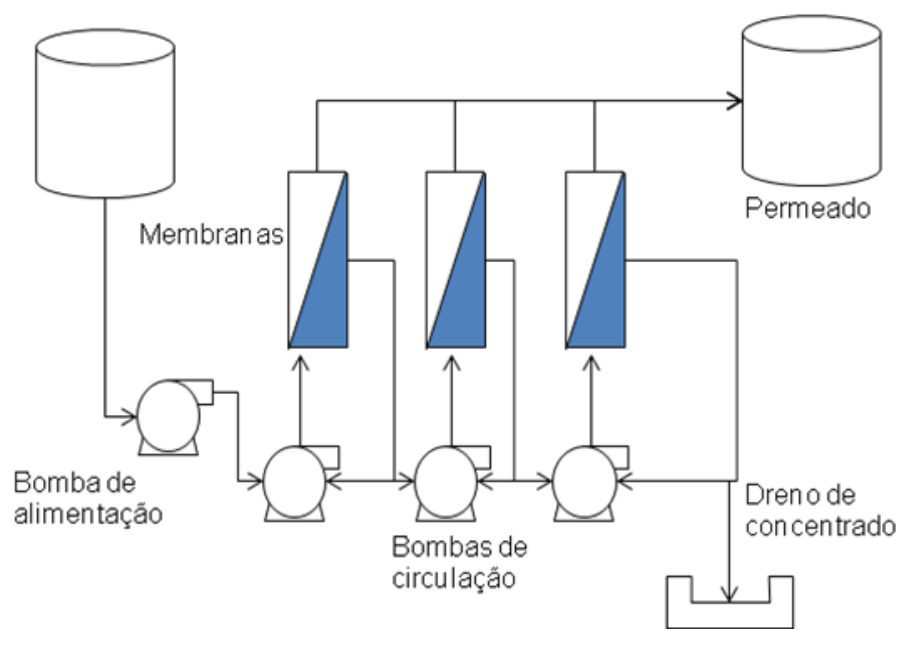

Figura 3.3 - Fluxograma de sistemas com múltiplos estágios e recirculação (ilustração do próprio autor). 


\subsubsection{Membranas pressurizadas com fluxo tangencial (cross-flow) sem recirculação}

Nesta configuração, assim como no arranjo anterior, a membrana permeia apenas uma parte da água que alimenta o sistema. De forma ao evitar a recirculação de concentrado o sistema opera com alta taxa de recuperação por elemento ou com diversos elementos em série, cada elemento é alimentado a partir concentrado do elemento anterior (Figura 3.4).

Esta configuração é aplicada a sistemas com membranas tubulares, fibra oca e em espiral e assemelha-se à utilizada em processos de Osmose Reversa e Nanofiltração. Neste processo, cada elemento de membrana trabalha em condições distintas.

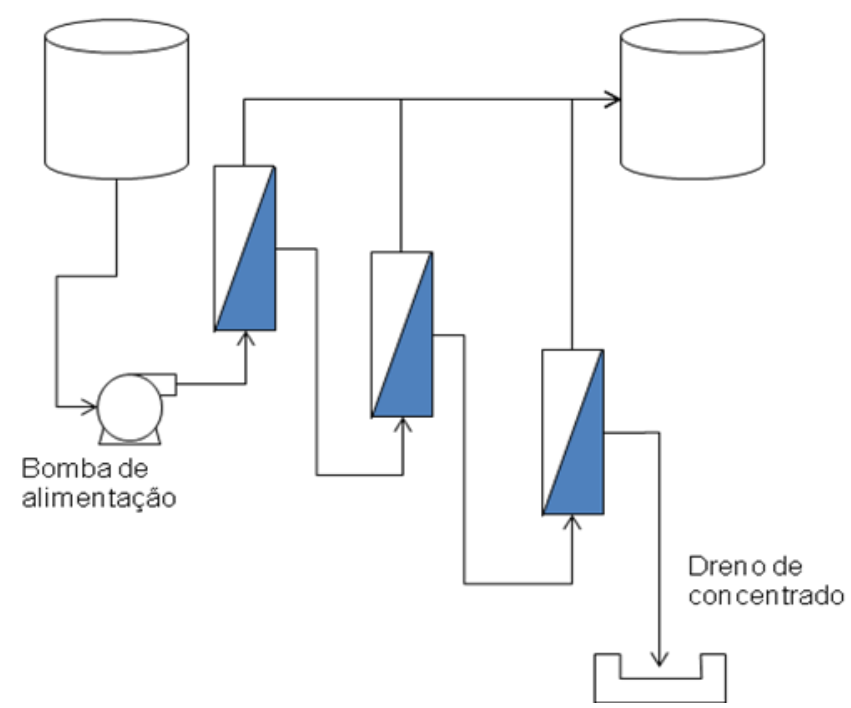

Figura 3.4 - Fluxograma de sistema de múltiplos estágios sem recirculação parcial (ilustração do próprio autor). 


\subsubsection{Membranas submersas}

A configuração de membranas submersas consiste em elementos de membranas imersos em um tanque, submetido à pressão atmosférica. A força motriz é a coluna de água sobre os elementos ou o vácuo, gerado por bomba ou sifão. Em virtude das baixas pressões de operação, este sistema é energeticamente eficaz, todavia, em virtude do baixo fluxo, a área de membranas necessária para o tratamento é superior aos sistemas com configurações pressurizadas (JUDD, 2011). Os sistemas baseados em membranas submersas utilizam a aeração (contínua ou intermitente) e a contralavagem para a remoção de depósitos. A Figura 3.5 ilustra o processo de separação com membranas submersas.

Os sistemas comercialmente disponíveis do mercado que se utilizam da configuração de membranas submersas são baseados em elementos com configuração em espiral, fibra oca ou placas planas. A maior parte das aplicações tem sido no tratamento de efluentes, através de biorreatores de membranas MBR ou em águas superficiais de elevada turbidez (TORAY, 2008).

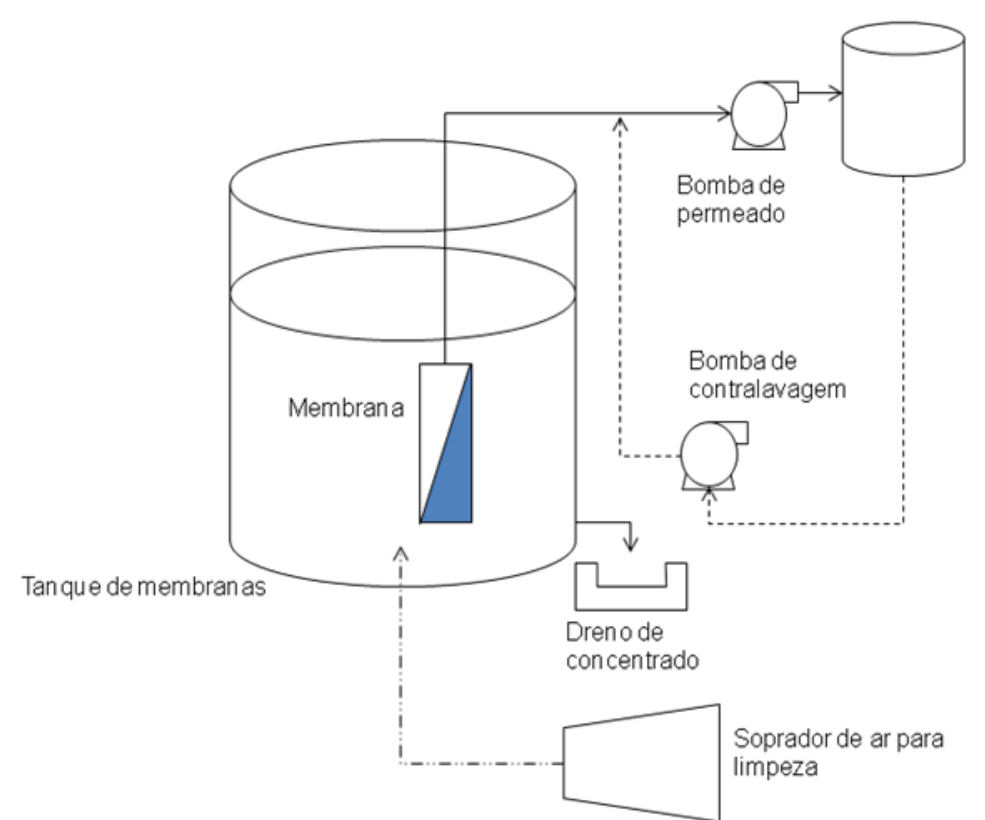

Figura 3.5 - Fluxograma de sistema com membranas submersas (ilustração do próprio autor) 


\subsubsection{Membranas pressurizadas com escoamento perpendicular (dead-end)}

Nesta configuração, a operação das membranas assemelha-se à dos filtros de areia de profundidade. Todo o fluxo de água que alimenta o sistema atravessa as membranas, daí a designação de escoamento perpendicular (Figura 3.6). Os sólidos acumulam-se no interior dos elementos e, periodicamente, interrompe-se a operação de filtração, para a limpeza das membranas através da lavagem ou contralavagem com o intuito de remover as partículas e reduzir a resistência à passagem da água. Trata-se de uma operação intermitente (Gráfico 3.7). Recentemente alguns fornecedores (Hyflux e Norit) passaram a recomendar um retorno parcial da água de alimentação para o tanque de alimentação de forma a reduzir o acúmulo de sólidos no interior dos elementos (HYFLUX, 2010).

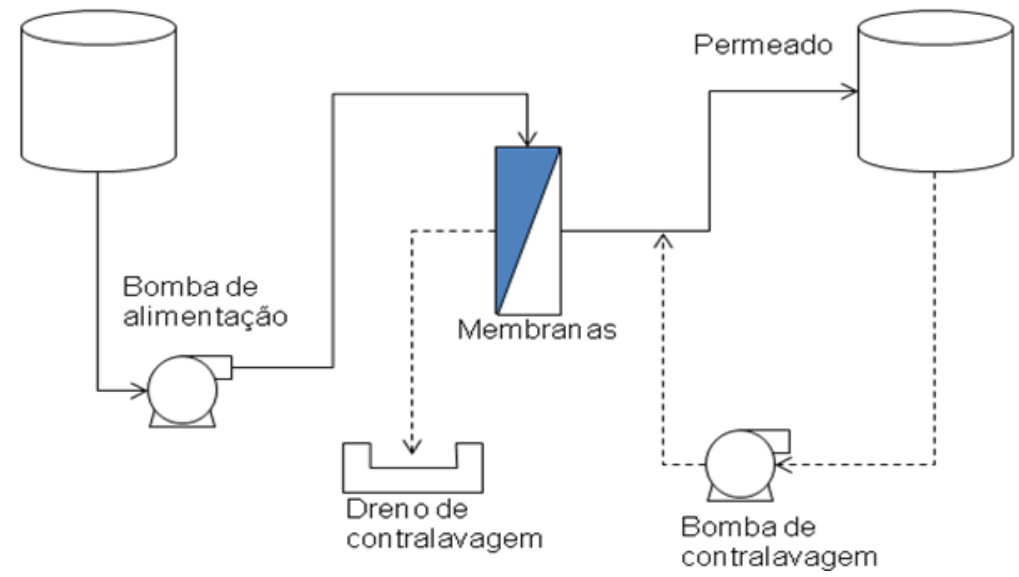

Figura 3.6 - Fluxograma de sistemas com membranas pressurizadas e filtração convencional (ilustração do próprio autor). 


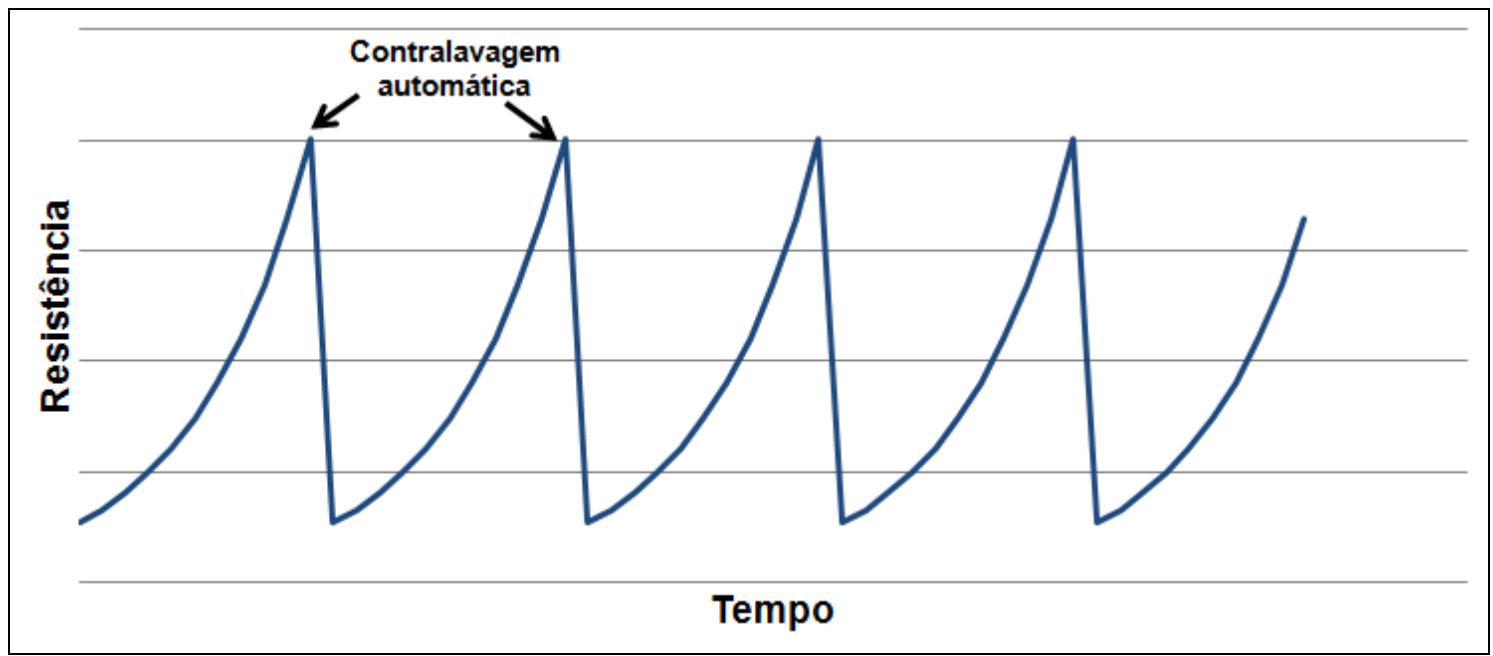

Figura 3.7 - Representação simulada do comportamento teórico da resistência em sistemas de filtração dead-end em função do acúmulo de sólidos ao longo do tempo. (ilustração do próprio autor).

De acordo com Pearce (2007), membranas pressurizadas que operam com fluxo perpendicular (dead-end) representam cerca de 70\% das aplicações no mercado atual, já que diversos fabricantes oferecem elementos que permitem este tipo de modo de operação. Mendret et al. (2009) complementa esta tendência colocando este processo como o mais econômico para o tratamento de fluidos de baixo valor agregado como é o caso da água em abastecimento público ou efluentes.

A configuração pressurizada permite o uso de elevadas áreas de filtração em pequeno volume, todavia, o teor e o tamanho dos sólidos na alimentação são limitados (TORAY, 2008; DOW, 2009) requerendo um tratamento preliminar da água.

Com o intuito de verificar semelhanças entre os módulos fornecidos por diferentes fabricantes, foi elaborada a tabela 3.2, a partir de suas fichas técnicas. O formato externo dos elementos, como apresenta a figura 3.8 também é muito semelhante. 
Tabela 3.2 - Comparativo entre membranas para saneamento.

\begin{tabular}{|c|c|c|c|c|c|c|}
\hline Fabricante & DOW & Toray & Polymem & Norit & Runda & Hyflux \\
\hline Origem & EUA/Japão & Japão & França & Holanda & China & Cingapura \\
\hline Tipo de membrana & Fibra oca & Fibra Oca & Fibra Óca & Capilar & Fibra oca & Fibra Oca \\
\hline Sentido de filtração & $\begin{array}{l}\text { Fora para } \\
\text { dentro }\end{array}$ & $\begin{array}{c}\text { Fora para } \\
\text { dentro }\end{array}$ & $\begin{array}{l}\text { Fora para } \\
\text { dentro }\end{array}$ & $\begin{array}{l}\text { Dentro } \\
\text { para fora }\end{array}$ & $\begin{array}{l}\text { Dentro } \\
\text { para fora }\end{array}$ & $\begin{array}{c}\text { Fora para } \\
\text { dentro }\end{array}$ \\
\hline $\begin{array}{l}\text { Composição do } \\
\text { polímero }\end{array}$ & PVDF & PVDF & PES & PES & PES & PES \\
\hline Área & 33 a $77 m^{2}$ & 7 a $72 m^{2}$ & 6 a $114 m^{2}$ & $40 \mathrm{~m}^{2}$ & 4 a $68 m^{2}$ & 23 a $60 m^{2}$ \\
\hline Diâmetro do poro & $0,03 \mu \mathrm{m}$ & $0,02 \mu \mathrm{m}$ & - & $0,02 \mu \mathrm{m}$ & - & - \\
\hline $\begin{array}{c}\text { Pressão de } \\
\text { operação (máxima) }\end{array}$ & 2,1 bar & 3 bar & 2,5 bar & 3,0 bar & 3,0 bar & 2,5 bar \\
\hline $\begin{array}{l}\text { Turbidez na } \\
\text { alimentação } \\
\text { (máxima) }\end{array}$ & 50 NTU & 30 NTU & - & - & 50 NTU & 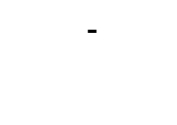 \\
\hline $\begin{array}{l}\text { Fluxo de filtração } \\
\text { (água bruta) }\end{array}$ & $\begin{array}{c}40 \mathrm{a} \\
120 \mathrm{~L} / \mathrm{m}^{2} \cdot \mathrm{h}\end{array}$ & $\begin{array}{c}63 \mathrm{a} \\
125 \mathrm{~L} / \mathrm{m}^{2} \cdot h\end{array}$ & - & - & - & $\begin{array}{l}50 \text { a } 90 \\
\mathrm{~L} / \mathrm{m}^{2} . \mathrm{h}\end{array}$ \\
\hline $\begin{array}{l}\text { Resistência } \\
\text { (água pura) }\end{array}$ & 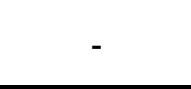 & $\begin{array}{c}1,16 \mathrm{x} \\
10^{12} \mathrm{~m}^{-1}\end{array}$ & $\begin{array}{r}3,08 \mathrm{x} \\
\times 10^{12} \mathrm{~m}^{-1} \\
\end{array}$ & $\begin{array}{c}0,58 \mathrm{x} \\
10^{12} \mathrm{~m}^{-1}\end{array}$ & $\begin{array}{r}5,78 \mathrm{x} \\
\times 10^{12} \mathrm{~m}^{-1} \\
\end{array}$ & \\
\hline
\end{tabular}

Fontes: PERCE 2007, TORAY 2008, DOW 2009, Runda 2009 e HYFLUX 2010 

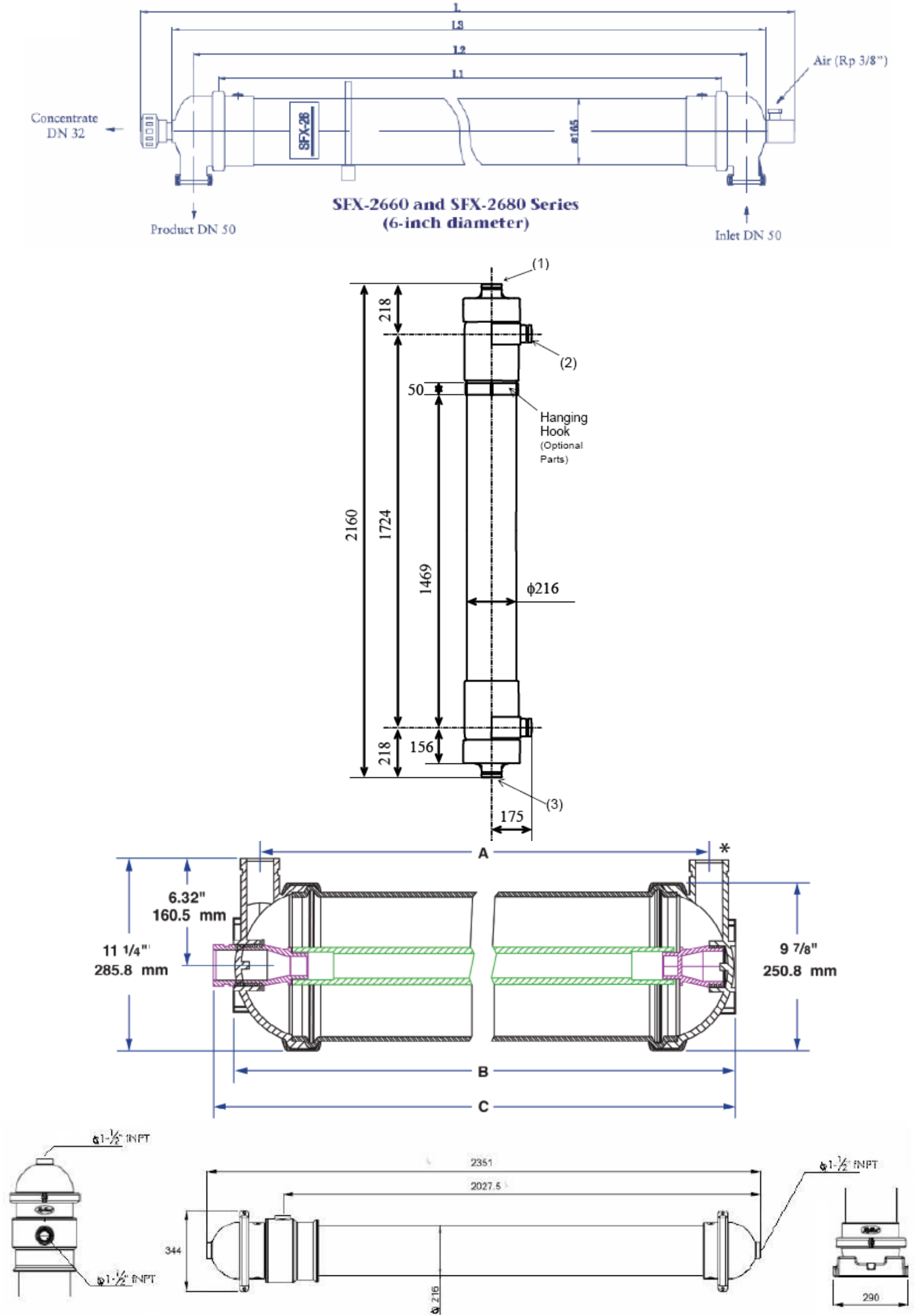

Figura 3.8 - Similaridades físicas entre os módulos de membranas de diferentes fabricantes (Hydranautics, DOW, Toray, Hyflux). 
A partir dos manuais de instalação e operação, também é possível identificar similaridades e etapas comuns à operação das diferentes membranas comerciais (Tabela 3.3) e descritos na seqüência.

Tabela 3.3 - Etapas de operação de sistemas de membranas.

\begin{tabular}{lcccc}
\hline \multicolumn{1}{c}{ Fabricante } & DOW & Toray & Norit & Hyflux \\
Filtração direta & $\mathrm{X}$ & $\mathrm{X}$ & $\mathrm{X}$ & $\mathrm{X}$ \\
Recirculação parcial & & & $\mathrm{X}$ & $\mathrm{X}$ \\
Contralavagem & $\mathrm{X}$ & $\mathrm{X}$ & $\mathrm{X}$ & $\mathrm{X}$ \\
Limpeza com ar & $\mathrm{X}$ & $\mathrm{X}$ & & $\mathrm{X}$ \\
Drenagem & $\mathrm{X}$ & $\mathrm{X}$ & $\mathrm{X}$ \\
Enchimento/Enxágue & $\mathrm{X}$ & $\mathrm{X}$ & $\mathrm{X}$ \\
Pré-operação & & & $\mathrm{X}$ & $\mathrm{X}$ \\
Limpeza química (eventual) & $\mathrm{X}$ & $\mathrm{X}$ & \\
\hline
\end{tabular}

Fontes: TORAY 2008, DOW 2009, NORIT 2007, HYFLUX 2010

Filtração: Consiste no processo de filtração propriamente dito. A bomba de alimentação garante a pressão mínima para a manutenção do fluxo de permeado. Conforme ocorre o acúmulo de sólidos no interior dos elementos, a permeabilidade diminui reduzindo a produção ou aumentando a pressão conforme o modo de operação definido. Segundo os fornecedores (TORAY 2008, DOW 2009, NORIT 2003), a duração da carreira de filtração usualmente varia entre 10 minutos e 1 hora com o intervalo usualmente baseado na concentração de sólidos da alimentação. Estudos como o realizado por Yun Ye et al. (2010) indicam que uma carreira de filtração muito longa pode levar à compactação dos depósitos levando à dificuldade na limpeza, desta forma, mesmo que a resistência das incrustações não atinja o patamar limitante, é recomendável a realização de uma limpeza.

Contralavagem: No decorrer do processo o acúmulo de sólidos no interior dos elementos reduz a permeabilidade das membranas. Neste caso ocorre o declínio da vazão, aumento de pressão ou ambos de acordo com a estratégia de produção adotada (pressão constante, fluxo constante ou potência constante). A contralavagem é realizada de forma automática, sempre que a pressão transmembrana atinge um determinado patamar ou por tempo. Consiste da reversão do 
sentido do fluxo da água, alimentando os elementos com permeado. Alguns fabricantes (TORAY, 2008 e DOW 2009) recomendam a dosagem de hipoclorito de sódio para o aumento da eficácia. Muitos fornecedores (TORAY 2008, DOW 2009, NORIT 2003, HYDRANAUTICS, 2006) fixam a duração da operação de contralavagem em aproximadamente30 segundos.

Limpeza com ar: Consiste na utilização de um sistema automático de aeração para promover a turbulência nos elementos e desprender os depósitos da superfície das membranas. Sopradores de ar e respiros devem ser previstos para este tipo de operação. Usualmente a limpeza com ar é realizada simultaneamente à contralavagem.

Drenagem: Permite a remoção dos sólidos desprendidos durante as etapas de contralavagem e limpeza com ar. É realizada por gravidade, automaticamente.

Enchimento/Enxágue: Consiste da alimentação do sistema com água bruta (sem permeação) com o intuito de remover sólidos remanescentes nos módulos. É realizada com o auxílio da bomba de alimentação de forma automática

Pré-Operação: A primeira água filtrada, após a lavagem, pode conter contaminantes ou resquícios de químicos utilizados para a limpeza. Durante a pré-operação, o permeado é descartado até que a qualidade desejada seja atingida.

Limpeza Química e Sanitização: É um procedimento manual que consiste da circulação de soluções químicas através dos elementos de membranas com o intuito de remover o material adsorvido nas membranas ou incrustações que não puderam ser removidas durante as etapas de contralavagem automática, além de propiciar a remoção de biofilme e a sanitização do sistema. Fabricantes costumam recomendar dois tipos de limpeza química (TORAY, 2008; HYFLUX, 2010), a de manutenção e a de recuperação. A limpeza preventiva ou de manutenção tem curta duração, de 30 minutos a 60 minutos e é realizada em uma única etapa em intervalos que variam de 1 dia a 7 dias. A limpeza de recuperação é realizada apenas quando constatada queda significativa da permeabilidade, usualmente de 1 a 3 meses, pode chegar a 
ter 24 de duração e consiste de diversas etapas de circulação e repouso de produtos químicos distintos (ácidos, bases, detergentes e sanitizantes).

Tendo em vista as semelhanças apresentadas, a princípio, existe a possibilidade de aplicação de um único modelo de dimensionamento para elementos de diferentes fornecedores.

\subsection{Princípios de operação das membranas}

\subsubsection{Força Motriz}

Em sistemas de separação por membranas, a separação da água dos sólidos requer a aplicação de energia. A energia, de acordo com o processo, pode ser proporcional ao gradiente de concentrações ao potencial elétrico ou ao gradiente de pressões. Os processos de micro e ultrafiltração utilizam como força motriz o diferencial de pressão entre as duas faces da membrana (JUDD; JEFFERSON, 2003). Este gradiente de pressão recebe a denominação de Pressão Transmembrana ou TMP (Transmembrane pressure) e é referenciado, nesta obra, através do símbolo $\Delta \mathrm{P}$. 


\subsubsection{Fluxo}

O transporte de água através das membranas de micro e de ultrafiltração pode ser explicado pelo princípio de escoamento em meios porosos estabelecido por Darcy e adaptado na forma do modelo de resistência de membranas. Nesses processos, o fluxo de água é proporcional à pressão e inversamente proporcional à resistência da membrana e à viscosidade conforme apresenta a equação 3.1 (CHERYAN, 1998).

$$
R=\frac{\Delta P}{\mu \cdot J}
$$

$\mathrm{J}=$ Fluxo volumétrico através da membrana.

$\mu=$ Viscosidade dinâmica da água

$\mathrm{R}=$ Resistência da membrana

$\Delta \mathrm{P}=$ Pressão na membrana

É importante ressaltar que a viscosidade dinâmica da água é amplamente influenciada pela temperatura. Um acréscimo da temperatura da água de $10^{\circ} \mathrm{C}$ para $20^{\circ} \mathrm{C}$ implica em um decréscimo de $61 \%$ na viscosidade que causa aumento do fluxo.

\subsubsection{Mecanismos de retenção e rejeição}

A rejeição pode ser entendida como a eficiência da membrana em reter um determinado composto. A rejeição é função de diversas características da membrana como a sua composição química, diâmetro e formato dos poros, índice de defeitos, interações hidrostáticas e características químicas e físicas do composto a ser retido. De acordo com Schippers e Verdouw (1980), as membranas de micro e ultrafiltração são capazes de reter as partículas pelos processos de filtração em superfície e de filtração em profundidade.

O mecanismo de retenção em superfície, predominante e desejável nos sistemas de ultrafiltração (AWWA,1999) baseia-se no diâmetro dos poros e no tamanho das 
partículas, a equação 3.2 proposta por Renkin (1955) correlaciona a rejeição da membrana com o diâmetro dos poros e das partículas.

$$
\text { Rejeição }=\left[1-2 \cdot\left(1-\frac{a}{r}\right)^{2}+1-\left(\frac{a}{r}\right)^{4}\right] \cdot 100 \%
$$

a = Raio da partícula

$r=$ Raio do poro

O mecanismo de retenção em profundidade, por sua vez, é bem mais complexo. Fenômenos de adsorção eletrostática, difusão Browniana, interceptação inercial e o efeito de coar combinam-se para a separação das partículas (MWH, 2004) Em virtude da dificuldade de determinar todas estas interações e das conseqüências negativas para a operação relacionadas às dificuldades de limpeza, a retenção em profundidade é indesejável em sistemas de membranas de micro/ultrafiltração ou estabelecida de forma empírica, com base em testes práticos.

\subsubsection{Polarização de concentrações}

Para uma determinada pressão de filtração, o acúmulo de soluto na superfície da membrana pode ser representado como um balanço entre a convecção das partículas para a superfície da membrana (concentração) e a difusão destas partículas no sentido inverso (retro-transporte) AWWA (1999). Este incremento de concentração de sólidos na interface membrana-líquido é denominado polarização de concentrações e é predominantemente influenciado pelas características hidrodinâmicas do sistema, bem como pelo fator de concentração de processo e é utilizado em diversos modelos de transporte por difusão (JUDD; JEFFERSON, 2003; SCHNEIDER; TSUTIA, 2004).

A polarização de concentrações em membranas de microfiltração e ultrafiltração aumenta a resistência da passagem da água, devido à formação de uma região de maior concentração de partículas junto a superfície da membrana. 
A partir de uma determinada pressão de operação do sistema, a camada de polarização pode se tornar uma camada gel e o fluxo de água através da membrana tende a se tornar independente da pressão transmembrana aplicada (figura 3.9). Sistemas são bem operados com pressões que variam entre $p_{2}$ e $p_{3}$ quando a espessura da camada é pequena. Sistemas que operam após o ponto $p_{4}$ são suscetíveis à incrustações permanentes além de um pior rendimento energético em função do aumento da espessura da camada e eventual aumento da densidade da mesma. Do ponto de vista de projeto de sistemas de tratamento de água, a operação nestas condições torna-se antieconômica devendo ser evitada.
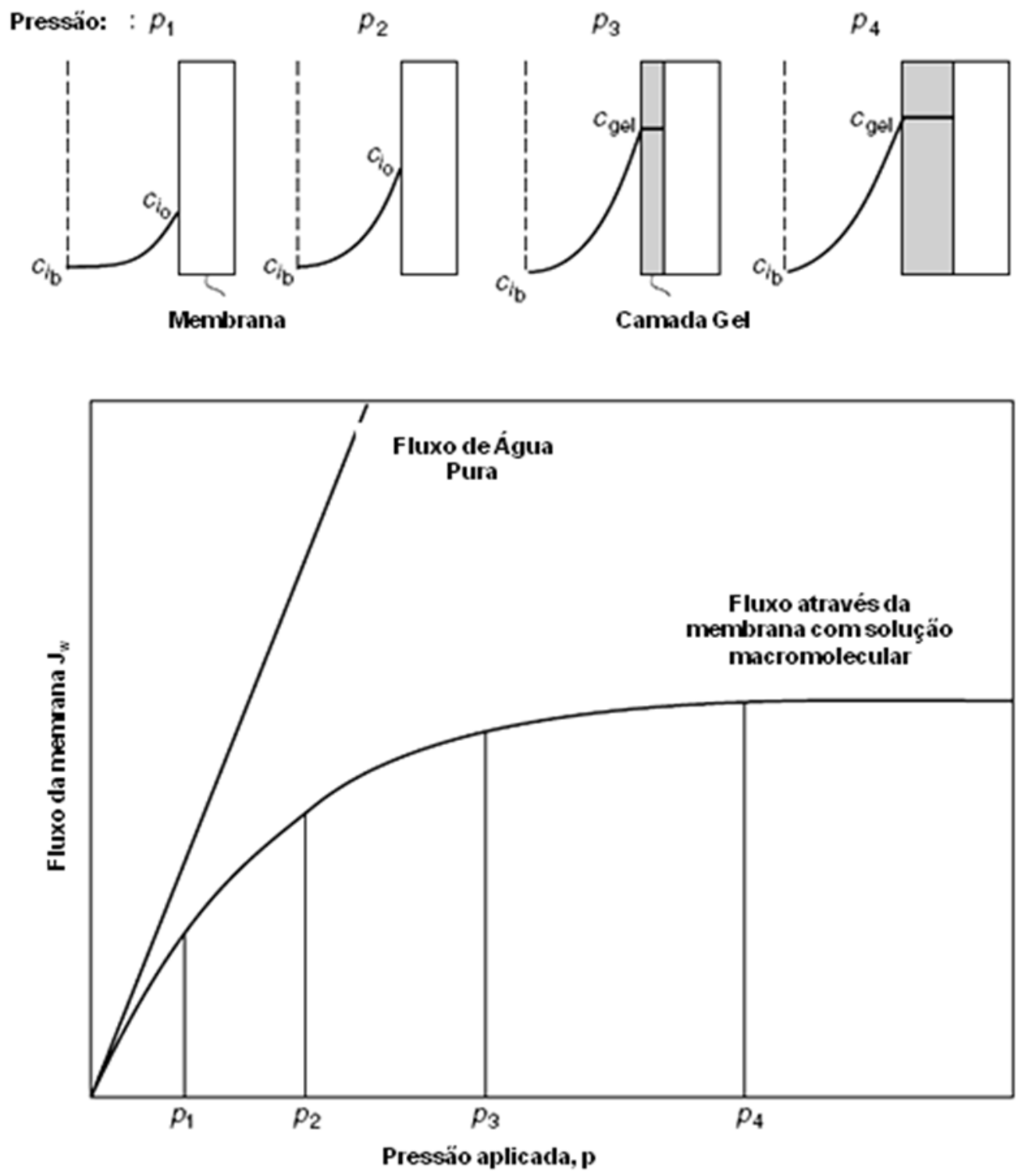

Figura 3.9 - Efeito da pressão sobre membranas de ultrafiltração e a formação da camada gel. (JUDD e JEFFERSON, 2003). 


\subsubsection{Formação de depósitos}

Segundo AWWA (1998) a formação de depósitos na superfície da membrana é a questão mais significante no que tange o projeto e a operação de sistemas baseados em membranas. A formação de depósitos ou fouling pode ser entendida como o acúmulo de materiais na superfície da membrana que leva ao aumento da resistência ao fluxo. Segundo Judd e Jefferson (2003) existem diversos modelos para a previsão dos depósitos, todavia, a complexidade física e química das águas brutas favorece o uso de coeficientes e calibração empíricos. A equação 3.3 representa a equação do fluxo com as mais significativas resistências das camadas de depósito, bem como dos efeitos da polarização de concentrações.

$$
J=\frac{\Delta P}{\mu \cdot\left(R_{0}+R_{c}+R_{a}\right)}
$$

$\mathrm{J}=$ Fluxo volumétrico através da membrana.

$\mu=$ Viscosidade dinâmica da água

$\mathrm{R}_{0}=$ Resistência da membrana

$\mathrm{R}_{\mathrm{c}}=$ Resistência da camada de torta

$\mathrm{R}_{\mathrm{a}}=$ Resistência dos depósitos adsorvidos

Os depósitos podem ser classificados em dois grandes grupos: os reversíveis e os irreversíveis. Os depósitos irreversíveis reduzem, ao longo do tempo, a permeabilidade das membranas enquanto que os depósitos reversíveis podem ser controlados através de operações de contralavagem, limpeza química ou enxágüe.

Hermia (1982) modelou mecanismos de bloqueio de membrana em regime de filtração perpendicular "dead-end" classificando-os em quatro modelos: a filtração em torta, o bloqueio intermediário de poros, o bloqueio padrão dos poros e o bloqueio completo dos poros. O modelo de Hermia assume que a migração dos sólidos para a superfície da membrana ocorre em virtude de forças convectivas, não há migração em direção oposta pela difusão ou outras forças. Os sólidos são tomados como partículas esféricas e a membrana é considerada plana com poros 
uniformes. A seguir são apresentados os mecanismos de bloqueio propostos para este modelo e relevantes para o desenvolvimento deste trabalho.

Bloqueio completo de poros: Trata-se de uma modelagem que considera o bloqueio da entrada dos poros por partículas retidas na superfície da membrana (figura 3.10). Cada partícula bloqueia uma área da membrana proporcional à área da de sua circunferência projetada. A redução do fluxo ocorre proporcionalmente à área coberta. Como não considera a superposição de partículas, o fluxo iguala-se a zero quando a área da membrana está completamente tomada (MHW, 2004; BLANKERT et al. , 2006; WANG et al. ,2008).

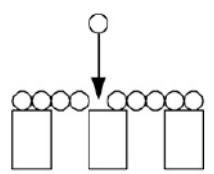

Figura 3.10 - Bloqueio completo de poros (BLANKERT et al., 2006)

Bloqueio padrão de poros: Assume que a membrana é constituída de poros cilíndricos, uniformes e igualmente distribuídos. As partículas acumulam-se no interior dos poros reduzindo o volume disponível (figura 3.11). O fluxo é proporcional ao volume disponível (MHW, 2004; BLANKERT et al. , 2006; WANG et al. ,2008).

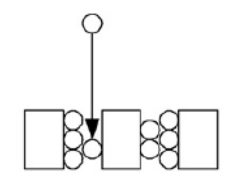

Figura 3.11 - Bloqueio padrão de poros (BLANKERT et al., 2006)

Bloqueio intermediário dos poros: também conhecido como obstrução de poros com superposição. Trata-se de uma extensão do modelo de bloqueio de poros.

Considera que as partículas também têm probabilidade de depositar-se sobre outras partículas na membrana (figura 3.12) sem necessariamente bloquear os poros (MHW, 2004; BLANKERT et al. , 2006; WANG et al. ,2008).

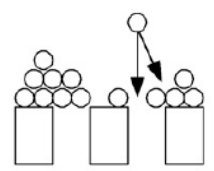

Figura 3.12 - Bloqueio intermediário de poros (BLANKERT et al., 2006) 
Filtração em torta: Este mecanismo considera a formação de uma torta de filtração na superfície da membrana (figura 3.13), desta forma, a resistência pode ser comparada a uma série de resistências somadas (resistência da membrana + resistência da torta). O material acumulado não tem influência sobre os poros ou redução da área dos mesmos (MHW, 2004; BLANKERT et al., 2006; WANG et al. ,2008)

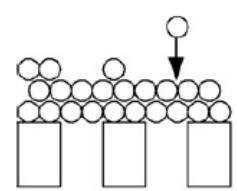

Figura 3.13 - Filtração em torta (BLANKERT et al., 2006)

As equações resultantes para cada mecanismo de bloqueio, a partir da proposta de Hermia são apresentadas na tabela 3.4. Onde w representa o volume filtrado por unidade de área e $w_{\mathrm{r}}, \mathrm{w}_{\mathrm{a}}$ e $\mathrm{w}_{\mathrm{v}}$ respectivamente os volumes de água necessários para formação da torta, bloqueio de poros e preenchimento de poros.

Tabela 3.4 - Equações de Hermia para a resistência da membrana (BLANKERT et al.,2006).

\begin{tabular}{cccc}
\hline Mecanismo & Equação da resistência & $\mathbf{C}$ & $\mathbf{m}$ \\
Filtração em torta & $R(\omega)=R_{0}\left(1+\frac{\omega}{\omega_{R}}\right)$ & $\frac{R_{0}}{\omega_{R}}$ & 0 \\
$\begin{array}{c}\text { Bloqueio } \\
\text { intermediário }\end{array}$ & $R(\omega)=R_{0} \cdot e^{\frac{\omega}{\omega_{a}}}$ & $\frac{1}{\omega_{a}}$ & 1 \\
Bloqueio padrão & $R(\omega)=R_{0}\left(1-\frac{\omega}{\omega_{v}}\right)^{-2}$ & $\frac{2}{\omega_{v} \cdot R_{0}}$ & $3 / 2$ \\
Bloqueio completo & $R(\omega)=R_{0} \cdot\left(1-\frac{\omega}{\omega_{a}}\right)^{-1}$ & $\frac{1}{\omega_{a} \cdot R_{0}}$ & 2 \\
\hline
\end{tabular}


Derivando-se as equações de Hermia, é possível obter uma única notação para a resistência da membrana, na forma de uma equação diferencial de primeira ordem (equação 3.4), independente do mecanismo (BLANKERT et al., 2006). "C" e "m" são as constantes apresentadas na tabela 3.2.

$$
\frac{d R}{d \omega}=C \cdot R^{m}
$$

O comportamento de cada uma das equações de resistência e mecanismos de bloqueio de poros é apresentado no gráfico 3.14.

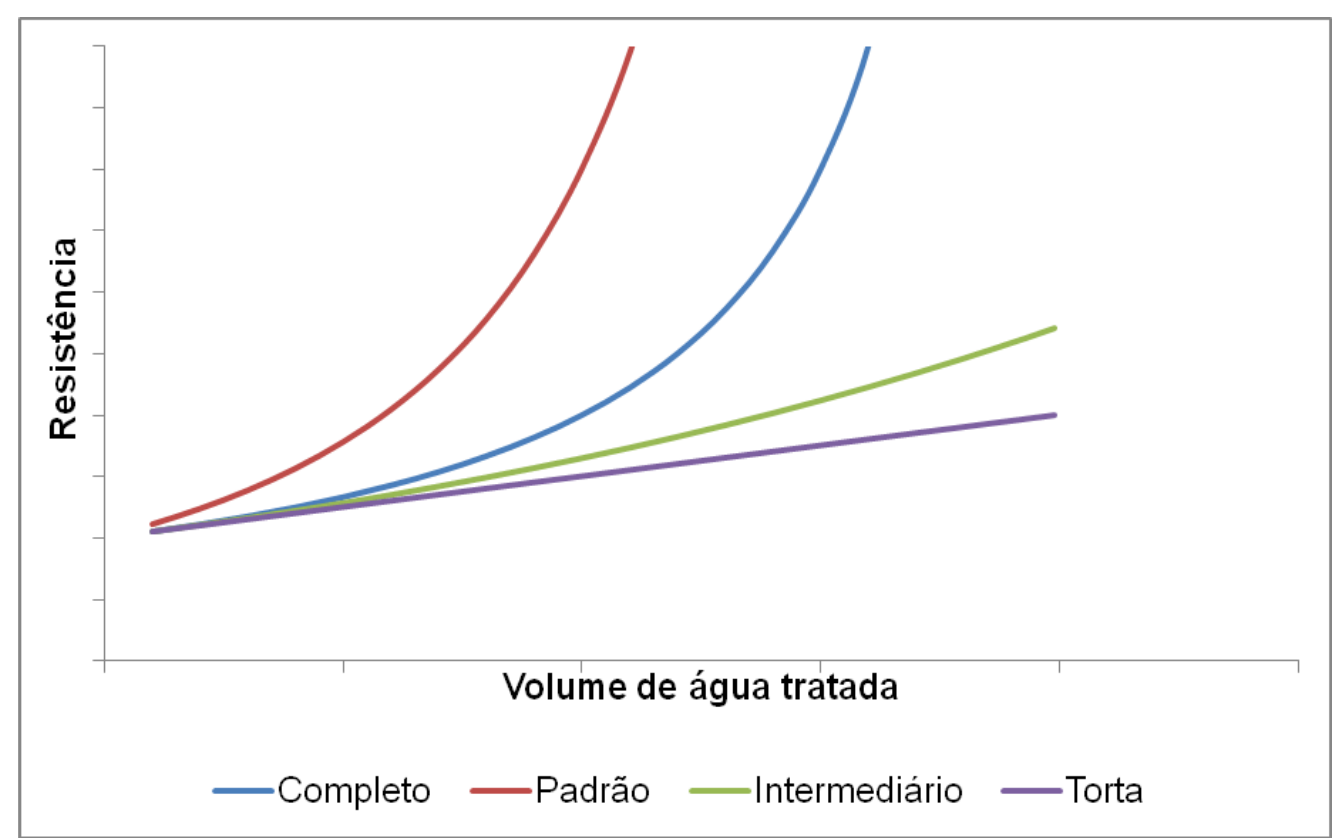

Figura 3.14 - Comportamento da resistência em função do volume filtrado para cada mecanismo de retenção de partículas (gráfico elaborado pelo próprio autor).

Em virtude do modelo de Hermia ter sido baseado no comportamento teórico de sólidos incompressíveis de formato esférico, alguns fenômenos que ocorrem na prática da operação de sistemas de ultrafiltração como a compressão da torta de sólidos e interações químicas entre a membrana e os contaminantes da água não podem ser previstos através deste tipo de equacionamento. Neste caso fatores adicionais podem ser acrescentados de forma a refletir este fenômeno como o 
proposto por Blankert et al. (2007) ao modificar as equações para o comportamento de filtração em torta não ideal.

Alguns estudos como os realizados por Wang e Tarabara (2008), Katsoufidou et al. (2010), Wang et al. (2008) e Mendret et al. (2009) apontam para uma combinação de mecanismos de obstrução de poros nas diferentes fases da filtração, iniciando pelo bloqueio de poros nos primeiros estágios, passando à filtração em torta nos estágios seguintes e, em condições específicas, atingindo o comportamento de compressão da torta de filtração ou compressão da camada gel em condições específicas.

Schippers e Verdouw (1980), ao estudar o comportamento de membranas de Ultrafiltração e de Osmose Reversa por material coloidal verificaram a predominância de mecanismo de filtração em torta e propuseram um índice padronizado denominado MFI (Modified Fouling Index) ou $\mathrm{MFI}_{0,45}$ para a medição deste potencial de acúmulo de depósitos em função da qualidade de água. O ensaio padrão de MFI é realizado em membranas de microfiltração de 0,45 $\mu \mathrm{m}$, com pressão constante de 2,1bar e duração de 15 a 20 minutos (volumes medidos a cada 30 segundos).

Posteriormente, Boerlage et al. (2002) modificaram a metodologia para uso de membranas de Ultrafiltração propondo um novo índice, o MFI-UF, que permite avaliar o efeito da colmatação das membranas por partículas de diâmetro muito inferior.

O índice MFI-UF pode ser experimentalmente determinado através da filtração da água bruta através de uma membrana de ultrafiltração em regime de fluxo constante. A partir da inclinação do trecho linear do gráfico de $\Delta \mathrm{P} \times \mathrm{t}$ e da relação apresentada na equação 3.5, o índice de fouling (I) pode ser obtido. (BOERLAGE et al., 2004)

Conhecido o índice de fouling, o valor de MFI é calculado de acordo com a relação apresentada na equação 3.6. Os valores de viscosidade $\left(\mu_{\mathrm{MFI}}\right)$, pressão $\left(\Delta \mathrm{P}_{\mathrm{MFI}}\right)$ e área da membrana $\left(A_{M F I}\right)$ são constantes conforme a padronização da metodologia 
de cálculo original do MFI proposta por Schippers e Verdouw (1980) de forma a permitir comparações.

$$
\begin{gathered}
\Delta P=J \cdot \mu \cdot R_{0}+J^{2} \cdot \mu . I . t \\
M F I=\frac{\mu_{M F I} \cdot I}{2 . \Delta P_{M F I} \cdot A_{M F I}{ }^{2}}
\end{gathered}
$$

$\mathrm{J}=$ Fluxo através da membrana $\left(\mathrm{m}^{3} / \mathrm{m}^{2} . \mathrm{s}\right)$

$\mathrm{t}=$ Duração do ensaio $(\mathrm{s})$

$\mathrm{I}$ = Índice de fouling $\left(\mathrm{m}^{-2}\right)$

$\Delta \mathrm{P}=$ Pressão aplicada durante o ensaio $(\mathrm{Pa})$

$\mathrm{R}_{0}=$ Resistência da membrana limpa $(1 / \mathrm{m})$

$\mu=$ Viscosidade dinâmica da água na temperatura do ensaio (Pa.s)

$A_{M F I}=$ Área da membrana padronizada de MFI (constante) $=13,8 \times 10^{-4} \mathrm{~m}^{2}$.

$\Delta \mathrm{P}_{\mathrm{MFI}}=$ Pressão do teste padronizado de $\mathrm{MFI}=2$ bar

$\mu_{\mathrm{MFI}}=$ Viscosidade dinâmica da água à temperatura de $20^{\circ} \mathrm{C}$ (Pa.s)

MFI-UF = Índice de "fouling" modificado $\left(\mathrm{s} / \mathrm{L}^{2}\right)$

A análise do comportamento do MFI e das curvas que levam a este índice permite identificar de forma padronizada o mecanismo de bloqueio de poros predominante (BOERLAGE et al., 2004) e, no caso de predominância do comportamento de torta, correlacionar de uma forma geral a concentração de partículas da água com o comportamento das membranas (CASTAING, 2009).

O MFI, todavia, é determinado com base em ensaios de curta duração, em membranas com características (material, porosidade, diâmetro dos poros e hidrofobicidade, etc..) distintas dos módulos de ultrafiltração disponíveis no mercado. Desta forma, interações mais complexas entre a água e a membrana como a formação de depósitos permanentes não são avaliadas ou previstas impossibilitando o seu uso como variável única na previsão do comportamento das membranas em projetos. Ainda assim, o MFI representa uma ferramenta importante e é largamente utilizado em estudos de caracterização de membranas e de eficácia do tratamento de água (DOW, 2004). 


\subsubsection{Recuperação}

A recuperação é definida pela relação entre água produzida (filtrada) e a água que alimenta o processo. A parcela de água não recuperada no processo de separação é denominada por concentrado, uma vez que esta acumulou os sólidos alimentados ao sistema. Usualmente, sistemas pressurizados de ultrafiltração têm taxas de recuperação de água variando entre 85 e 95\% (EPA, 2001). Alguns estudos como o de Lautenschlager (2006), baseiam-se na recuperação global de água como função objetivo para a otimização em função da importância deste fator na composição dos custos do tratamento.

Em sistemas do tipo "dead-end" ou "cross-flow", a recuperação pode ser definida através da equação 3.7.

$$
Y=\frac{V-V_{b}-V_{d}}{V+V_{c}}
$$

$Y=$ recuperação

$\mathrm{V}=$ volume total de água filtrada ao longo do ciclo.

$\mathrm{V}_{\mathrm{b}}=$ volume de água consumido durante o ciclo de contralavagem

$V_{d}=$ volume consumido durante a drenagem das membranas

$\mathrm{V}_{\mathrm{c}}=$ volume de concentrado produzido durante a operação (quando há fluxo tangencial parcial)

\subsection{Dimensionamento econômico de sistemas de ultrafiltração}

O dimensionamento ótimo econômico de sistemas de ultrafiltração consiste da fixação de variáveis de projeto tais como quantidade de membranas, vazões, dosagem de químicos e duração dos ciclos de operação de tal forma que a soma dos custos de capital e de operação dentro de um período definido seja mínima.

Na seqüência são apresentados os conceitos e metodologias utilizadas para a busca racional da configuração ótima para o processo de separação por membranas. 
Um dos conceitos mais aplicados na otimização de processos de separação por membranas é do Custo Total da Posse ou TCO (Total Costs of Ownership). O Custo Total da Posse é uma função econômica que leva em consideração todas as despesas relativas ao tratamento de água pelo processo de membranas, desde o investimento inicial até a os custos de operação, manutenção e paradas ao longo da vida útil do equipamento (DARAMOLA, KEESMAN; 2008). O TCO é usualmente representado na unidade de custo por volume de água produzida (exemplo: $\mathrm{R} \$ / \mathrm{m}^{3}$ ).

A composição do TCO, para fins de cálculo, é dividida em duas partes, a primeira refere-se aos custos de capital da planta. Representa a soma dos custos para a implantação do empreendimento amortizados durante a vida útil da planta de tratamento. Em função do retorno de investimento para o empreendedor, os custos financeiros e taxas de juros devem ser considerados na composição desta fração (PICKERING; WIESNER, 1992).

A segunda parte da composição do TCO é representada pelos custos operacionais como: energia elétrica, consumo de água, consumo de produtos químicos e reposição de membranas. Daramola e Keesman (2008) apresentam como fatores mais significativos para a composição dos custos operacionais os seguintes itens: energia elétrica, produtos químicos, reposição membranas, água e disposição de efluentes. Pickering e Wiesner (1992), além dos itens apresentados por Daramola, consideram a mão de obra nesta composição. AWWA (2005) considera as mesmas variáveis apresentados pelos autores anteriores na composição dos custos operacionais.

A composição da função do TCO constitui a primeira etapa para o desenvolvimento do projeto ótimo. Guadix et al. (2004) propuseram a divisão desta composição em dois modelos: o modelo físico e o modelo econômico. Dentro do modelo físico estão todas as condições de projeto e operação dos sistemas de membranas. O modelo econômico, por sua vez, incorpora os custos de capital e operacional associados. 


\subsubsection{Modelo Físico}

O dimensionamento de sistemas de membranas é baseado na definição de um fluxo de projeto. O fluxo de projeto influencia na área de membranas, nas pressões de operação (equação 3.1) e no desempenho operacional do sistema. Como as membranas representam uma porcentagem significativa do investimento na planta e nos custos operacionais (reposição), a fixação do número de elementos torna-se um dos fatores mais importantes nas etapas de projeto.

Durante a operação de sistemas dead-end, os sólidos acumulam-se na superfície da membrana reduzindo a permeabilidade e, conseqüentemente, o desempenho do sistema. Esta redução provoca um aumento de pressão (consumo energético) ou redução da vazão de permeado (queda da produtividade). Ao atingir um determinado patamar, deve ser realizada uma contralavagem das membranas com o intuito de remover o material acumulado e recuperar a permeabilidade.

Considerando esta característica inerente do processo, torna-se necessário considerar, na seleção do fluxo de projeto a queda de permeabilidade e o intervalo entre as operações de contralavagem.

Blankert et al. (2006) elaboraram, com base nas equações de bloqueio de poros de Hermia (1982), um modelo que define a trajetória da permeabilidade em função do tempo. Este tipo de análise, denominada dinâmica, permite aperfeiçoar o processo ao longo de todo o ciclo operacional ao invés de apenas em pontos específicos do ciclo de filtração. Os mesmos autores (BLANKERT et al. 2007) publicaram um outro equacionamento baseado na teoria de resistência de compressão da torta de filtração, segundo eles, os resultados são mais realistas em sistemas que trabalham com fluxo constante e incremento de pressão, todavia, a obtenção de dados experimentais com relação à compressão de torta é mais difícil.

O estado do fluxo e da pressão, com base na teoria de bloqueio de poros, pode ser representado através das equações 3.8 e 3.9 .

$$
J=J_{0} \cdot \gamma^{-s}
$$




$$
\Delta P(t)=\Delta P_{0} \cdot \gamma^{1-s}
$$

$\mathrm{J}_{0}$ e $\Delta \mathrm{P}_{0}$ representam respectivamente o fluxo inicial e a respectiva pressão efetiva de filtração com membrana limpa.

A variável " $\gamma$ " representa a relação entre a resistência com o acúmulo de sólidos (R) e a resistência da membrana limpa $\left(R_{0}\right)$, Blankert et al. (2006) a definem como a "dificuldade de operação". A variável "s", por sua vez, é caracterizada pelo modo de operação do processo.

- Operação com fluxo constante: s=0 (usual em processos industriais);

- Operação com pressão constante $s=1$;

- Operação com potência constante s=0,5;

A parametrização de " $\gamma$ " em função da duração do ciclo de filtração, definida pela variável "t" é dada pelas equações 3.10 e 3.11

$$
\begin{aligned}
& \gamma(t)=\left[1+(s-m+1) \cdot K_{0} \cdot t\right]^{\frac{1}{s-m+1}} \text { para }(\mathrm{s}-\mathrm{m}+1) \neq 0 \\
& \gamma(t)=e^{k_{0} \cdot t} \quad \text { para }(\mathrm{s}-\mathrm{m}+1)=0
\end{aligned}
$$

Onde

$$
K_{0}=C \cdot J_{0} \cdot R_{0}^{(m-1)}
$$

A constante $C$ representa o fator de depósito e pode ser facilmente obtida através de

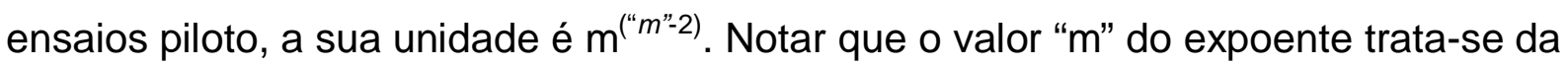
constante "m", que depende do mecanismo de retenção predominante no sistema e também pode ser determinada através de ensaios em piloto ou em células de fluxo.

Com a trajetória da formação de depósitos definida, é possível relacionar a duração do ciclo de filtração com o fluxo através das membranas e com a pressão de 
operação. Integrando-se a potência (fluxo e resistência) obtém-se o consumo energético do ciclo de filtração (equação 3.12).

$$
E=\frac{A}{\eta} \cdot \int_{0}^{t} J \cdot \Delta P \cdot d t
$$

$\mathrm{A}=$ Área total instalada de membranas.

$\eta$ = Rendimento global (elétrico + mecânico) do sistema de bombeamento.

Blankert et al. (2006) apresentaram a equação 3.13 para o consumo energético em função da evolução da curva $\gamma$ durante o ciclo de filtração composta com base na equação 3.10 e na equação 3.12 :

$$
E=\mu \cdot R_{0} J_{0}^{2} \int_{0}^{T} \gamma^{1-2 s} \cdot d t
$$

Fixando-se o tempo do ciclo de filtração é possível, então, determinar o fluxo inicial do sistema (quantidade de membranas), para um determinado consumo energético objetivo.

Ainda com relação à quantidade de membranas, deve-se considerar que ao longo do período de operação da planta, as mesmas deverão ser substituídas. Zondervan et al. (2007) propuseram um modelo estatístico baseado na distribuição de Weibull para estimar a vida útil de membranas de fibra oca e concluíram que o comportamento dos depósitos é o fator que mais influencia neste quesito em função da quantidade de ciclos de contralavagem. Um incremento de $70 \%$ na resistência das membranas foi o ponto ideal encontrado para a realização das operações de contralavagem com o intuito de maximizar a vida útil dos elementos filtrantes.

Quanto ao ciclo de contralavagem, Zondervan e Roffel (2008), consideram que a mesma deve ser realizada utilizando o fluxo máximo admissível pela membrana (dado do fabricante) devendo apenas a duração do mesmo ser passível de uma otimização. No projeto de sistemas de ultrafiltração, dispondo-se da quantidade de membranas e do fluxo máximo de limpeza é possível definir a bomba a ser utilizada. O volume do tanque de limpeza e a recuperação global do processo dependem da duração desta etapa devendo ser incorporados no modelo econômico. Yun Ye et al. 
(2010), ao contrário de Zondervan e Roffel verificaram que nem sempre o fluxo máximo de contralavagem leva à melhor recuperação da permeabilidade e que esta operação é eficaz na remoção da torta de filtração porém não dos poros bloqueados.

\subsubsection{Modelo Econômico}

Na composição do modelo econômico, convêm dividir a modelagem em dois grandes grupos, os custos de implantação (CAPEX) e os custos de operação (OPEX).

Na literatura existem diversas referências sobre a composição dos custos de implantação. Pickering e Weisner (1992) e Owen et al. (1995) dividiram estes valores em dois grandes grupos: custos relacionados à membranas e os custos não relacionados às membranas. Os custos relacionados à membranas podem ser levantados em função da área requerida para o sistema, Pickering e Weisner (1992) propuseram a equação 3.14 para esta determinação. A quantidade de elementos pode então ser obtida dividindo-se a área necessária pela área do elemento selecionado.

$$
A=Q_{r e q} \cdot \frac{t_{t}}{J \cdot\left(t-t_{f}\right)-J_{b} \cdot t_{b}}
$$

Aonde:

$\mathrm{Q}_{\text {req }}=$ Vazão demandada

$A=$ Área da membrana

$t_{t}=$ Duração total de um ciclo

$t_{b}=$ Duração da contralavagem

$\mathrm{J}=$ Fluxo de permeação

$\mathrm{J}_{\mathrm{b}}=$ Fluxo de contralavagem

$\mathrm{t}=$ Duração do período de filtração

$t_{f}=$ Duração do período de pré-operação (descarte de permeado)

Os custos não relacionados às membranas incluem todos os serviços de implantação, terreno, tubulações, instrumentação, automação e bombas. Pickering e Weisner (1992) utilizaram modelos empíricos da época para estas estimativas. A 
AWWA (2005) publicou em seu manual as mais recentes curvas gerais de custos de implantação de sistemas de membranas de micro e ultrafiltração com base na vazão produzida. De acordo com os autores estas curvas são resultado de um estudo realizado pelo comitê de membranas da AWWA com base em um extenso banco de dados de unidades em operação em 2003. Gaudix et al. (2004) apresentaram uma equação empírica para os custos de capital de bombas conforme apresentado na equação 3.15 .

$$
C=2590 . W^{0,79}
$$

Aonde:

$\mathrm{C}=$ Custo da bomba (USD)

W = Potência da bomba (kW)

Os custos totais de capital podem considerar a amortização do investimento. Uma forma representar a anualização do CAPEX, com base nos princípios de contabilidade e utilizada por Pickering e Weisner (1992) na equação 3.16 abaixo.

$$
C A P E X_{a}=C A P E X \cdot\left[\frac{i \cdot(1+i)^{U}}{(1+i)^{U}-1}\right]
$$

aonde:

$\mathrm{U}=$ período de amortização (anos)

$\mathrm{i}=$ taxa de juros anual

CAPEX $_{a}=$ Custos de capital anuais considerando os custos de capital

Para a composição dos custos operacionais, é possível dividir a composição de acordo com os componentes mais significativos anteriormente apresentados:

- energia elétrica;

- água (captação e disposição de efluentes);

- produtos químicos;

- reposição de membranas;

- mão de obra. 
O consumo de energia elétrica em sistemas de micro e ultrafiltração é representado pela potência consumida por bombas durante as etapas de operação e contralavagem (Blankert et al. 2006). Sistemas atuais utilizam uma etapa adicional de limpeza com ar que também deve ser considerada. No modelo físico anteriormente apresentado o equacionamento do consumo energético durante a filtração permite determinar os custos da operação. Outros autores como Pickering e Weisner (1992) e Daramola e Keesman (2008) utilizam a mesma metodologia de cálculo.

Em estudos publicados sobre o consumo de produtos químicos, convencionou-se adotar uma dosagem constante, tornando a quantidade consumida proporcional à vazão de produção (DARAMOLA; KEESMAN, 2008; PICKERING; WEISNER, 1992). Esta posição é compreensível em função da grande variação da qualidade da água de alimentação, principalmente em corpos de água superficiais. Programas computacionais e planilhas eletrônicas de dimensionamento oferecidas por fabricantes de membranas costumam relacionar a dosagem com características de qualidade da água como turbidez ou sólidos suspensos totais. A relação utilizada por estas ferramentas, todavia, não foi encontrada na literatura.

Os custos da água bruta e, principalmente, do tratamento e disposição de efluentes gerados são significativos. O consumo de água de contralavagem e enxágüe de membranas representa a geração de efluentes. Zondervan et al., (2008) apresentam, em um estudo de caso, esta fração como equivalente a $50 \%$ dos custos operacionais totais de sistemas de ultrafiltração. O equacionamento considera o balanço de água de alimentação e produção de concentrado em função das durações e vazões das etapas de operação e contralavagem.

A fração da composição do custo relativa à mão de obra e outros custos indiretos (alugueis, administração, etc..), embora possam representar uma fração significativa do TCO são considerados constantes, independente do dimensionamento do sistema. Não foram encontradas na literatura referências sobre a relação entre componentes indiretos do TCO e o dimensionamento dos sistemas. 
Os custos de reposição de membranas são expressivos em sistemas de micro e ultrafiltração. Modelos de custos econômicos usualmente adotados fixam uma vida útil entre 3 e 7 anos para esta composição. Pickering e Weisner (1992) fixaram uma vida útil esperada para os elementos de membranas e acrescentaram o custo de capital, de forma permitir verificar os impactos do investimento no valor do metro cúbico de água. A distribuição anual foi realizada através da equação 3.17.

$$
C_{m a}=\frac{i}{(i+1)^{U_{m}}-1} \cdot N \cdot C_{m} C \mathrm{Cm}
$$

Aonde:

$\mathrm{U}_{\mathrm{m}}=$ vida útil da membrana em anos

$\mathrm{C}_{\mathrm{m}}=$ custo unitário das membranas

$\mathrm{C}_{\mathrm{ma}}=$ Custo das membranas distribuído anualmente

$\mathrm{i}=$ taxa de juros anual

$\mathrm{N}=$ quantidade de elementos de membrana instalados

Quando se trata de analisar o custo do sistema ao longo de sua vida útil, os custos operacionais passam a ser significativos. Uma das ferramentas disponíveis para este tipo de análise é a Análise de Custos ao Longo do Ciclo de Vida, apresentada em detalhes no manual $n^{\circ} 135$ publicado pelo National Institute of Standards and Technology (NIST) em 1995. Os cálculos propostos por Pickering e Weisner, em 1992 estão de acordo com a metodologia proposta pelo NIST.

De forma a ilustrar a distribuição dos custos operacionais entre diferentes autores foi elaborada a tabela 3.5 comparando a participação de componentes individuais na composição final do custo. É possível observar que o custo de água e membranas tem um papel importante na composição dos custos finais, a participação da energia elétrica varia bastante, possivelmente em função da configuração da instalação utilizada (cross-flow ou dead-end). 
Tabela 3.5 - Composição dos custos operacionais segundo a literatura.

\begin{tabular}{|c|c|c|c|c|c|c|c|c|}
\hline Autor/Referência & $\stackrel{\circ}{\frac{1}{<}}$ & 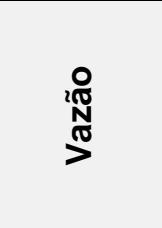 & 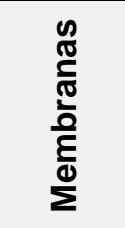 & 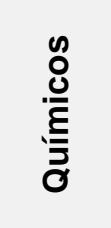 & $\begin{array}{l}\frac{\pi}{\sigma} \\
\frac{\sigma}{\varpi} \\
\frac{\omega}{\omega}\end{array}$ & 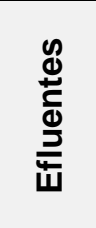 & $\stackrel{\frac{\pi}{2}}{\frac{\pi}{<}}$ & 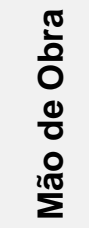 \\
\hline Pickering e Weisner & 1992 & $200 \mathrm{~m}^{3} / \mathrm{h}$ & $84 \%$ & & $16 \%$ & & & \\
\hline Daramola e Keesman & 2001 & $160 \mathrm{~m}^{3} / \mathrm{h}$ & $49,5 \%$ & $7,5 \%$ & $9,5 \%$ & $34 \%$ & & \\
\hline Mierzwa et al. & 2008 & $360 \mathrm{~m}^{3} / \mathrm{h}$ & $25 \%$ & $6 \%$ & $52 \%$ & $7 \%$ & & $10 \%$ \\
\hline Zondervan et al. & 2008 & & $35 \%$ & $10 \%$ & $7 \%$ & $3 \%$ & $45 \%$ & \\
\hline
\end{tabular}




\section{MÉTODOS E MATERIAIS}

\subsection{Metodologia de desenvolvimento}

O desenvolvimento deste trabalho foi dividido em duas etapas. A primeira consiste na concepção do modelo de dimensionamento e a segunda na validação dos resultados deste modelo com os dados obtidos em uma planta real, conforme ilustra o diagrama 4.1.

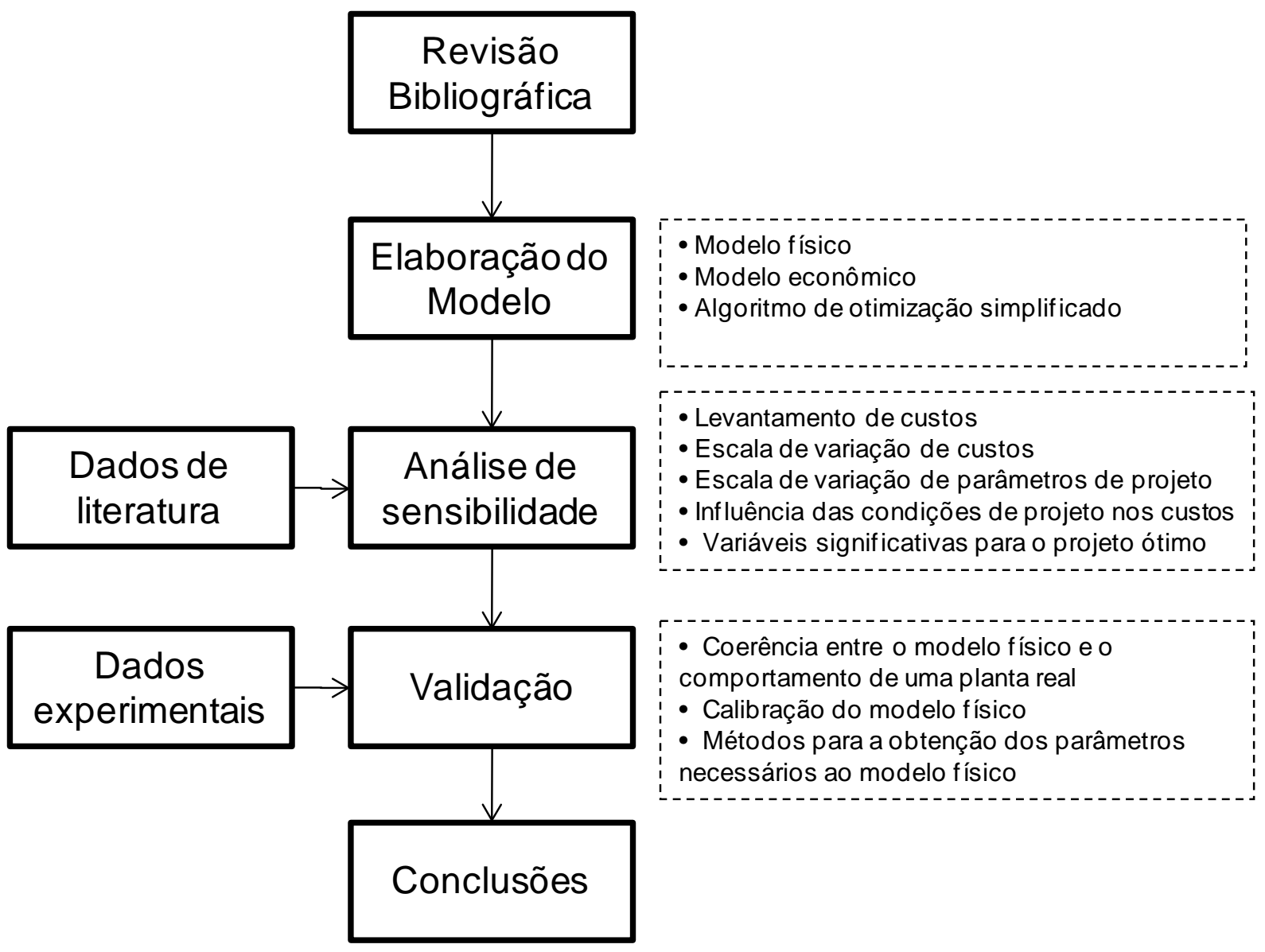

Figura 4.1 - Fluxograma de trabalho 


\subsection{Definição do processo de ultrafiltração genérico a ser modelado}

A configuração do sistema de ultrafiltração considerada para a elaboração do modelo de otimização (figura 4.2) trata de um arranjo genérico dead-end, conforme proposto por distintos fornecedores de membranas (Toray 2008; DOW, 2009; Hyflux 2010).

A princípio, esta configuração pode ser utilizada com elementos fornecidos por qualquer fabricante que atenda ao padrão de filtração dead-end com membranas de fibra-oca pressurizadas. As características de dimensionamento dos equipamentos, entretanto, deverão ser alteradas de acordo com as recomendações dos fabricantes. 


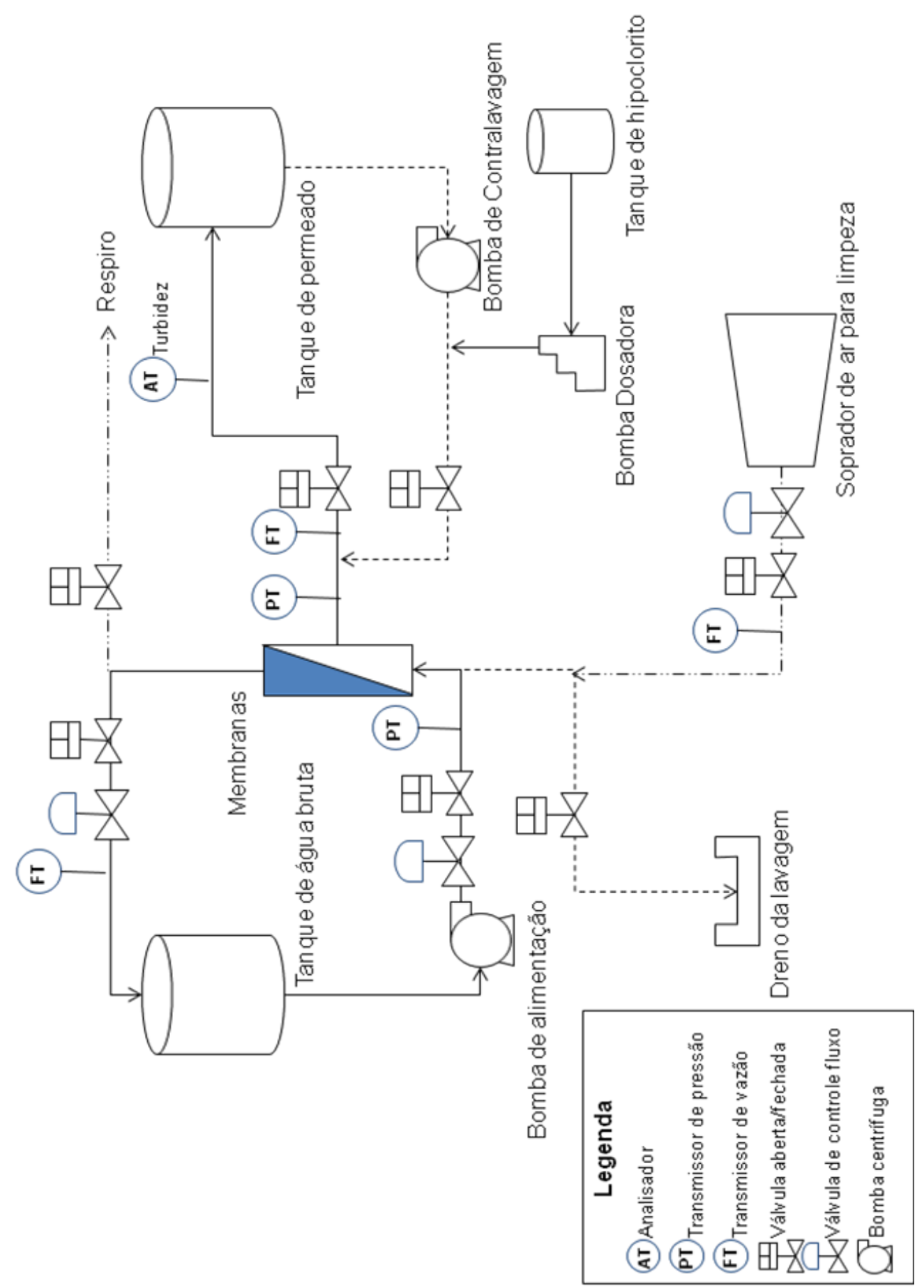

Figura 4.2 - Fluxograma do processo genérico de ultrafiltração modelado. 
A água de alimentação, proveniente de mananciais de superfície, subterrâneos ou de um sistema para tratamento de efluentes é pressurizada até o patamar de operação da ultrafiltração por uma bomba centrífuga, a seguir passa por uma préfiltração com telas de abertura inferiores a 200 micrômetros, para a remoção de materiais grosseiros e fibras que possam danificar fisicamente as membranas.

Após a pré-filtração a água pode receber dosagem de coagulante e de cloro com o objetivo de condicionar quimicamente a mesma e controlar o crescimento microbiano. A necessidade ou não da dosagem de químicos depende das características do manancial. De qualquer forma, para o projeto de sistemas alimentados por água de superfície é prudente conceber a estação prevendo este tipo de flexibilidade.

Na seqüência, a água quimicamente condicionada alimenta os vasos de membranas. Pode haver produção de uma corrente de concentrado no caso do sistema utilizar fluxo tangencial parcial.

Usualmente, para sistemas de fibras com sentido de filtração de fora para dentro, procura-se manter a produção contínua (fluxo constante) em detrimento do aumento da pressão de alimentação. Esta estratégia consiste do modo de operação padrão do modelo genérico.

Ao atingir uma pressão previamente estabelecida ou um determinado tempo de campanha, o sistema de controle interrompe o funcionamento da bomba de alimentação e alinha um conjunto de válvulas automáticas de forma a iniciar o ciclo de lavagem.

O ciclo de limpeza inicia-se com a contralavagem das membranas utilizando permeado. Uma bomba específica para esta finalidade pressuriza o permeado armazenado em um tanque de forma a inverter o sentido da passagem de água através das membranas. Esta operação tem duração estimada em 1 minuto podendo ser otimizada de acordo com a eficácia da limpeza observada. A contralavagem pode ser realizada com dosagem de hipoclorito de sódio para aumento da eficiência. 
Na segunda etapa do ciclo de limpeza, ar proveniente de um soprador ou compressor é aplicado na extremidade inferior do vaso de forma a propiciar arraste de partículas depositadas na superfície da membrana. A limpeza com ar usualmente é realizada simultaneamente com a contralavagem de qualquer forma, é possível estender a aeração para antes ou depois da contralavagem com o intuito de economizar água.

A terceira etapa da limpeza consiste na drenagem dos vasos de membranas para a remoção de todos os sólidos desprendidos durante as etapas anteriores.

A quarta etapa consiste do enchimento dos vasos de membranas com água bruta, algumas vezes também denominada enxágüe quando a volume é superior ao necessário para o preenchimento dos elementos.

\subsection{Considerações para a concepção do modelo de dimensionamento}

Neste trabalho, os parâmetros de projeto a serem determinados pelo modelo de dimensionamento foram fixados na forma das seguintes variáveis:

- Quantidade de membranas;

- Pressão e vazão da bomba de alimentação;

- Pressão e vazão da bomba de contralavagem;

- Volume do tanque de contralavagem;

- Duração dos ciclos operacionais;

- Consumo diário de produtos químicos;

- Recuperação global do sistema;

- Pressão e vazão do sistema de aeração.

O modelo de dimensionamento proposto teve como premissa a otimização do projeto de sistemas de micro e ultrafiltração do tipo dead-end do ponto de vista econômico, ou seja, menores custos ao longo do ciclo de vida da planta. O modelo foi concebido com base no princípio de bloqueio de poros de Hermia (1982), adaptado por Blankert (2006) utilizando como valores de entrada dados de ensaios 
simples, em células de fluxo ou em unidades piloto, com o intuito de permitir dimensionar equipamentos de forma rápida e relativamente segura, dispensando Iongos estudos de viabilidade. O uso de um equacionamento simplificado também possibilita a aplicação do mesmo em membranas de fabricantes distintos.

O modo de operação foi considerado o de fluxo constante, e pressão variável, padrão para este tipo de configuração no saneamento público e recomendado pelos fabricantes de membranas (Toray 2008; DOW, 2009; Hyflux 2010).

Para o sistema genérico proposto, são apresentados na tabela 4.1 os parâmetros de projeto considerados necessários para dimensionar processo (colunas) e as variáveis de entrada necessárias à sua composição (linhas). Esta relação foi utilizada como base para o equacionamento do modelo físico. 
Tabela 4.1 - Correlação entre os parâmetros de projeto e variáveis de entrada necessárias ao cálculo. Variáveis destacadas representam aquelas que podem ser especificadas pelo projetista, permitindo, desta forma a otimização do projeto.

Variáveis de entrada Parâmetros de projeto

Quantidade de elementos

Área específica dos elementos

Constante de formação de

depósitos

Coeficiente de incremento de resistência

Coeficiente de pressão e fluxo

Pressão máxima admissível

Taxa de recirculação parcial

Fluxo na contralavagem

Resistência da membrana

Temperatura

Duração da etapa de filtração

Duração da drenagem

Duração da limpeza

Duração do enxágüe

Duração da aeração

Vazão específica de ar

Vazão média de produto desejada $\quad X$

Rendimento da bomba de

alimentação

Rendimento da bomba de

contralavagem

Rendimento do soprador

Dosagem de cloro durante a

limpeza

Dosagem de coagulante

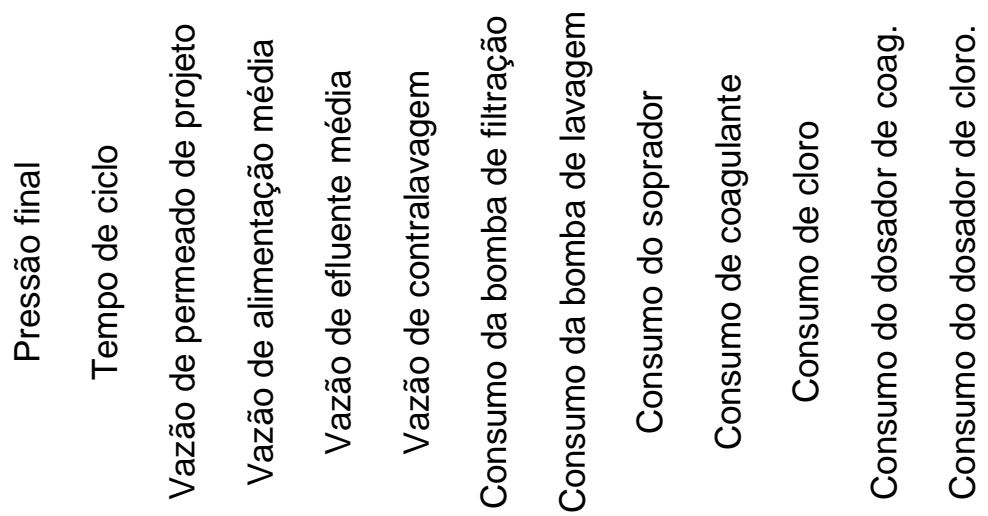

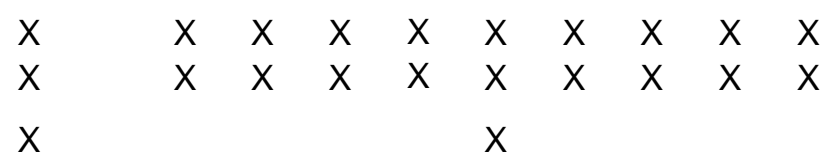

$x$

$x+x$

$x \quad x$

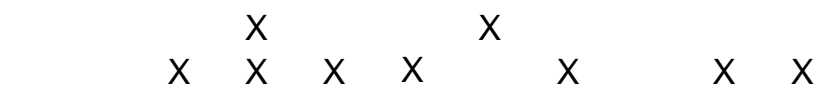

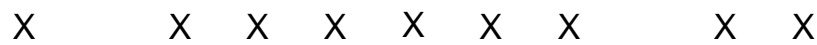

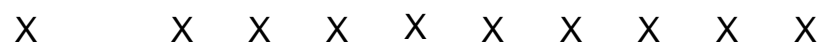

$\begin{array}{llllllllllllllllll}x & x & x & x & x & & x & & x\end{array}$

$\begin{array}{llllll}x & x & x & x & x\end{array}$

$\begin{array}{llllllllllllllllll}x & x & x & x & x & x & x\end{array}$

$\begin{array}{llll}x & x & x & x\end{array}$

$x \quad x \quad x$

$X$

$x$

$x \quad x \quad x$

$x$

$x \quad x$

$x$

$x$

$x$

A lista de entradas do modelo conta com parâmetros de entrada aperfeiçoáveis e não aperfeiçoáveis. As variáveis aperfeiçoáveis podem ser entendidas como valores definidos pelo projetista, que afetam o comportamento do sistema e que podem ser alterados de forma a minimizar os custos totais. As variáveis não aperfeiçoáveis, por sua vez, são definidas por condições alheias ao controle do projetista. Como 
exemplo de variáveis não aperfeiçoáveis é possível indicar a área específica das membranas e rendimentos de bombas, que são definidos pelos fabricantes bem como os coeficientes de formação de depósitos que dependem das interações entre a água e a membrana.

Com base nesta premissa e nas variáveis de projeto previamente estabelecidas, as seguintes variáveis foram consideradas aperfeiçoáveis:

- Quantidade de elementos de membrana;

- Taxa de recirculação parcial;

- Fluxo de contralavagem;

- Vazão específica de ar;

- Duração da etapa de filtração;

- Duração da etapa de drenagem;

- Duração da etapa de limpeza em contralavagem;

- Duração do enxágüe;

- Duração da etapa de aeração;

- Dosagem de cloro durante a limpeza;

- Dosagem de coagulante durante a operação; 
Das variáveis aperfeiçoáveis levantadas para o processo, no escopo de desenvolvimento proposto para este trabalho, permitem a otimização apenas aquelas diretamente relacionadas através do modelo de bloqueio de poros de Hermia (1982): a duração do ciclo de filtração (t) e quantidade de elementos instalados (N). A equação 4.1, baseada no princípio da permeabilidade, ilustra esta relação.

$$
\Delta P(t, N)=\frac{R(t) \cdot Q(t)}{\mu \cdot A(N)}
$$

Aonde:

$\Delta \mathrm{P}=$ Pressão diferencial, implica no consumo de energia elétrica.

$\mathrm{R}(\mathrm{t})=$ Resistência da membrana, aumenta ao longo do tempo de acordo com o acúmulo de sólidos.

$\mathrm{Q}(\mathrm{t})=$ Vazão de projeto. Aumenta quando a duração do ciclo de filtração diminui em função do consumo de permeado durante cada contralavagem.

$A(N)=$ Área de membranas de acordo com a quantidade de elementos instalados $(N)$.

$\mu=$ Viscosidade da água.

Se por um lado a simplificação através do modelo de Hermia facilita o projeto uma vez que requer poucos estudos em campo e análises em laboratório, por outro, pode levar ao super ou subdimensionamento do equipamento em caso de inadequação do comportamento das membranas às curvas teóricas previstas. A comparação dos resultados do modelo com dados de plantas em operação permite verificar o desvio das simplificações adotas em relação à realidade um sistema de ultrafiltração. A partir destas comparações é possível estabelecer coeficientes de ajuste ou concluir que o modelo é ineficaz para o propósito de dimensionamento.

Fenômenos como a redução da vida útil das membranas em função do excesso de ciclos de limpeza, freqüência de limpezas químicas, influencia do tempo, vazão de contralavagem, e aeração no resultado da limpeza, relação dose/eficácia de produtos químicos e formação de biofilmes não puderam ser previstos a partir das ferramentas obtidas na literatura. Desta forma, as variáveis aperfeiçoáveis relacionadas foram consideradas constantes devendo ser estimadas ou fixadas pelo projetista. Em futuros aperfeiçoamentos do modelo físico, outras relações, como a relação entre vazão de ar e duração da etapa de limpeza com ar poderão ser integradas de forma, possibilitar a otimização destes dois parâmetros. 
Os custos atribuídos às variáveis de projeto atuam como pesos classificando a importância de cada um dos índices. Ao longo da análise de sensibilidade, foram realizados experimentos para verificar o impacto da alteração das variáveis econômicas no projeto do sistema de ultrafiltração.

A concepção do processo de dimensionamento ótimo (figura 4.3) foi dividida em blocos de forma a possibilitar a validação, teste e conferência de cada um dos mecanismos individualmente. No caso de fracasso ou resultados diferentes dos esperados em uma das etapas, as demais ainda podem contar com aplicação prática. A descrição de cada um dos blocos é apresentada na seqüência:

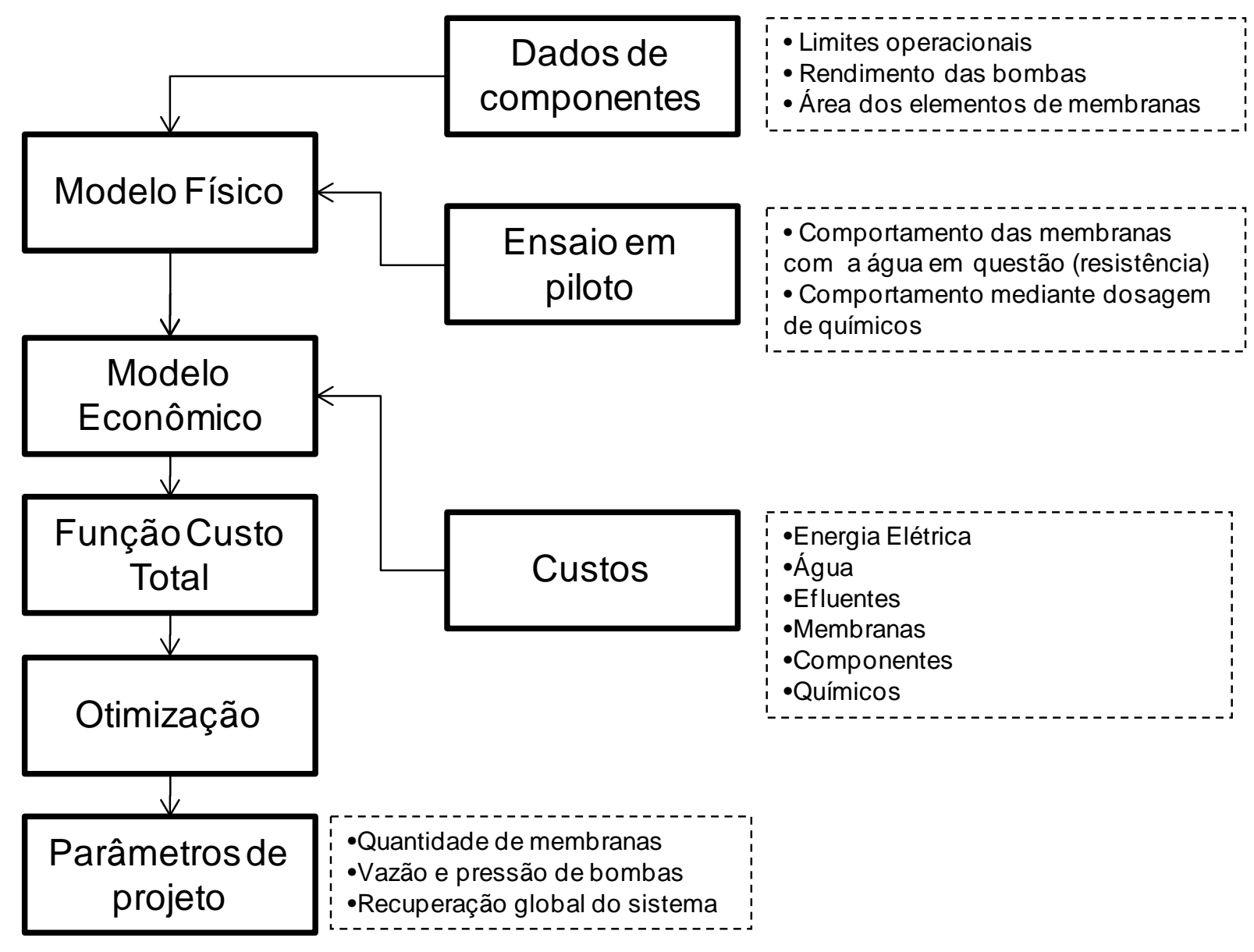

Figura 4.3 - Processo de dimensionamento econômico

1. Modelo Físico envolvendo as variáveis de dimensionamento, comportamento hidráulico das membranas e suas respectivas influências na operação do 
sistema baseando-se nos modelos de bloqueio de poros propostos por Hermia (1982).

2. Modelo Econômico: Atribui custos às variáveis de dimensionamento permitindo avaliar o impacto econômico de cada um dos parâmetros de projeto.

3. Composição do TCO (Custos Totais de Propriedade): A partir dos valores determinados no modelo econômico, é composta a função objetivo com base nos custos totais de propriedade. Uma análise de sensibilidade permite identificar variáveis mais significativas, candidatas à otimização.

4. Otimização das variáveis aperfeiçoáveis do TCO de forma a encontrar os parâmetros ótimos de projeto. Neste trabalho, apenas a relação entre a duração do ciclo e a quantidade de membranas foi incluída no algoritmo uma vez que para as demais não foi possível levantar modelos de comportamento.

\subsection{Métodos utilizados para a análise de sensibilidade}

A função de TCO é composta de uma série de características do sistema definidas pelas variáveis aperfeiçoáveis e não aperfeiçoáveis e por fatores econômicos, os dois últimos grupos estão fora do controle dos projetistas. A análise de sensibilidade tem como objetivo verificar a influência das decisões do projeto (dimensionamento) no TCO, permitindo identificar as variáveis que mais influenciam nos custos dentro de escalas viáveis em um projeto.

Dentre os inúmeros métodos e modelos matemáticos disponíveis para a realização de análises de sensibilidade, foi utilizada para a verificação das entradas do modelo uma metodologia determinística, baseada na técnica unidimensional OAT (One At the Time). Neste tipo de análise, uma variável é alterada enquanto as outras permanecem constantes permitindo verificar, desta forma, o efeito da variável individual na composição do custo total. Exemplos da aplicação desta metodologia são discutidos no manual do NIST (1995) e por Pannel (1997) e foram utilizados como base para a elaboração da metodologia da análise de sensibilidade. A avaliação OAT tem como limitação a ineficiência na medição de efeitos combinados 
entre duas ou mais variáveis sobre a função objetivo. É esperado que o entendimento das equações que compõem o modelo permita identificar estes efeitos paralelamente aos resultados da metodologia OAT.

No projeto de sistemas de ultrafiltração, os resultados das decisões de projeto são ponderados pelos custos a que estão ligados de forma a compor o valor final do tratamento. Dependendo de fatores econômicos alguns itens como energia elétrica, água e até a quantidade de membranas podem ser muito ou pouco significativos na contribuição sobre o TCO. A análise da sensibilidade, considerando a mudança das variáveis econômicas pode ser realizada através de cenários em que condições específicas de mercado são verificadas.

A qualidade da análise de sensibilidade, no caso do modelo proposto, é influenciada também pela proporcionalidade entre os itens que compõem o processo. As variáveis aperfeiçoáveis de projeto devem ser alteradas dentro de intervalos realistas, respeitando os limites físicos, recomendações de fabricantes e perdas aceitáveis no processo não permitindo valores completamente arbitrários. A forma encontrada para garantir esta proporcionalidade foi alimentar o modelo com informações provenientes de um projeto real ou dentro das recomendações dos fabricantes, bem como custos dentro do contexto atual, limitando a variação das entradas a possíveis restrições físicas ou faixas usuais de projeto.

Os indicadores de sensibilidade adotados na análise do TCO, definidos conforme Pannel (1997) são:

- Elasticidade - Representa a variação do TCO em função de um incremento unitário na variável de projeto. Determinada através da equação 4.2.

- Índice de Sensibilidade - Representa a amplitude de variação do TCO no intervalo em que as variáveis de projeto podem ser alteradas. Do ponto de vista prático permite identificar variáveis que, apesar de possuírem uma grande influência na composição do TOC (elasticidade), dentro de seu intervalo de variação afetam de forma mínima os custos. Determinado através da equação 4.3. 


$$
\begin{aligned}
e & =\frac{\delta Y}{\delta X} \cdot \frac{X}{Y} \\
S I & =Y_{\max }-Y_{\min }
\end{aligned}
$$

Aonde:

$\mathrm{e}=$ Elasticidade

$\mathrm{SI}=$ Índice de Sensibilidade

$Y=$ Valor do TCO de referência, com base em recomendações dos fornecedores de membranas.

$\mathrm{Y}_{\text {máx }}=$ Valor do TCO máximo, para o limite superior ou inferior da variável em análise.

$\mathrm{Y}_{\text {mín }}=$ Valor do TCO mínimo, para o limite superior ou inferior da variável em análise.

$X=$ Valor de referência da variável em análise, recomendação dos fornecedores de membranas.

\subsection{Metodologia utilizada para a determinação dos parâmetros de comportamento das membranas}

Os parâmetros de bloqueio dos poros das membranas bem como a permeabilidade da mesma são imprescindíveis para a alimentação do modelo físico. A determinação destes coeficientes pode ser realizada a partir dos resultados obtidos em unidade piloto ou através de arranjos experimentais em laboratório com membranas e amostras da água que se deseja estudar.

Para o arranjo experimental em laboratório ou em piloto, foi elaborado um protocolo de determinação. O levantamento dos parâmetros foi dividido em suas seqüências. Na primeira, o arranjo experimental é utilizado para a determinação da resistência da membrana com água pura. A resistência usualmente pode ser calculada através dos dados fornecidos nos catálogos dos fabricantes. Confrontar os dados dos fabricantes com os obtidos no laboratório permite verificar a confiabilidade das informações de catálogo e ao mesmo tempo validar a o equipamento experimental.

A segunda seqüência consiste da medição dos coeficientes de bloqueio de poros ( $m, R_{0}$ e $\left.C\right)$ das membranas utilizando água bruta e a mesma instalação experimental. Os dados obtidos alimentarão o modelo físico e o modelo de dimensionamento econômico. 


\subsubsection{Resistência da membrana}

O método para a determinação da resistência da membrana consiste medir a relação entre a vazão permeada e a pressão trans-membrana. Através da equação 3.1 a resistência da membrana é determinada. O ensaio é realizado com água isenta de sólidos e, para fluxo constante, é esperado que não exista aumento da pressão ao longo do ciclo de filtração uma vez que não há formação de depósitos.

\subsubsection{Coeficientes de bloqueio de poros}

O fluxo através das membranas pode ser definido através da equação 4.4 aonde d $\omega$ representa o volume filtrado por unidade de área de membrana e dt o intervalo de tempo.

$$
J=\frac{d \omega}{d t}
$$

Os coeficientes de bloqueio de poros, conforme constatado por Hermia (1982), determinam a relação 3.4 aonde $\mathrm{R}$ é a resistência total conforme a definição da equação 3.1. Extraindo o logaritmo dos dois termos que compõem esta relação, é possível representá-la na forma da equação 4.5, uma reta com abscissa $\ln (R)$ e ordenada $\ln (d w / d R)$. Desta forma, os valores $C$ e m equivalem à interceptação e a declividade respectivamente.

$$
\ln \left(\frac{d R}{d \omega}\right)=\ln (C)+m \cdot \ln (R)
$$

O método para a determinação dos coeficientes de formação de depósitos consiste em, através da elaboração de uma reta com dados de volume filtrado em função de tempo, estimar os parâmetros C e m para a membrana em questão. 


\subsection{Unidade piloto de ultrafiltração}

A verificação do modelo físico foi realizada em uma unidade piloto de ultrafiltração pertencente à empresa Perenne. O equipamento foi instalado em um galpão pertencente laboratório de microbiologia do ICB-USP, localizado às margens da Raia Olímpica da Cidade Universitária, um lago artificial utilizado em práticas desportivas. A proximidade da planta piloto com o manancial permitiu a operação contínua do sistema de Ultrafiltração, alimentado com água captada diretamente da raia.

A unidade (figura 4.4) é capaz de produzir até $8 \mathrm{~m}^{3} / \mathrm{h}$ de água tratada e aceita múltiplas configurações de membranas, incluindo tubulares, fibras-ocas, espirais bem como múltiplas alternativas de operação como cross-flow, dead-end e crossflow parcial. Todas as condições de operação de uma planta real de ultrafiltração podem ser simuladas através deste sistema.

As características técnicas do equipamento bem como os instrumentos utilizados e seus respectivos limites e precisão são apresentados abaixo.

- Sistema: Unidade Piloto Perenne UF-1

- Fabricante/ano: Perenne/2010

- Condição de operação: dead-end

- Leituras de pressão: Na alimentação e no permeado

- Instrumentos de leitura de pressão (primeira parte dos ensaios): Transdutor digital com escala 0 a 6 bar com célula de cerâmica (precisão +/- 0,018 bar) e indicação no painel com resolução de 0,1 bar.

- Instrumentos de leitura pressão (segunda parte dos ensaios): Manômetro digital com escala de -1 a 10 bar, precisão de 0,005 bar e indicação no display com resolução de 0,01 bar.

- Leituras de vazão: No permeado, no concentrado e na linha de ar através de rotâmetros. 
- Escala dos rotâmetros: 0,6 a 6m³/h para água (precisão +/- 0,12m³/h) e 0 a 4Nm³/h (precisão +/- 0,08 Nm³/h) para ar.

- Automação: Através de válvulas pneumáticas atuadas por CLP.

- Ajuste de vazão: Manual através de válvulas diafragma.

- Controlador Lógico Programável (CLP): Posicionamento de válvulas, alarmes, coleta de dados (datalog) e execução das etapas de operação e limpeza.

- Aeração: através de compressor de ar dedicado e regulador de vazão.

- Membrana: Hyflux 600ETN de fibra oca pressurizada e $23 \mathrm{~m}^{2}$ de área.

- Leitura de turbidez: Turbidímetro HACH 2100P com escala de 0 a $1000 N T U$ e precisão de 0,01NTU.

- Leitura de temperatura e pH: Analisador Multiparâmetro Hach HQ30d com precisão de $0,3^{\circ} \mathrm{C}$ para temperatura e 0,6 para $\mathrm{pH}$.

Outras características da instalação são apresentadas na seqüência:

- Manancial: Raia Olímpica da Cidade Universitária - São Paulo.

- Período de operação: Outubro/2010 e Janeiro/2011

- Clima durante a operação: Poucas chuvas em outubro e muito chuvoso em janeiro. A qualidade de água, todavia, manteve-se praticamente constante como será apresentado na seção de resultados deste texto.

- Captação: Direta e contínua, em superfície.

- Pré-tratamento: Filtros rápidos de piscina com areia grossa com $20 \mathrm{~cm}$ de camada filtrante para a remoção de sólidos grosseiros.

- Destino do permeado: Tanque de alimentação dos sistemas de Osmose Reversa.

- Dosagem de químicos: Não foi realizada a dosagem de coagulante.

- Recirculação: Não foi utilizado o regime de cross-flow parcial ou recirculação da corrente de alimentação.

O processo de tratamento é apresentado no fluxograma apresentado na figura 4.5. A água foi captada diretamente da raia (figura 4.6), a aproximadamente $1 \mathrm{~m}$ de distância da margem e $30 \mathrm{~cm}$ de profundidade e encaminhada através de uma bomba até um reservatório superior de equalização de pressão com 300L de 
capacidade. De forma a garantir a renovação da água, o reservatório extravasa continuamente levando a um tempo de residência de aproximadamente 4,5 minutos. Á água então era encaminhada por gravidade até o pré-filtro alimentando na seqüência o sistema de Ultrafiltração, que opera de acordo com as fases descritas anteriormente no item 4.2 desta metodologia.

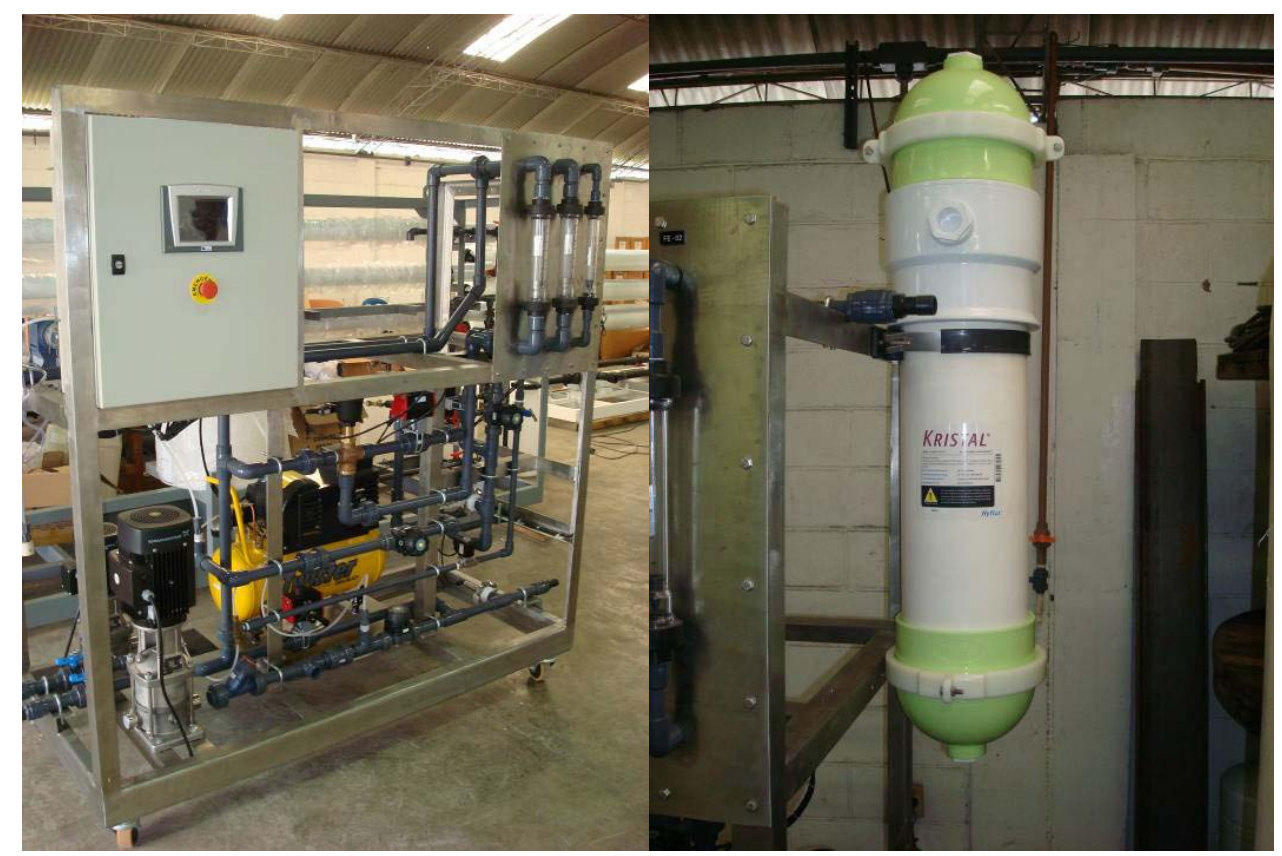

Figura 4.4 - Unidade de ultrafiltração (esquerda) e módulo instalado (direita)

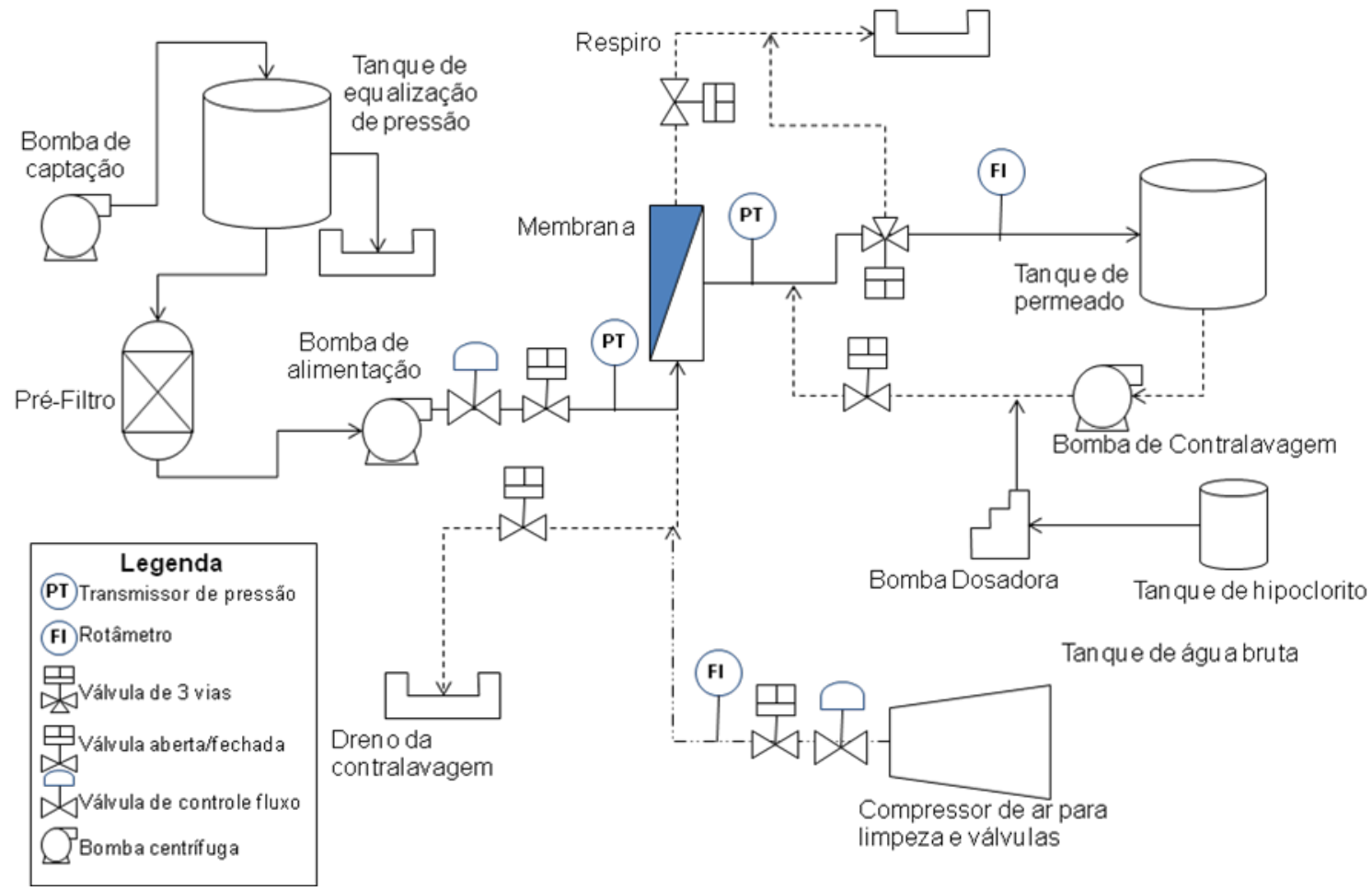

Figura 4.5 - Fluxograma simplificado do processo de tratamento e da Unidade Piloto 


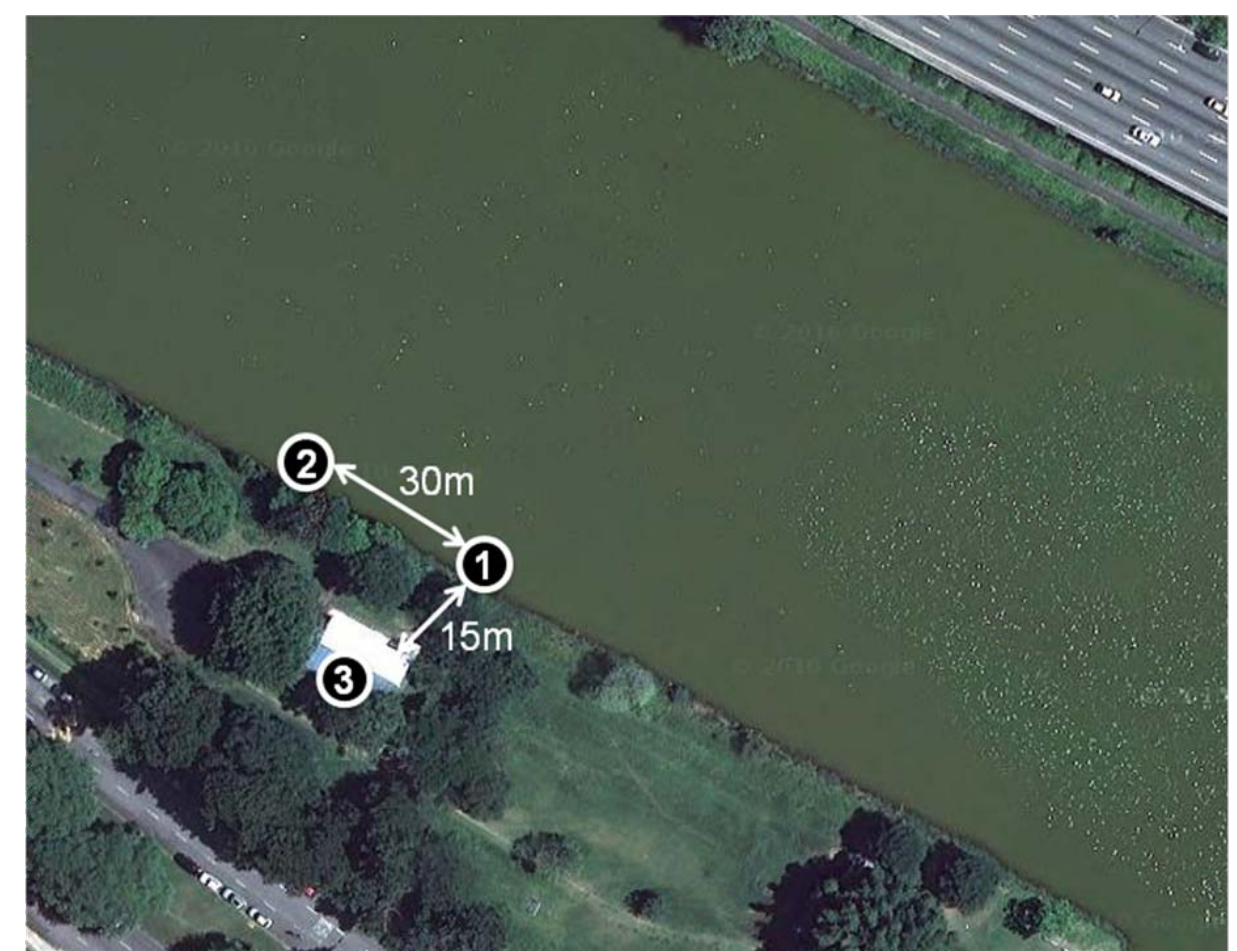

Figura 4.6 - Localização da captação (1), descarte de permeado/concentrado (2) e da planta piloto (3) na Raia Olímpica da USP. (Fonte da fotografia: http://maps.google.com)

Os ensaios na unidade de ultrafiltração foram conduzidos em 9 fases e acompanhados por um técnico especializado, responsável pela coleta de dados.

As primeiras 5 fases foram executadas no mês de novembro/2010, logo no início do período chuvoso. De forma a coletar dados mais precisos (precisão da leitura de pressão 10 vezes superior), em janeiro/2011 um novo ciclo de coleta de dados foi iniciado. A membrana permaneceu fora de operação por 2 meses e, severamente colmatada, deu início à fase VI.

Durante cada uma das fases, foram alteradas as condições de operação de forma a verificar a influência no comportamento do sistema conforme o indicado na tabela 4.2. Na fase I foi utilizada água limpa, isenta de sólidos, para a medição da permeabilidade da membrana e ajustes no equipamento.

A limpeza química de manutenção foi realizada em duas ocasiões. Após a fase VI foi utilizada uma solução de Hidróxido de Sódio (pH 11) e tempo de circulação de 1 
hora. Após a fase VII foi utilizada uma solução com Hipoclorito de Sódio (500mg/L) e Hidróxido de Sódio (pH 11) com uma hora de circulação.

Tabela 4.2 - Fases de operação da unidade piloto de Ultrafiltração.

\begin{tabular}{|c|c|c|c|c|c|c|}
\hline \multirow{2}{*}{$\begin{array}{l}\text { Primeira parte } \\
\text { Parâmetro }\end{array}$} & & \multicolumn{5}{|c|}{ Fase } \\
\hline & & I (água limpa) & II & III & IV & V \\
\hline Fluxo & $\mathrm{L} / \mathrm{m}^{2} \cdot \mathrm{h}$ & 50 & 50 & 60 & 70 & 65 \\
\hline Vazão de permeado & L/h & 1150 & 1150 & 1380 & 1600 & 1500 \\
\hline Tempo de ciclo & $\min$ & 30 & 30 & 30 e 45 & 45 & 45 \\
\hline Duração do ensaio & $\mathrm{h}$ & 120 & 48 & 72 & 2 & 3 \\
\hline Segunda parte & & \multicolumn{5}{|c|}{ Fase } \\
\hline Parâmetro & & VI (membrana suja) & VII (limp & parcial) & VIII & IX \\
\hline Fluxo & $\mathrm{L} / \mathrm{m}^{2} \cdot \mathrm{h}$ & 60 & & & 60 & 70 \\
\hline Vazão de permeado & $\mathrm{L} / \mathrm{h}$ & 1380 & & & 1380 & 1600 \\
\hline Tempo de ciclo & $\min$ & 20 & & & 30 e 45 & 45 \\
\hline Duração do ensaio & $\mathrm{h}$ & 2 & & & 18 & 6 \\
\hline
\end{tabular}

A contralavagem automática foi executada de acordo com as recomendações do fabricante da membrana não sendo alterada durante as fases de operação do piloto conforme as condições indicadas na tabela 4.3.

Tabela 4.3 - Condições da contralavagem.

\begin{tabular}{llr}
\hline \multicolumn{1}{c}{ Parâmetro } & \multicolumn{1}{c}{ Unidade } & Valor \\
Vazão de ar & $\mathrm{Nm} 3 / \mathrm{h}$ & 2,8 \\
Vazão de contralavagem & $\mathrm{L} / \mathrm{h}$ & 2000 \\
Dosagem de cloro na contralavagem & $\mathrm{mg} / \mathrm{L}$ & 10 \\
Duração da contralavagem com aeração & $\mathrm{S}$ & 60 \\
Duração da contralavagem sem aeração & $\mathrm{s}$ & 30 \\
Duração da drenagem com contralavagem & $\mathrm{s}$ & 30 \\
Duração do enchimento & $\mathrm{s}$ & 20 \\
\hline
\end{tabular}

De forma a possibilitar a avaliação das curvas de obstrução das membranas, coletas de dados a cada dois minutos foram realizadas durante a primeira, durante a quinta e durante a $23^{a}$ hora da operação. Entre a segunda e a quarta hora de operação, em cada uma das fases, os valores foram medidos imediatamente antes e imediatamente após a contralavagem automática. Os parâmetros de processo foram coletados manualmente conforme a tabela 4.4 . 
Tabela 4.4 - Freqüência e dados coletados ao longo da operação.

\begin{tabular}{|c|c|c|c|c|c|c|c|}
\hline \multirow[b]{2}{*}{ Frequência } & \multirow[b]{2}{*}{ 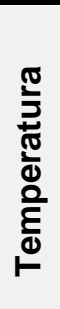 } & \multicolumn{2}{|c|}{ Turbidez } & \multicolumn{2}{|c|}{ Pressão } & \multicolumn{2}{|c|}{ Vazão } \\
\hline & & 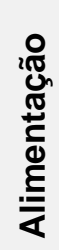 & 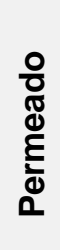 & 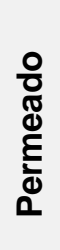 & 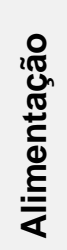 & 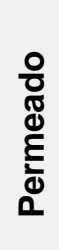 & 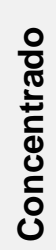 \\
\hline Após a regulagem na partida & $x$ & $x$ & $x$ & $x$ & $x$ & $x$ & $x$ \\
\hline A cada 2 min durante a primeira hora. & & & & $x$ & $x$ & $x$ & $x$ \\
\hline $\begin{array}{l}\text { Imediatamente antes das contralavagens a } \\
\text { cada } 1 \text { hora por } 3 \text { horas }\end{array}$ & $x$ & $x$ & $x$ & $x$ & $x$ & $x$ & $x$ \\
\hline $\begin{array}{l}\text { Imediatamente após a contralavagens a } \\
\text { cada } 1 \text { hora por } 3 \text { horas }\end{array}$ & $x$ & $\mathrm{x}$ & $x$ & $x$ & $x$ & $x$ & $x$ \\
\hline A cada 2 min. durante a quinta hora & & & & $x$ & $x$ & $x$ & $x$ \\
\hline A cada 2 min. durante a última hora. & & & & $x$ & $x$ & $x$ & $x$ \\
\hline Antes de desligar & $x$ & $x$ & $x$ & $x$ & $x$ & $x$ & $x$ \\
\hline
\end{tabular}

Durante os 13 dias de operação da unidade piloto de Ultrafiltração, foram tomadas 1033 séries de parâmetros operacionais compostas dos seguintes índices: turbidez da alimentação, turbidez do permeado, pressão de alimentação, temperatura e vazão de permeado. 


\subsection{Método para a otimização discreta da função custo}

Neste trabalho, a minimização da função de custo total foi realizada considerando duas variáveis de projeto através de um algoritmo de busca discreta em um espaço bidimensional pré-definido. A metodologia de cálculo do algoritmo é apresentada nesta seção enquanto que a adaptação do mesmo ao problema de otimização do TCO é discutida em detalhes na seção de resultados.

A função objetivo a ser minimizada é definida na forma $F(x, y)$ na qual $x, y$ representam as variáveis de projeto. Considerando os valores $x$ e y discretos, maiores do que zero, e limitados superiormente pelas constantes i e j definidas pelos projetistas em função de limites físicos ou limites impostos pelos fornecedores de tecnologia, é possível compor uma matriz denominada "origem" contendo os valores admissíveis para a função $F(x, y)$ dentro deste espaço conforme ilustra a figura 4.7.

\begin{tabular}{|c|c|c|c|}
\hline$F(1,1)$ & $F(1,1)$ & $F(1, \ldots)$ & $F(1, j)$ \\
\hline$F(2,0)$ & $\ldots$ & $\ldots$ & $\ldots$ \\
\hline$F(\ldots, 0)$ & $\ldots$ & $\ldots$ & $\ldots$ \\
\hline$F(1,0)$ & $\ldots$ & $\ldots$ & $F(i, j)$ \\
\hline
\end{tabular}

Figura 4.7 - Matriz de origem contendo todas as possíveis combinações de resultados para a função $F(x, y)$.

A partir do cálculo de todos os valores da matriz de origem, inicia-se o processo de busca definindo o valor mínimo inicial, variável $\mathrm{M}$, como o obtido na primeira linha e na primeira coluna da matriz. Conforme a matriz origem é percorrida, se o valor da posição é igual a M, a mesma é armazenada na matriz denominada "resultado" (figura 4.8), que possui capacidade igual à matriz de origem e que contém as coordenadas dos mínimos obtidos. Se o valor encontrado na posição atual é inferior a $\mathrm{M}$, a matriz resultado é esvaziada e a variável $\mathrm{M}$, assim como o primeiro item da matriz resultado assumem o novo valor mínimo. 


\begin{tabular}{|c|c|c|c|}
\hline & $M 1$ & $M 2$ & $\ldots$ \\
\hline$x$ & & & \\
\hline$y$ & & & \\
\hline$F(x, y)$ & & & \\
\hline
\end{tabular}

Figura 4.8 - Matriz de resultados com todas as ocorrências do valor mínimo para a função objetivo.

No final da busca, a matriz resultado contém os valores mínimos locais da função objetivo.

\subsection{Ferramentas computacionais}

Os modelos físico e econômico foram adaptados a uma planilha do Microsoft Excel 2007 para cálculo e análise dos resultados. Na planilha, cada célula recebeu o nome de uma variável, apresentando os resultados de forma tabular conforme ilustra a figura 4.9 .

A otimização numérica se deu através de um aplicativo programado na linguagem VBA (Visual Basic for Applications) acoplado à planilha. 


\section{Modelo Físico}

\section{A \\ B \\ C \\ D \\ E}

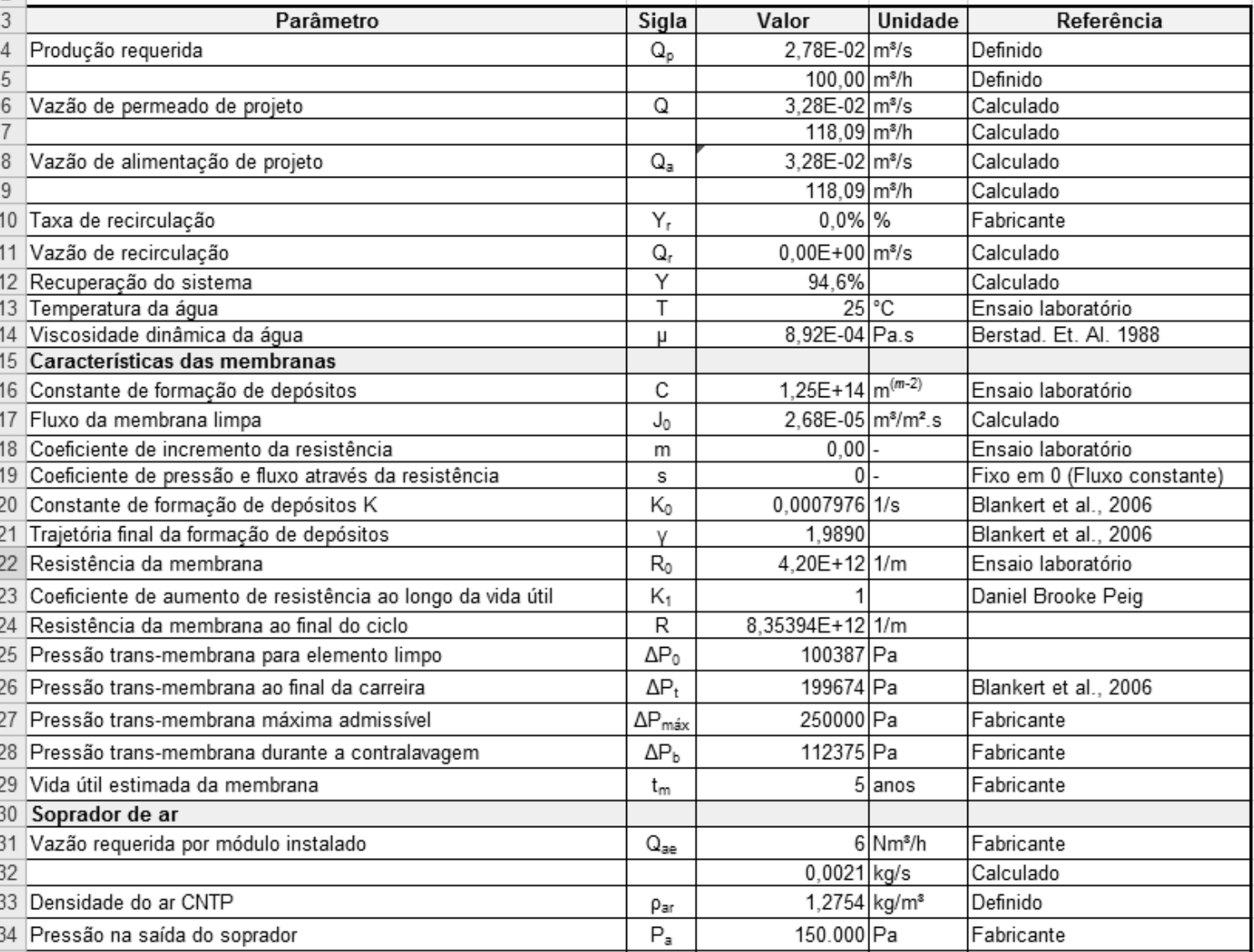

34 Pressão na saída do soprador

$150.000 \mathrm{~Pa}$

Fabricante

Figura 4.8 - Composição do modelo de dimensionamento na forma de planilha de cálculo. 


\section{RESULTADOS}

\subsection{Concepção do Modelo Físico}

O modelo físico tem como objetivo a simulação das características aperfeiçoáveis do sistema de tratamento a ser projetado e suas relações. Durante a concepção do modelo, foi considerada a aplicabilidade do mesmo na rotina de projetos de engenharia, ou seja, os dados de entrada devem ser de fácil obtenção: características das membranas disponibilizadas em catálogos técnicos e informações referentes à água a ser tratada e sua interação com a membrana, levantadas a partir de ensaios simples em laboratório ou em células de fluxo.

O modelo físico considerou o arranjo genérico definido na figura 4.2 da metodologia deste trabalho. Todas as equações utilizadas na concepção deste modelo foram desenvolvidas pelo próprio autor deste trabalho com base na revisão da bibliografia e balanços de massa de água, energia e produtos químicos.

Considerando que o controle do equipamento de ultrafiltração é realizado com base em medidas de vazão, diferencial de pressão e temporizadores; estas grandezas foram priorizadas no equacionamento permitindo assim uma associação mais simples com a programação e operação do equipamento.

O modelo físico inicia-se pela determinação da vazão de projeto, esta vazão representa o quanto de água efetivamente deverá ser filtrado através da membrana de forma a produzir a vazão média de produto desejada, levando em conta as demandas da contralavagem e os períodos em que o sistema deixa de produzir em virtude da operação de limpeza.

A vazão de projeto, neste caso, é calculada através da equação 5.1 composta pelo consumo na contralavagem $\left(\mathrm{Q}_{\mathrm{b}}\right)$ e da demanda de permeado exigida pela planta $\left(Q_{p}\right)$. A produção, conforme apresentado anteriormente é constante, independe do acúmulo de sólidos no interior dos elementos, em função disso, esta equação não 
deve ser aplicada em casos de operação com fluxo declinante. A limpeza química de manutenção pode ser considerada, na vazão de projeto, como um período em que o sistema não produz água.

$$
Q=\frac{\left(Q_{p} \cdot t+Q_{p} \cdot t_{f}+Q_{b} \cdot t_{b}\right)}{t_{t}}+\frac{Q_{p} \cdot t_{m}}{86400 \cdot I_{m}}
$$

$\mathrm{Q}=$ Vazão de permeado de projeto $\left(\mathrm{m}^{3} / \mathrm{s}\right)$

$\mathrm{t}=$ Duração da etapa de filtração (s)

$\mathrm{Q}_{p}=$ Vazão de água tratada final desejada $\left(\mathrm{m}^{3} / \mathrm{s}\right)$

$\mathrm{Q}_{\mathrm{b}}=$ Vazão de contralavagem $\left(\mathrm{m}^{3} / \mathrm{s}\right)$

$t_{t}=$ Duração total do ciclo - ver próxima equação (s)

$t_{f}=$ Duração da etapa de pré-operação ou enxágue (s)

$t_{b}=$ Duração da etapa de contralavagem (s)

$\mathrm{I}_{\mathrm{m}}=$ Intervalo entre limpezas de manutenção (dias)

$\mathrm{t}_{\mathrm{m}}=$ Duração das limpezas de manutenção (s)

O tempo total de ciclo representa a duração de um ciclo de operação+limpeza. A sua composição foi representada através da equação 5.2.

$$
t_{t}=t+t_{b}+c_{t a} \cdot t_{a}+t_{d}+t_{f}
$$

$\mathrm{t}_{\mathrm{t}}=$ Duração total do ciclo (s)

$\mathrm{t}=$ Duração da etapa de filtração $(\mathrm{s})$

$\mathrm{t}_{\mathrm{b}}=$ Duração da etapa de contralavagem (s)

$t_{a}=$ Duração da etapa de aeração (s)

$\mathrm{ct}_{\mathrm{a}}=$ Coeficiente da limpeza com ar. Igual a zero quando a limpeza com ar é realizada

simultaneamente à contralavagem com água, igual a 1 quando a limpeza com ar é realizada em momentos distintos. Pode assumir outros valores quando há sobreposição da limpeza com ar e da contralavagem.

$t_{d}=$ Duração da etapa de enchimento e drenagem (s)

$t_{f}=$ Duração da etapa de enxágue ou pré-operação (s) 
A vazão de alimentação considera a possibilidade de recirculação parcial conforme representado na equação 5.3. A recirculação parcial representa uma tendência para o projeto de novos sistemas baseados em fibras ocas pressurizadas a partir de 2010 e tem como objetivo propiciar a movimentação dos sólidos no interior do elemento, evitando o acúmulo e até a sedimentação.

$$
Q_{f}=Q \cdot\left(1+Y_{r}\right)
$$

$\mathrm{Q}_{\mathrm{f}}=$ Vazão de alimentação $\left(\mathrm{m}^{3} / \mathrm{s}\right)$

$\mathrm{Q}=$ Vazão de projeto $\left(\mathrm{m}^{3} / \mathrm{s}\right)$

$\mathrm{Y}_{\mathrm{r}}=$ Razão de recirculação (\%)

A vazão de contralavagem é determinada através da equação 5.4. O fluxo de contralavagem $\left(\mathrm{J}_{\mathrm{b}}\right)$ é definido pelos fabricantes das membranas, todavia, pode ser determinado através da pressão máxima admissível pelo capilar da membrana e da resistência da membrana conforme a equação 3.1. (BLANKERT et al. 2006).

$$
Q_{b}=J_{b} \cdot A
$$

$\mathrm{Q}_{\mathrm{b}}=$ Vazão de contralavagem $\left(\mathrm{m}^{3} / \mathrm{s}\right)$

$\mathrm{J}_{\mathrm{b}}=$ Fluxo de contralavagem $\left(\mathrm{m}^{3} / \mathrm{m}^{2} . \mathrm{s}\right)$

$A=$ Área total instalada $\left(m^{2}\right)$

Para a elaboração deste modelo, optou-se por utilizar o número de elementos como variável discreta de otimização, ao invés do fluxo. Esta escolha foi fundamentada na isenção de etapas extras de cálculo necessárias para arredondar o fluxo desejado em função da área disponível em elementos comerciais e a facilidade de trabalhar com números inteiros e discretos no processo de otimização numérica. A área de membranas, em função do número de elementos, é apresentada na equação 5.5.

$$
A=A_{m} \cdot N
$$


O fluxo, determinado através da equação 3.1 e a resistência da membrana $\left(R_{0}\right)$ permitem, então, calcular a pressão transmembrana inicial $\left(\Delta \mathrm{P}_{0}\right)$, relativa ao elemento limpo no início do ciclo. A pressão diferencial inicial, ao longo do tempo de ciclo (t) eleva-se de acordo com a evolução do depósito de partículas na superfície da membrana chegando a $\Delta P$ no final do ciclo de permeação (equação 5.6) de acordo com a trajetória proposta por Blankert et al. (2006) representada através das equações 3.8 e 3.9 .

Uma forma de incorporar um fator de segurança ao dimensionamento do sistema é utilizar um valor de resistência (R) conservador, estimado para o final da vida útil das membranas. A resistência final pode ser interpretada como o efeito da camada de incrustações permanentes (não laváveis) na redução da permeabilidade das membranas incrementando assim o valor de $\mathrm{R}_{0}$. Este incremento de resistência foi incorporado no modelo através do coeficiente $\mathrm{K}_{1}$ sobre os resultados finais de pressão, resistência e energia. A aplicação do $\mathrm{K}_{1}$ parte da hipótese que mesmo após a formação de um acúmulo permanente de sólidos na membrana, o comportamento da trajetória da formação de depósitos permanece inalterado, conforme ilustra a figura 5.1. Cabe ressaltar que o $\mathrm{K}_{1}$, por levar em consideração apenas a resistência ao final da vida útil das membranas, aumenta grandezas relativas aos custos nos primeiros anos de operação do sistema, enquanto o efeito das incrustações permanentes é menor que o valor estipulado.

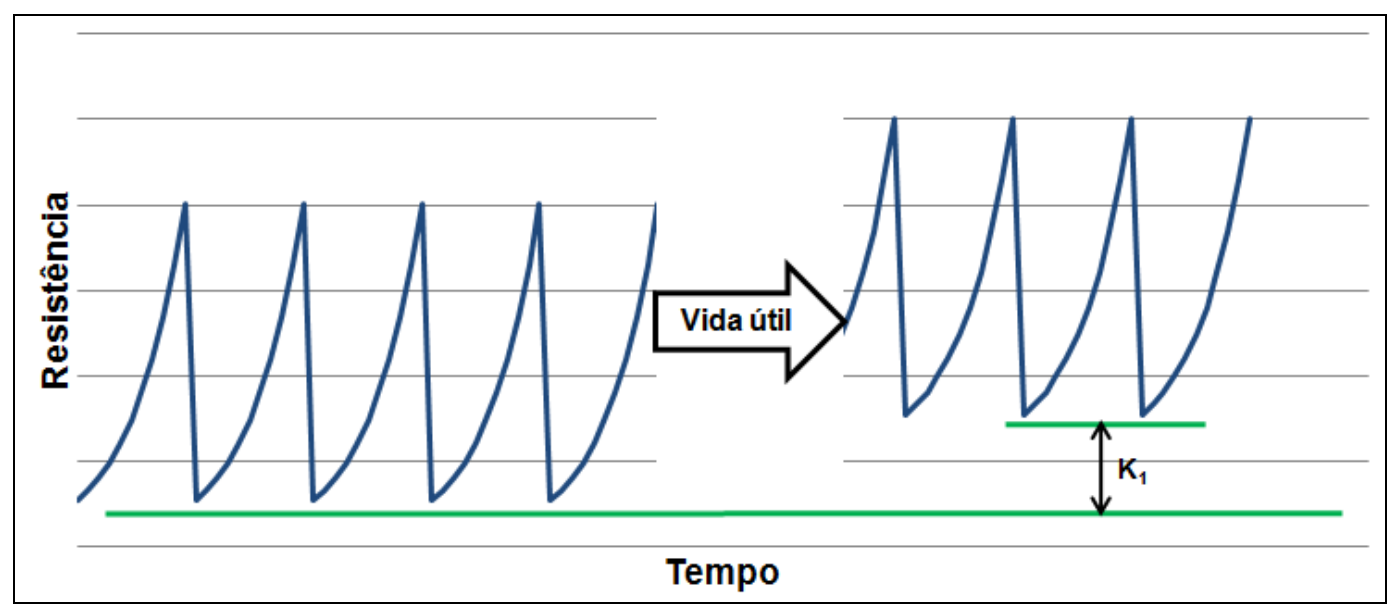

Figura 5.1 - Atuação do coeficiente $K_{1}$ sobre o perfil de resistência das membranas. A trajetória é mantida inalterada. 
A equação 5.7 apresenta o valor de R em função do coeficiente de aumento de resistência para o final da vida útil das membranas $\left(K_{1}\right)$ e da resistência da membrana limpa $R_{0}$. A equação 5.6 da evolução da pressão analogamente incorpora o coeficiente de aumento de resistência. Quando $K_{1}$ assume o valor 1, não há qualquer incremento na resistência inicial, ao assumir valores maiores, a resistência inicial aumenta proporcionalmente.

$$
\begin{gathered}
\Delta P(t)=\Delta P_{0} \cdot\left(\gamma+K_{1}-1\right)^{1-s} \\
R(t)=R_{0} \cdot\left(\gamma+K_{1}-1\right)
\end{gathered}
$$

No caso de fluxo variável, o coeficiente de aumento influencia no fluxo conforme a equação 5.8, todavia, esta é apresentada apenas como referência já que o modelo físico proposto não considera este modo de operação.

$$
J(t)=J_{0} \cdot\left(\gamma+K_{1}-1\right)^{-s}
$$

O modelo de Hermia requer quatro parâmetros para a composição da curva de evolução dos depósitos ( $m, R_{0}$ e $C$ ) obtidos através de ensaios em laboratório ou estudos em piloto. $\mathrm{O}$ coeficiente $\mathrm{K}_{1}$ pode ser fixado com base na experiência em operação de sistemas anteriores ou no risco aceitável de queda de desempenho de membranas.

O valor de $\Delta \mathrm{P}$ é sempre limitado pelos fabricantes de forma a preservar a integridade mecânica das fibras de membrana, todavia, o uso de pressões maiores também está limitado à resistência da camada gel que limita o ganho de fluxo conforme mencionado anteriormente. Em um projeto real, convém projetar a bomba para uma pressão ligeiramente superior à máxima admissível pela membrana, aproveitando assim a capacidade dos elementos de membranas até o final de sua vida útil. De forma a não danificar as membranas novas, torna-se necessária a inclusão de uma válvula para limitação da pressão na saída da bomba, o que, do ponto de vista econômico é condenável em instalações de grande porte em função da perda de energia ocasionada pela válvula. A alternativa mais adequada do ponto 
de vista energético para este caso é o uso de um inversor de freqüência, que ajusta a rotação do motor da bomba e conseqüentemente a curva de pressões conforme a demanda da unidade.

O consumo energético durante a carreira de filtração foi calculado com base na integração da curva da pressão apresentada por Blankert et al. (2006), indicada na equação 5.9. Fatores referentes a vazão de recirculação $\left(Y_{R}\right)$, ao rendimento da bomba (n) e a área de membranas (A) foram acrescentados para ajuste da função teórica à realidade do modelo.

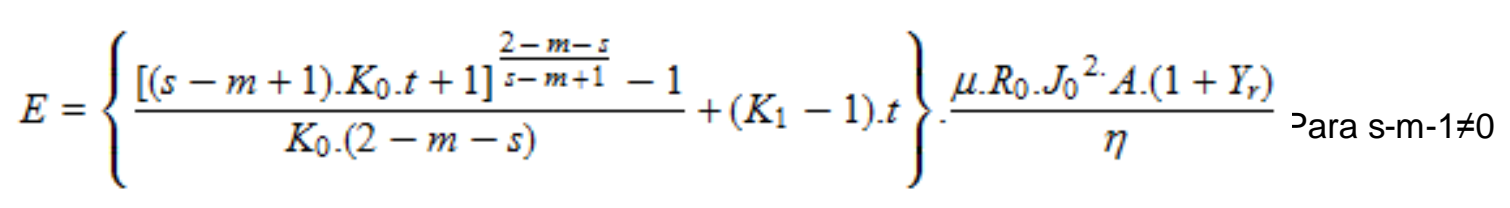

$$
\begin{aligned}
& E=\left[t \cdot e^{(1-2 s) \cdot K_{0} \cdot t}+\left(K_{1}-1\right) \cdot t\right] \cdot \frac{\mu \cdot R_{0} \cdot J_{0}^{2} \cdot A \cdot\left(1+Y_{r}\right)}{\eta}
\end{aligned}
$$

$E=$ Energia elétrica consumida ao longo da filtração (J)

$A=$ Área de membranas $\left(\mathrm{m}^{2}\right)$

$\mathrm{t}=$ Duração do ciclo de filtração $(\mathrm{s})$

$\mathrm{K}_{0}=$ Coeficiente de formação de depósitos $\left(\mathrm{s}^{-1}\right)$

$\mathrm{K}_{1}$ = Coeficiente de redução de fluxo ao longo da vida útil da membrana

$\eta=$ Rendimento global da bomba (elétrico + mecânico)

$\mathrm{Y}_{\mathrm{R}}=$ Taxa de recirculação

$s=$ Modo de operação

$\mathrm{m}$ = Mecanismo de formação de depósitos predominante

$\mathrm{R}_{0}=$ Resistência da membrana limpa $\left(\mathrm{m}^{-1}\right)$

$\mathrm{J}_{0}=$ Fluxo de operação $\left(\mathrm{m}^{3} / \mathrm{m}^{2} . \mathrm{s}\right)$

O consumo energético da contralavagem foi baseado na hipótese de que os poros são desobstruídos instantaneamente após a inversão de fluxo, ou seja, não há variação de pressão significativa ao longo da limpeza. O fluxo de contralavagem é usualmente, fornecido pelos fabricantes de membranas. De qualquer forma, foram consideradas para a elaboração deste modelo duas alternativas, uma pressão máxima admissível na contralavagem que limita o fluxo de acordo com a resistência 
mecânica da membrana e os valores de vazão recomendados. Em qualquer um dos casos, o consumo energético é determinado através das equações 5.10 e 5.11. No caso de determinação do fluxo em função da pressão máxima admissível, a equação 5.12, pode ser utilizada.

$$
E_{b}=\frac{A}{\eta_{b}} \cdot \int_{0}^{t_{b}} J_{b} \cdot \Delta P . d t
$$

Integrando:

$$
\begin{gathered}
E_{b}=\mu \cdot R_{0} \cdot K_{1} \cdot J_{b}{ }^{2} \cdot t_{b} \cdot \frac{A}{\eta_{b}} \\
J_{b}=\frac{\Delta P_{\max }}{\mu \cdot R_{0} \cdot K_{1}}
\end{gathered}
$$

$E_{b}=$ Energia elétrica consumida na contralavagem ( $\mathrm{J}$ )

$\mathrm{A}=$ Área de membranas $\left(\mathrm{m}^{2}\right)$

$t_{b}=$ Duração da contralavagem (s)

$\mathrm{R}_{0}=$ Resistência da membrana limpa $\left(\mathrm{m}^{-1}\right)$

$\mathrm{K}_{1}=$ Coeficiente de redução de fluxo ao longo da vida útil da membrana

$\Delta \mathrm{P}_{\text {máx }}=$ Pressão máxima admissível pela membrana $(\mathrm{Pa})$

O consumo energético durante a etapa de aeração foi determinado através da equação 5.13, proposta por Metcalf \& Eddy (2004) e modificada para as unidades utilizadas neste trabalho. A pressão de saída do compressor ou soprador de ar foi fixada como o a coluna de água sobre os elementos de membranas, simplificada na forma de comprimento do elemento (instalado na vertical). A vazão específica de ar é indicada nos manuais dos fabricantes de elementos e considerada constante. 


$$
E_{a}=\frac{Q_{a \varepsilon} \cdot N \cdot \rho_{a} \cdot R \cdot\left(T_{a}+273\right) \cdot 1000}{29,7 \cdot 0,283 \cdot \eta_{a}} \cdot\left[\left(\frac{P_{a}}{P_{a t m}}\right)^{0,281}-1\right] \cdot t_{a}
$$

Aonde:

$E_{a}=$ Consumo energético do soprador (J)

$\mathrm{Q}_{\mathrm{ae}}=$ Vazão específica de ar por elemento de membrana $\left(\mathrm{Nm}^{3} / \mathrm{h}\right)$

$\mathrm{N}=$ Quantidade de membranas instaladas

$\mathrm{R}=$ Constante universal dos gases

$\mathrm{T}_{\mathrm{a}}=$ Temperatura do ar na alimentação $\left({ }^{\circ} \mathrm{C}\right)$

$\eta_{\mathrm{a}}=$ Rendimento global do soperador (mecânico + elétrico)

$\mathrm{P}_{\mathrm{a}}=$ Pressão absoluta na saída do soprador $(\mathrm{Pa})$

$P_{\text {atm }}=$ Pressão atmosférica $(\mathrm{Pa})$

A potência elétrica média da planta, em kW, pode ser determinada através da equação 5.14 .

$$
W=\frac{E a+E b+E}{1000 \cdot t_{t}}
$$

A dosagem de produtos químicos (coagulante e hipoclorito) foi considerada constante durante as etapas em que são utilizados. O consumo, desta forma, é determinado através da multiplicação da dosagem pelo volume produzido ao longo do ciclo, equações 5.15 e 5.16. O uso contínuo de hipoclorito na alimentação do sistema é uma estratégia proposta por alguns fabricantes para reduzir o crescimento de biofilme ao longo da operação. Na contralavagem, são recomendadas doses maiores para auxiliar a limpeza e reduzir o consumo de água. É importante ressaltar que a equação de dosagem de coagulante é válida apenas para operação com fluxo constante $(s=0)$. 


$$
\begin{gathered}
M_{c g}=\frac{D_{c g} \cdot t \cdot Q \cdot 3,6}{t_{t}} \\
M_{c l}=\frac{\left(D_{c l} \cdot t \cdot Q+D_{c l b} \cdot t_{b} \cdot Q_{b}\right) \cdot 3,6}{t_{t}}
\end{gathered}
$$

Aonde:

$\mathrm{M}_{\mathrm{cg}}=$ Consumo médio de coagulante $(\mathrm{kg} / \mathrm{h})$

$\mathrm{M}_{\mathrm{cl}}=$ Consumo médio de cloro $(\mathrm{kg} / \mathrm{h})$

$\mathrm{D}_{\mathrm{cl}}=$ Dosagem de cloro contínua $(\mathrm{mg} / \mathrm{L})$

$D_{c l b}=$ Dosagem de cloro na contralavagem $(\mathrm{mg} / \mathrm{L})$

$\mathrm{D}_{\mathrm{cg}}=$ Dosagem de coagulante contínua $(\mathrm{mg} / \mathrm{L})$

$\mathrm{t}=$ Duração do ciclo de filtração $(\mathrm{s})$

$t_{b}=$ Duração do ciclo de contralavagem (s)

$\mathrm{Q}_{\mathrm{b}}=$ Vazão de contralavagem $\left(\mathrm{m}^{3} / \mathrm{s}\right)$

$\mathrm{Q}=$ Vazão de permeado $\left(\mathrm{m}^{3} / \mathrm{s}\right)$

Finalmente, torna-se necessário obter uma modelagem adequada para a viscosidade, de grande influência sobre a permeabilidade das membranas. Os valores de viscosidade tabelados na literatura (METCALF \& EDDY, 2003 e MWH, 2004) usualmente variam a cada $1^{\circ} \mathrm{C}$ levando a grandes descontinuidades no cálculo da resistência e conseqüentemente à elevada imprecisão no modelo físico. De forma a permitir o cálculo da viscosidade em função da temperatura com décimos de grau, foi incluída no modelo a equação 5.17, proposta por Berstad et al. (1988) calibrada para água em condições de pressão atmosférica e temperaturas entre $19,5^{\circ} \mathrm{C}$ e $25,5^{\circ} \mathrm{C}$.

$$
\mu=\exp \left(1,85191-\frac{3201,27}{(T+273)}+\frac{779359}{(T+273)^{2}}\right) \cdot 10^{-3}
$$

Aonde:

$\mu=$ Viscosidade dinâmica da água (Pa.s)

$\mathrm{T}=$ Temperatura da água $\left({ }^{\circ} \mathrm{C}\right)$ 


\subsection{Concepção do Modelo Econômico: Custos de Capital}

A modelagem dos custos de capital foi simplificada de forma a considerar os custos relacionados a membranas e, em segunda instância, custos diretamente relacionados à quantidade de membranas instaladas, à duração dos ciclos ou aos perfis de pressão. A seleção dos componentes dos custos de capital (CAPEX) diretamente relacionados com as variáveis de projeto que se deseja aperfeiçoar é apresentada na tabela 5.1, elaborada com base no equacionamento estabelecido para o modelo físico. Entende-se custos de engenharia, obras civis, terreno, licenças ambientais, mão-de-obra, tubulações, instrumentos, painéis elétricos e estruturas metálicas estão mais ligados ao porte da planta (vazão de permeado), não sendo influenciados de forma significativa pela configuração de elementos de membranas e condições operacionais aperfeiçoáveis pela minimização do TCO.

A conseqüência negativa desta simplificação é que o TCO considerado para o dimensionamento não representará o TCO real da planta, ou seja, não será possível utilizá-lo para avaliação econômica de um empreendimento ou determinação dos custos da água tratada. Por outro lado, a quantidade de dados necessários para a realização do dimensionamento econômico é significativamente reduzida, facilitando o desenho do equipamento. 
Tabela 5.1 - Componentes do CAPEX influenciados pelas características do processo.

Componentes do CAPEX

Membranas de Ultrafiltração

Estrutura do sistema

Tubulação

Instrumentação e Controle

Bomba de alimentação

Bomba de contralavagem

Sistema dosador de cloro

Sistema dosador de coagulante

Tubulação

Construção civil

Terreno

Engenharia

Tanque de contralavagem

Tanque de coagulante

Tanque de cloro

Centro de Controle de Motores

Controlador Lógico Programável

Licenciamento

Sistemas de tratamento de efluentes

Soprador de ar
Parâmetros aperfeiçoáveis do

processo
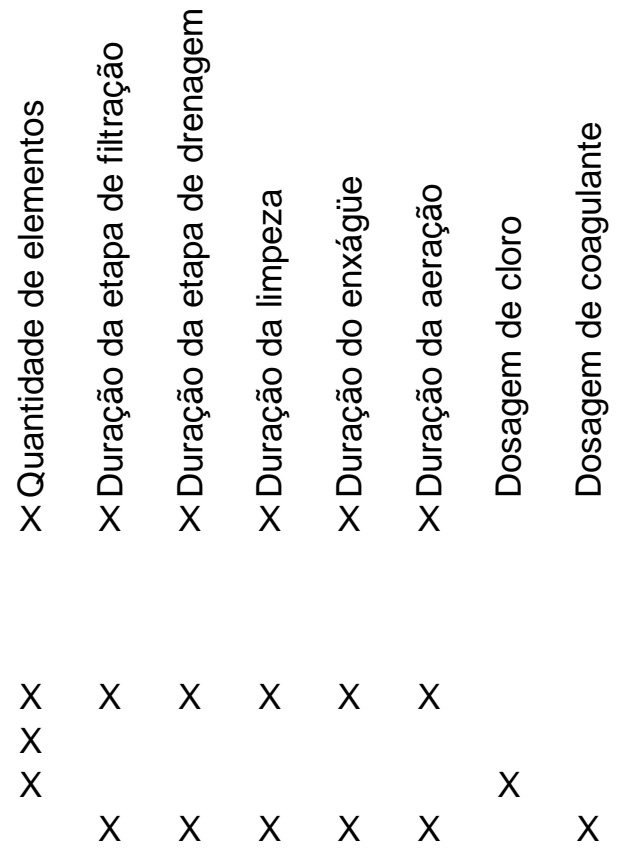

$\begin{array}{lllllllll}X & & & X & & & & \\ & x & x & x & x & x & & x \\ x & x & x & x & x & x & x & \end{array}$

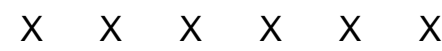

A composição do CAPEX se dá pela somatória da multiplicação do valor dos componentes do sistema pela quantidade utilizada. Esta quantidade é definida através dos resultados do modelo físico e é apresentada através da equação 5.18.

Os custos do CAPEX não relacionados a membranas foram desconsiderados nesta primeira versão do modelo de cálculo em virtude da ausência de curvas de custos confiáveis e atualizadas para a determinação do custo unitário. 
Aonde:

$\mathrm{C}_{\mathrm{m}}=$ Custo unitário das membranas (\$/elemento)

$\mathrm{N}=$ Quantidade de elementos instalados (unidades)

\subsection{Concepção do Modelo Econômico: Custos Operacionais}

O modelo de custos operacionais (OPEX) foi elaborado com base nas variáveis mais impactantes no TCO, conforme a revisão da literatura:

- energia elétrica

- custo da água

- custo da disposição/tratamento de efluentes

- produtos químicos

- reposição de membranas

De forma análoga aos custos de capital, foi elaborada a tabela 5.2 que correlaciona variáveis aperfeiçoáveis do modelo físico com a sua respectiva influência nos componentes do CAPEX.

Tabela 5.2 - Componentes do OPEX influenciados pelas características do processo.

Componentes do OPEX

Parâmetros aperfeiçoáveis do

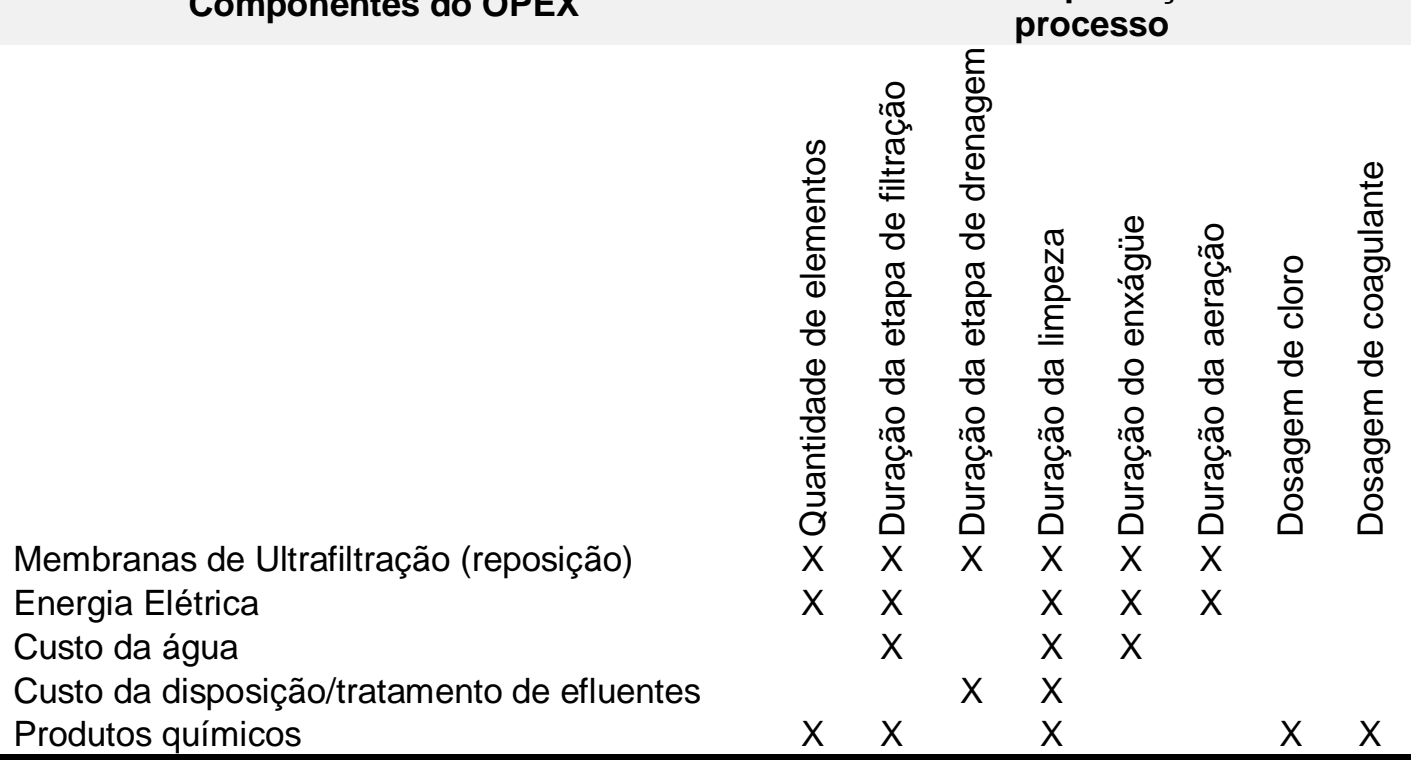


Assim como na composição do CAPEX, custos relativos a aluguéis, mão de obra e manutenção de máquinas e instrumentos não foram considerados por estarem mais relacionados com o porte da planta do que com o dimensionamento ótimo. O cálculo foi realizado através da multiplicação do custo unitário pela quantidade de insumos consumidos em um ano conforme as equações 5.19 a 5.22.

Cabe ressaltar que o custo de energia elétrica varia em função da época do ano (período seco ou de chuvas) bem como ao longo do dia. A equação determinada considera um valor fixo para $\mathrm{C}_{\mathrm{e}}$, que deve ser determinado pelo usuário já considerando esta sazonalidade.

$$
\begin{gathered}
C_{s a}=C_{\varepsilon} \cdot W \cdot 8760 \\
C_{a a}=C_{a} \cdot Q \cdot 31536000 \\
C_{d a}=C_{d \cdot} \cdot Q\left(1-\frac{Q_{p}}{Q}\right) \cdot 31536000 \\
C_{q a}=\left(C_{c l} \cdot M_{c l}+C_{c g} \cdot M_{c g}\right) \cdot 8760
\end{gathered}
$$

$\mathrm{C}_{\mathrm{ea}}=$ Custo de energia elétrica anualizado (\$/ano)

$\mathrm{C}_{\mathrm{e}}=$ Custo de energia elétrica $(\$ / \mathrm{kWh})$

$\mathrm{C}_{\mathrm{aa}}=$ Custo da água bruta anualizado (\$/ano)

$\mathrm{C}_{\mathrm{a}}=$ Custo da água bruta $\left(\$ / \mathrm{m}^{3}\right)$

$\mathrm{C}_{\mathrm{da}}=$ Custo da disposição/tratamento de efluentes anualizado (\$/ano)

$\mathrm{C}_{\mathrm{d}}=$ Custo da disposição/tratamento de efluentes $\left(\$ / \mathrm{m}^{3}\right)$

$\mathrm{C}_{\mathrm{cg}}=$ Custo do coagulante $(\$ / \mathrm{kg})$

$\mathrm{C}_{\mathrm{cl}}=$ Custo do cloro $(\$ / \mathrm{kg})$

$\mathrm{C}_{\mathrm{qa}}=$ Custo de produtos químicos anualizado (\$/ano)

$\mathrm{M}_{\mathrm{cg}}=$ Consumo médio de coagulante $(\mathrm{kg} / \mathrm{h})$

$\mathrm{M}_{\mathrm{cl}}=$ Consumo médio de cloro $(\mathrm{kg} / \mathrm{h})$

No caso de membranas, a reposição não ocorre continuamente, é realizada de forma integral em períodos que variam de 3 a 5 anos. Como não é possível, através do modelo proposto determinar exatamente esta duração, é fixada uma durabilidade 
em função da garantia dada pelo fornecedor ou expectativa de vida do elemento. A forma adotada para inclusão distribuída destes valores nos custos operacionais foi através da determinação do valor das parcelas anuais relativas a este investimento futuro, desta forma, o custo de reposição anual de membranas é indicado através da equação 5.23. Do ponto de vista prático, este valor representa o montante que deveria ser economizado anualmente de forma a permitir a reposição completa das membranas ao final da vida útil fixada.

$$
C_{m a}=C_{m} \cdot N \cdot \frac{i}{(1+i)^{U_{m}}-1}
$$

aonde:

$\mathrm{C}_{\mathrm{ma}}=$ Custo anualizado da reposição de membranas

$\mathrm{N}=$ Quantidade de elementos instalados

$\mathrm{C}_{\mathrm{m}}=$ Custo unitário do elemento de membranas

$\mathrm{U}_{\mathrm{m}}=$ Vida útil dos elementos de membranas (anos)

$\mathrm{i}=$ Taxa de juros anual

Os custos operacionais anuais da planta compõem o OPEX da forma apresentada na equação 5.24 .

$$
O P E X=C_{s a}+C_{a a}+C_{d a}+C_{q a}+C_{m a}
$$

Aonde:

$\mathrm{C}_{\mathrm{ea}}=$ Custo de energia elétrica anualizado

$\mathrm{C}_{\mathrm{aa}}=$ Custo da água bruta anualizado

$\mathrm{C}_{\mathrm{da}}=$ Custo da disposição/tratamento de efluentes anualizado

$\mathrm{C}_{\mathrm{qa}}=$ Custo de produtos químicos anualizado

$\mathrm{C}_{\mathrm{ma}}=$ Custo anualizado de membranas 


\subsection{Composição do TCO}

O custo total de propriedade (TCO) foi composto da somatória dos custos de capital e dos custos operacionais ao longo da vida útil $(U)$ da planta de ultrafiltração. Quanto maior o valor de $U$, menor deverá ser a participação dos custos de capital no TCO.

A equação 5.25 apresenta a composição final da TCO. Com o intuito de verificar o impacto das taxas de retorno de investimento foi utilizado o método do Valor Presente Líquido que permitiu uma aproximação dos custos operacionais à data zero conforme a metodologia de análise de ciclo de vida recomendada no manual do NIST (FULLER; PETERSEN, 1995). Foram considerados pagamentos anuais com juros "i" para o cálculo do Fator de valor presente uniforme (VPU) apresentado na equação 5.26 .

$$
\begin{gathered}
T C O=C A P E X+O P E X . V P U \\
V P U=\frac{(1+i)^{U}-1}{(1+i)^{U} \cdot i}
\end{gathered}
$$

\subsection{Equacionamento completo do modelo}

As equações que compõem o modelo físico bem como seu encadeamento são apresentadas na figura 5.2. A figura 5.3 ilustra a relação entre as equações do modelo econômico. 


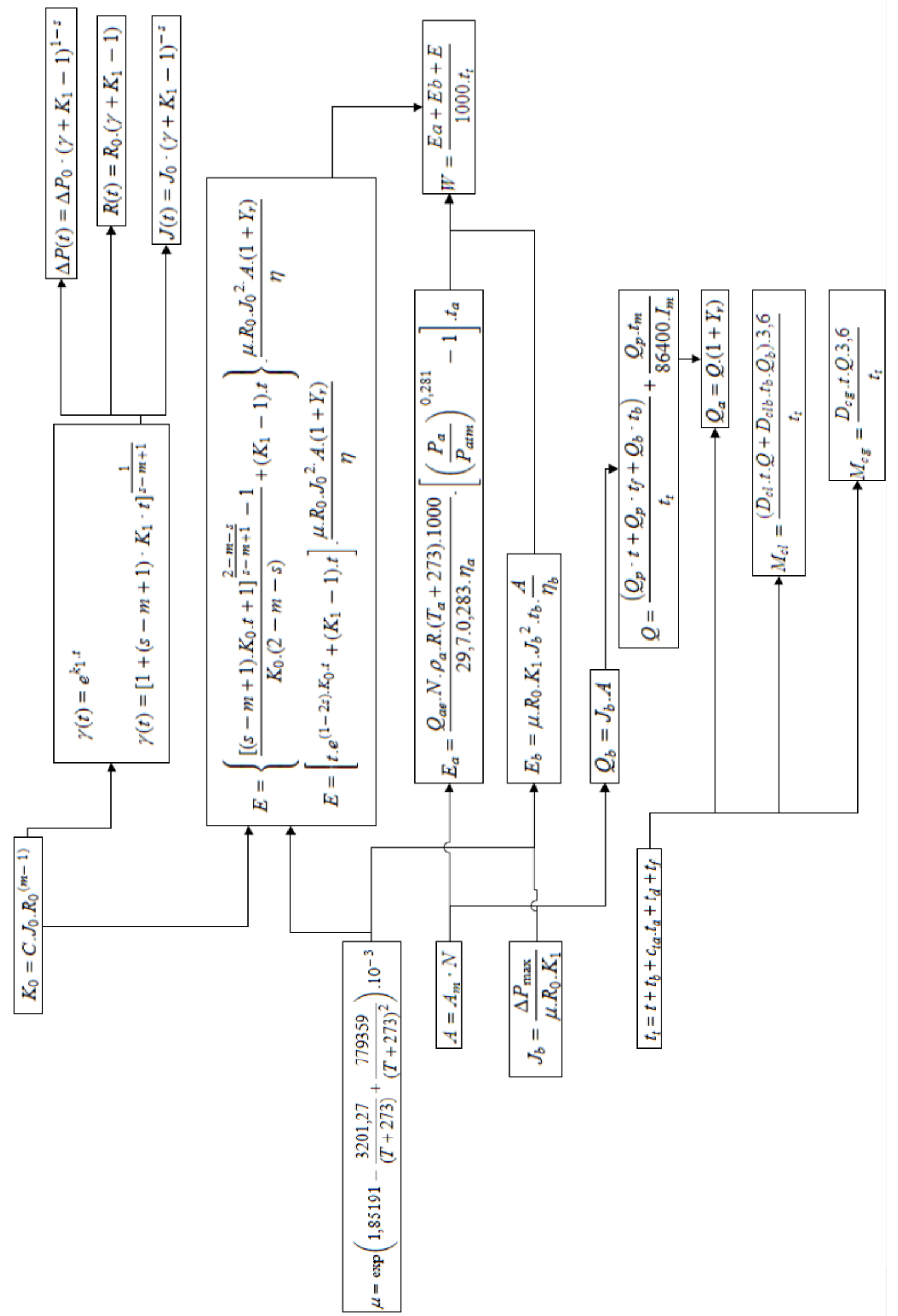

Figura 5.2 - Equacionamento e encadeamento lógico do modelo físico. 


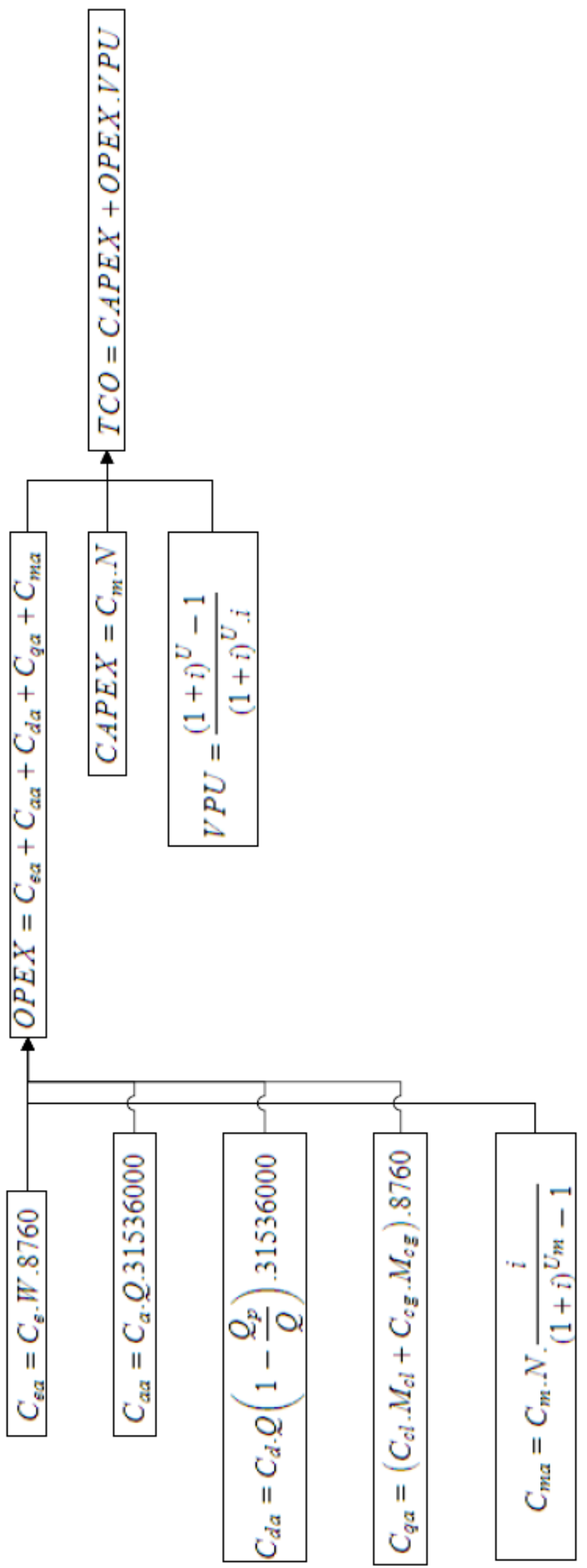

Figura 5.3 - Equacionamento e encadeamento lógico do modelo econômico. 


\subsection{Análise de sensibilidade}

Para o modelo em questão, a análise de sensibilidade considerou as variáveis aperfeiçoáveis levantadas durante a etapa de concepção do modelo, utilizando como referência valores e faixas recomendadas através das orientações de projeto da Toray (aplicativo proprietário de distribuição restrita) indicadas na tabela 5.3. A coluna referência fornecedor indica a recomendação típica do fabricante da membrana, a coluna "intervalo fornecedor" representa a faixa típica de variações (máximo e mínimo) em projeto conforme recomendações no manual. O intervalo considerado representa a faixa de variação a ser estudada durante a análise de sensibilidade. Durante a revisão da literatura não foram encontradas referências de valores superiores ou inferiores aos limites considerados para este tipo de aplicação.

Tabela 5.3 - Escala das variáveis aperfeiçoáveis na análise de sensibilidade.

\begin{tabular}{|c|c|c|c|}
\hline Variável & $\begin{array}{l}\text { Referência } \\
\text { Fornecedor }\end{array}$ & $\begin{array}{l}\text { Intervalo } \\
\text { Fornecedor }\end{array}$ & $\begin{array}{c}\text { Intervalo } \\
\text { Considerado }\end{array}$ \\
\hline Quantidade de elementos de membrana & 22 elementos & 15 a 38 el. & 15 a 38 el. \\
\hline Fluxo de contralavagem & $108 \mathrm{~L} / \mathrm{m}^{2} . \mathrm{h}$ & 72 a $108 \mathrm{~L} / \mathrm{m}^{2} . \mathrm{h}$ & 60 a $130 \mathrm{~L} / \mathrm{m}^{2} . \mathrm{h}$ \\
\hline Vazão específica de ar & $6 \mathrm{Nm}^{3} / \mathrm{h}$ & 4,8 a $9 \mathrm{Nm}^{3} / \mathrm{h}$ & 0 a $10 \mathrm{Nm}^{3} / \mathrm{h}$ \\
\hline Duração da etapa de filtração & $30 \mathrm{~min}$ & 20 a 40min & 10 a 50min \\
\hline Duração da etapa de contralavagem & $60 s$ & $60 s$ & 15 a $120 s$ \\
\hline $\begin{array}{l}\text { Duração da etapa de drenagem e } \\
\text { enchimento }\end{array}$ & $85 s$ & 70 s a $115 s$ & 30 a $120 s$ \\
\hline Duração da etapa de enxágue & Os & $0 \mathrm{~s}$ & 0 a $15 s$ \\
\hline Duração da etapa de aeração & $60 s$ & 30 a $60 s$ & 10 a $120 s$ \\
\hline Dosagem de cloro durante a limpeza & $10 \mathrm{mg} / \mathrm{L}$ & 0 a $10 \mathrm{mg} / \mathrm{L}$ & 0 a $50 \mathrm{mg} / \mathrm{L}$ \\
\hline Dosagem de coagulante durante a operação & $1 \mathrm{mg} / \mathrm{L}$ & 0 a 3mg/L & 0 a $10 \mathrm{mg} / \mathrm{L}$ \\
\hline
\end{tabular}

Referência do fornecedor Toray (2008) para água de superfície com turbidez inferior a 10 NTU, vazão de $100 \mathrm{~m}^{3} / \mathrm{h}$ e membranas modelo HFU-2020 (fluxo de $72,9 \mathrm{~L} / \mathrm{m}^{2} . \mathrm{h}$ ).

Tendo em vista que o modelo físico requer parâmetros de comportamento da membrana para a determinação do perfil de pressões (relações de Hermia) e que nesta etapa deseja-se apenas verificar a influencia do consumo energético nos 
custos totais, não importando o comportamento específico da curva, foi fixado um valor de $C\left(8,24 \times 10^{13}\right)$ de forma que ocorra o incremento da pressão de alimentação até $150 \mathrm{KPa}$ em 30 minutos de operação. O uso deste patamar baseou-se em faixas típicas observadas pelo autor em plantas em operação devendo bastar para aferir a análise de sensibilidade. O valor de "m", foi fixado em 0 simulando o mecanismo de filtração em torta.

O valor da resistência inicial, necessário à aplicação do modelo de Hermia foi calculado de acordo com as informações de catálogo para este modelo de membrana $\left(R_{0}=1,63 \times 10^{12}\right)$ com coeficiente e vida útil de 5 anos. $O$ valor de $K_{1}$ foi fixado em 1 em função da análise já considerar uma curva pré-definida para a obstrução dos poros

Os custos de referência para o modelo econômico foram estimados com base nas fontes e considerações apresentadas na tabela 5.4. O valor de produtos químicos foi levantado com base em resultados de licitações públicas para estações de tratamento de água uma vez que esta costuma ser a modalidade padrão para a compra de commodities em empresas privadas e de saneamento no Brasil e, salvo exceções de formação de cartel, é bem alinhado com os valores de atacado do mercado. Para um cenário adicional da análise de sensibilidade foram levantados, com base em referências da literatura, os mesmos custos para uma planta situada na Europa. O objetivo foi verificar se a proporcionalidade das variáveis se mantém em cenários econômicos distintos. Os valores utilizados são apresentados na tabela 5.5 . 
Tabela 5.4 - Custos unitários para calibração do modelo de dimensionamento tendo como referência de fornecimento um consumidor industrial instalado região do Vale do Paraíba (possui cobrança pela água instaurada).

\begin{tabular}{|c|c|c|c|}
\hline Componente & $\begin{array}{c}\text { Considerações para } \\
\text { orçamento }\end{array}$ & $\begin{array}{l}\text { Custo } \\
\text { unitário }\end{array}$ & Fonte \\
\hline $\begin{array}{l}\text { Membranas de } \\
\text { ultrafiltração }\end{array}$ & HFU-2020 no Brasil & $\mathrm{R} \$ 8500,00$ & $\begin{array}{l}\text { Estimativa Perenne } \\
\text { Equipamentos e Sistemas } \\
\text { de Água S/A (2010) }\end{array}$ \\
\hline Energia elétrica & Grupo A3a & $\mathrm{R} \$ / \mathrm{kWh} 0,163$ & AES Eletropaulo \\
\hline Água & Captação + Consumo & $\mathrm{R} \$ / \mathrm{m}^{3} 0,03$ & Relatório CEIVAP (2008) \\
\hline $\begin{array}{l}\text { Disposição final de } \\
\text { efluentes }\end{array}$ & $\mathrm{DBO}_{5}=50 \mathrm{mg} / \mathrm{L}$ & $\mathrm{R} \$ / \mathrm{m}^{3} 0,0035$ & Relatório CEIVAP (2008) \\
\hline $\begin{array}{l}\text { Tratamento de } \\
\text { efluentes }\end{array}$ & $\begin{array}{l}\text { Referencia } 1999(\mathrm{R} \$ \\
0,094) \text { atualizado pelo } \\
\text { índice IPCA até } 2009\end{array}$ & $\mathrm{R} \$ / \mathrm{m}^{3} 0,20$ & $\begin{array}{l}\text { Sampaio e Gonçalves } \\
\text { (1999) }\end{array}$ \\
\hline Hipoclorito de Sódio & $\begin{array}{l}10 \% \text { de concentração e } \\
\text { transporte incluso }\end{array}$ & $\mathrm{R} \$ / \mathrm{kg} \mathrm{0,92}$ & $\begin{array}{l}\text { Tomada de preços } \\
\text { Prefeitura de Pitangueiras } n^{\circ} \\
\text { 03/2009 }\end{array}$ \\
\hline $\begin{array}{l}\text { Coagulante Policloreto } \\
\text { de Alumínio }\end{array}$ & $\begin{array}{l}\text { Produto puro, sólido e } \\
\text { transporte incluso }\end{array}$ & $\mathrm{R} \$ / \mathrm{kg} 1,70$ & $\begin{array}{l}\text { Pregão } n^{\circ} 000071 / 2010 \\
\text { 29/4/2010 SEMAE } \\
\text { Piracicaba }\end{array}$ \\
\hline
\end{tabular}

Além dos custos foram fixados o período de amortização do investimento (5 anos), a taxa anual de juros (6\% ao ano, BNDES 2010). No cenário Holandês foi considerada a mesma taxa de juros.

Tabela 5.5 - Custos dos insumos na Holanda convertidos (1 Euro = R $\$ 2,186$ ).

\begin{tabular}{|c|c|}
\hline Componente & Custo unitário \\
\hline Membranas de ultrafiltração & $\mathrm{R} \$ 6592,00$ \\
\hline Energia elétrica & $\mathrm{R} \$ / \mathrm{kWh} 0,21$ \\
\hline Água & $\mathrm{R} \$ / \mathrm{m}^{3} 0,065$ \\
\hline Disposição final de efluentes & - \\
\hline Tratamento e descarte de efluentes & $\mathrm{R} \$ / \mathrm{m}^{3} 0,54$ \\
\hline Hipoclorito de Sódio & $\mathrm{R} \$ / \mathrm{kg} 1,09$ \\
\hline Coagulante & $\mathrm{R} \$ / \mathrm{kg} \mathrm{10,9}$ \\
\hline
\end{tabular}

Fonte: Zondervan et al., 2008 
A análise de sensibilidade foi conduzida em três cenários.

- Sistema implantado no Brasil com cobrança pela água;

- Sistema implantado no Brasil sem cobrança pela água;

- Sistema implantado na Europa;

Os gráficos apresentados nas figuras 5.4, 5.5 e 5.6 consistem dos resultados do modelo genérico para os custos em cada cenário, ilustrando o peso de cada uma das variáveis econômicas na composição do TCO.

Na composição final dos custos, observa-se que variáveis relacionadas à energia elétrica e ao consumo de produtos químicos, nas condições usuais de projeto, contribuem em proporções inferiores a 10\% do TCO em todos os cenários. Os custos da água, tratamento de efluentes e membranas são responsáveis pelos restantes $90 \%$ pesando sobre as variáveis de projeto relacionadas. No caso da Europa é notável a inversão da participação das membranas (importadas no Brasil) com os custos de água e tratamento de efluentes no TCO.

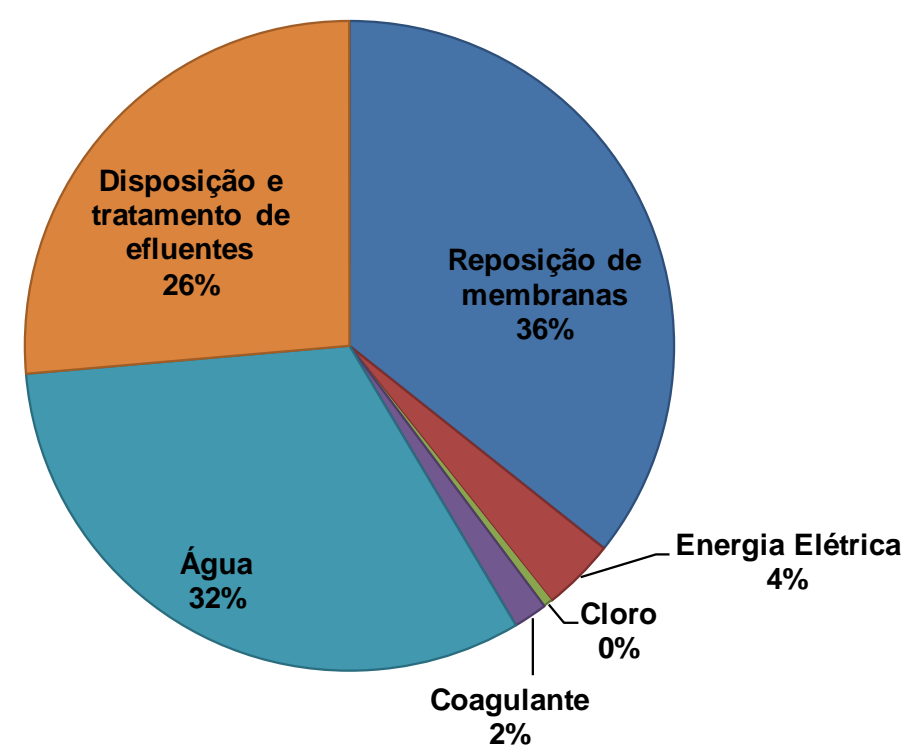

Figura 5.4 - Contribuição dos fatores econômicos no TCO de um sistema instalado no Brasil com a cobrança pelo uso da água e lançamento de efluentes instaurada. 


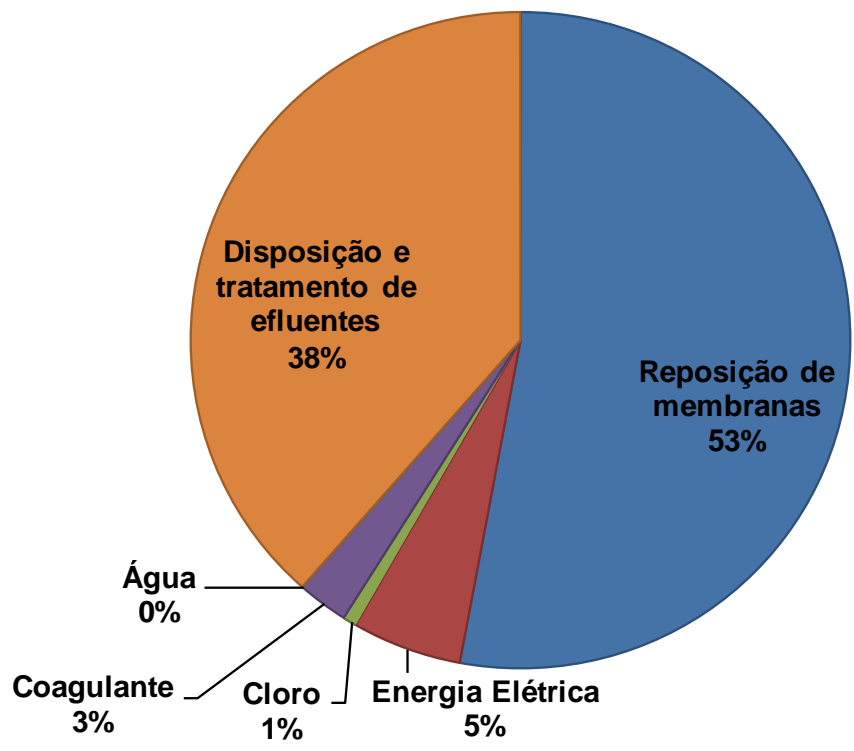

Figura 5.5 - Contribuição dos fatores econômicos no TCO de um sistema instalado no Brasil sem a cobrança pelo uso da água e lançamento de efluentes instaurada.

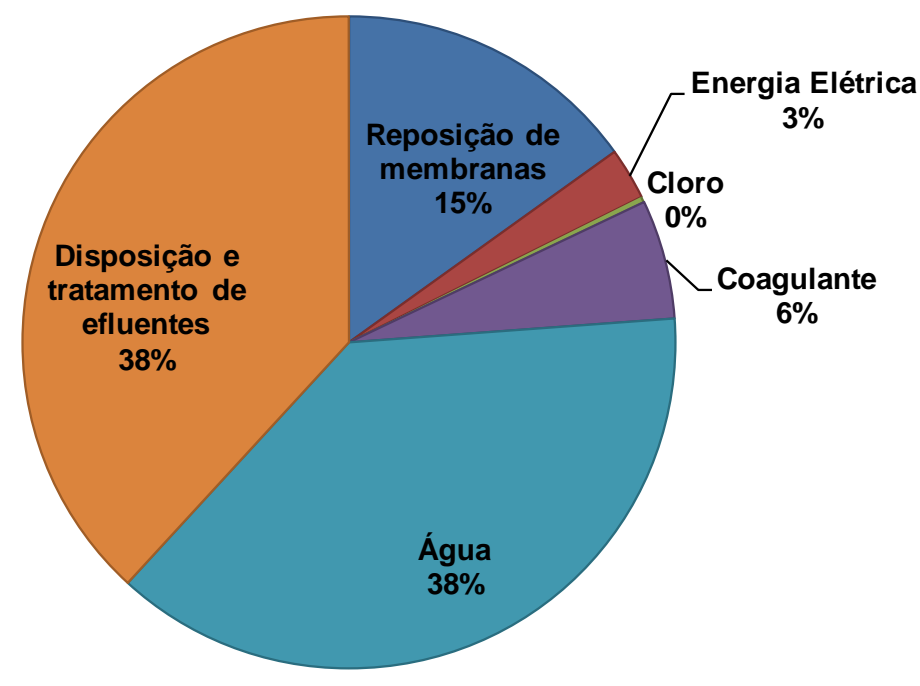

Figura 5.6- Contribuição dos fatores econômicos no TCO de um sistema instalado na Holanda.

Os resultados da análise de sensibilidade são apresentados nas tabelas 5.6, 5.7 e 5.8 para cada cenário respectivamente, o valor dos custos foi apresentado com precisão de centésimos de centavo para ilustrar a magnitude da influência. 
Tabela 5.6 - Análise de sensibilidade para sistema instalado no Brasil COM COBRANÇA pela captação da água e lançamento de efluentes.

\begin{tabular}{|c|c|c|c|c|c|}
\hline Variável & Referência & $\begin{array}{l}\text { TCO (R\$) } \\
\text { Mínimo }\end{array}$ & Máximo & $\begin{array}{c}\mathrm{e} \\
(\mathrm{x} 1000)\end{array}$ & $\begin{array}{c}\mathrm{SI} \\
(\mathrm{R} \$ \mathrm{1000})\end{array}$ \\
\hline Quantidade de membranas & & 0,1059 & 0,1937 & 636 & 88 \\
\hline Fluxo de contralavagem & & 0,1267 & 0,1346 & 92 & 8 \\
\hline Vazão específica de ar & & 0,1321 & 0,1321 & 0 & 0 \\
\hline Duração da etapa de filtração & & 0,1863 & 0,1221 & -364 & 64 \\
\hline Duração da etapa de contralavagem & & 0,1180 & 0,1508 & 142 & 33 \\
\hline Duração enchimento/drenagem & 0,1321 & 0,1260 & 0,1360 & 71 & 10 \\
\hline Duração enxágüe & & 0,1321 & 0,1354 & 0 & 3 \\
\hline Duração aeração & & 0,1321 & 0,1387 & 27 & 7 \\
\hline Dosagem de cloro na limpeza & & 0,1317 & 0,1337 & 3 & 2 \\
\hline Dosagem de coagulante na operação & & 0,1306 & 0,1457 & 11 & 15 \\
\hline
\end{tabular}

Tabela 5.7 - Análise de sensibilidade para sistema instalado no Brasil SEM COBRANÇA pela captação da água e pelo lançamento de efluentes.

\begin{tabular}{|c|c|c|c|c|c|}
\hline & & TCO (R\$) & & $\bar{e}$ & \\
\hline Variável & Referência & Mínimo & Máximo & $(x 1000)$ & $(\mathrm{R} \$ \times 1000)$ \\
\hline Quantidade de membranas & & 0,0773 & 0,1634 & 800 & 86 \\
\hline Fluxo de contralavagem & & 0,0983 & 0,1051 & 102 & 7 \\
\hline Vazão específica de ar & & 0,1029 & 0,1029 & 0 & 0 \\
\hline Duração da etapa de filtração & & 0,1494 & 0,0945 & -400 & 55 \\
\hline Duração da etapa de contralavagem & & 0,0980 & 0,1191 & 117 & 21 \\
\hline Duração enchimento/drenagem & 0,1029 & 0,0977 & 0,1063 & 79 & 9 \\
\hline Duração enxágue & & 0,1029 & 0,1058 & 0 & 3 \\
\hline Duração aeração & & 0,1029 & 0,1086 & 30 & 6 \\
\hline Dosagem de cloro na limpeza & & 0,1025 & 0,1046 & 4 & 2 \\
\hline Dosagem de coagulante na operação & & 0,1014 & 0,1165 & 15 & 15 \\
\hline
\end{tabular}

Tabela 5.8 - Análise de sensibilidade para sistema instalado na Holanda.

\begin{tabular}{|c|c|c|c|c|c|}
\hline Variável & Referência & $\begin{array}{l}\text { TCO (R\$) } \\
\text { Mínimo }\end{array}$ & Máximo & $\begin{array}{c}\mathrm{e} \\
(\mathrm{x} 1000)\end{array}$ & $\begin{array}{c}\text { SI } \\
(R \$ 1000)\end{array}$ \\
\hline Quantidade de membranas & & 0,1708 & 0,2595 & 430 & 89 \\
\hline Fluxo de contralavagem & & 0,1835 & 0,2033 & 155 & 20 \\
\hline Vazão específica de ar & & 0,1971 & 0,1971 & 0 & 0 \\
\hline Duração da etapa de filtração & & 0,3380 & 0,1700 & -639 & 168 \\
\hline Duração da etapa de contralavagem & & 0,1613 & 0,2446 & 242 & 83 \\
\hline Duração enchimento/drenagem & 0,1971 & 0,1814 & 0,2070 & 123 & 26 \\
\hline Duração enxágue & & 0,1971 & 0,2057 & 0 & 9 \\
\hline Duração aeração & & 0,1971 & 0,2141 & 47 & 17 \\
\hline Dosagem de cloro na limpeza & & 0,1966 & 0,1990 & 2 & 2 \\
\hline Dosagem de coagulante na operação & & 0,1874 & 0,2841 & 49 & 97 \\
\hline
\end{tabular}

Nos três cenários analisados, a quantidade de membranas, a duração da contralavagem e a duração da carreira de filtração se mostraram as variáveis de projeto de maior influência na composição do TCO evidenciados por ambos os indicadores selecionados. 
Ainda com relação à quantidade de membranas e a duração da carreira de filtração observa-se uma inversão da elasticidade e sensibilidade entre os casos no Brasil e na Europa. As durações das etapas, no segundo cenário impactam de forma mais significativa os custos do que a própria quantidade de membranas. Esta constatação é de grande importância para os projetos uma vez que a otimização no cenário Brasileiro automaticamente priorizará uma freqüência maior de limpezas e uma quantidade menor de membranas enquanto que para o caso Europeu passa a ser o inverso.

O fluxo de contralavagem, apesar de contar com uma grande elasticidade nos três casos analisados, apresentou valores baixos para o índice de sensibilidade. Este comportamento indica que a variável conta com um grande peso na composição do TCO, todavia, dentro dos limites de variação admissíveis para um projeto, pouco influencia na redução ou incremento dos custos. Tendo em vista apenas este comportamento, o fluxo de contralavagem não deveria ser apontado como um candidato prioritário à otimização, todavia, a sua comprovada (YUN YE et al. 2010) relação com a duração da limpeza, não permite desconsiderá-lo.

As variáveis relacionadas à vazão de ar e uso de cloro na limpeza não apresentaram influências significativas sobre a composição do TCO dentro das faixas de variação de projeto podendo ser eliminadas em favor da simplificação do modelo.

Considerando que o consumo de ar pouco influencia no TCO, uma alternativa para a melhoria do projeto é o uso do ar comprimido para acelerar a expulsão de água na etapa de drenagem reduzindo, desta forma, a sua duração. Para tanto bastaria programar o fechamento da válvula de ventilação enquanto a aeração prossegue desde a limpeza. 


\subsection{Análise de consistência do modelo físico}

O objetivo das atividades na seqüência é verificar se um sistema real de ultrafiltração baseado em membranas pressurizadas em operação dead-end possui aderência às funções propostas por Hermia através dos resultados obtidos durante a operação do sistema piloto.

A proposta inicial do projeto era avaliar o comportamento do sistema de ultrafiltração apenas no período compreendido entre as fases I a V, com a membrana nova. Posteriormente surgiu a oportunidade de realizar um novo ensaio, nas mesmas condições. Considerando os valores escalonados de pressão, obtidos nas primeiras fases do experimento, a unidade piloto foi modificada e recebeu um novo sensor de pressão, que permitiu obter dados com uma precisão 10 vezes superior.

Como as condições do manancial, da membrana e dos próprios instrumentos de medição foram distintas nos dois períodos, a análise dos dados foi dividida em dois grandes blocos, compreendendo o primeiro e o segundo período respectivamente. No primeiro período foi possível medir as características da membrana com água limpa e das primeiras semanas em funcionamento. No segundo período, a membrana com mais de um mês de operação já apresentava sinais de formação de depósitos permanentes e o fouling, possivelmente devido à formação de biofilmes.

Durante o primeiro período de avaliação, a turbidez da água bruta manteve-se estável, com valor médio de 4 NTU (desvio padrão de 0,57) enquanto que a turbidez do permeado manteve-se na média de 0,17 NTU (desvio padrão de 0,14) conforme apresenta o gráfico da figura 5.7. As descontinuidades na coleta de dados referemse ao período noturno durante o qual, em função das limitações do CLP, não era possível armazenar as informações coletadas. O segundo período, com início em janeiro de 2011 contou com turbidez média de 3 NTU na alimentação (desvio padrão de 0,43 NTU) e 0,27 NTU (desvio padrão de 0,13) no permeado conforme apresenta o gráfico 5.8 . 


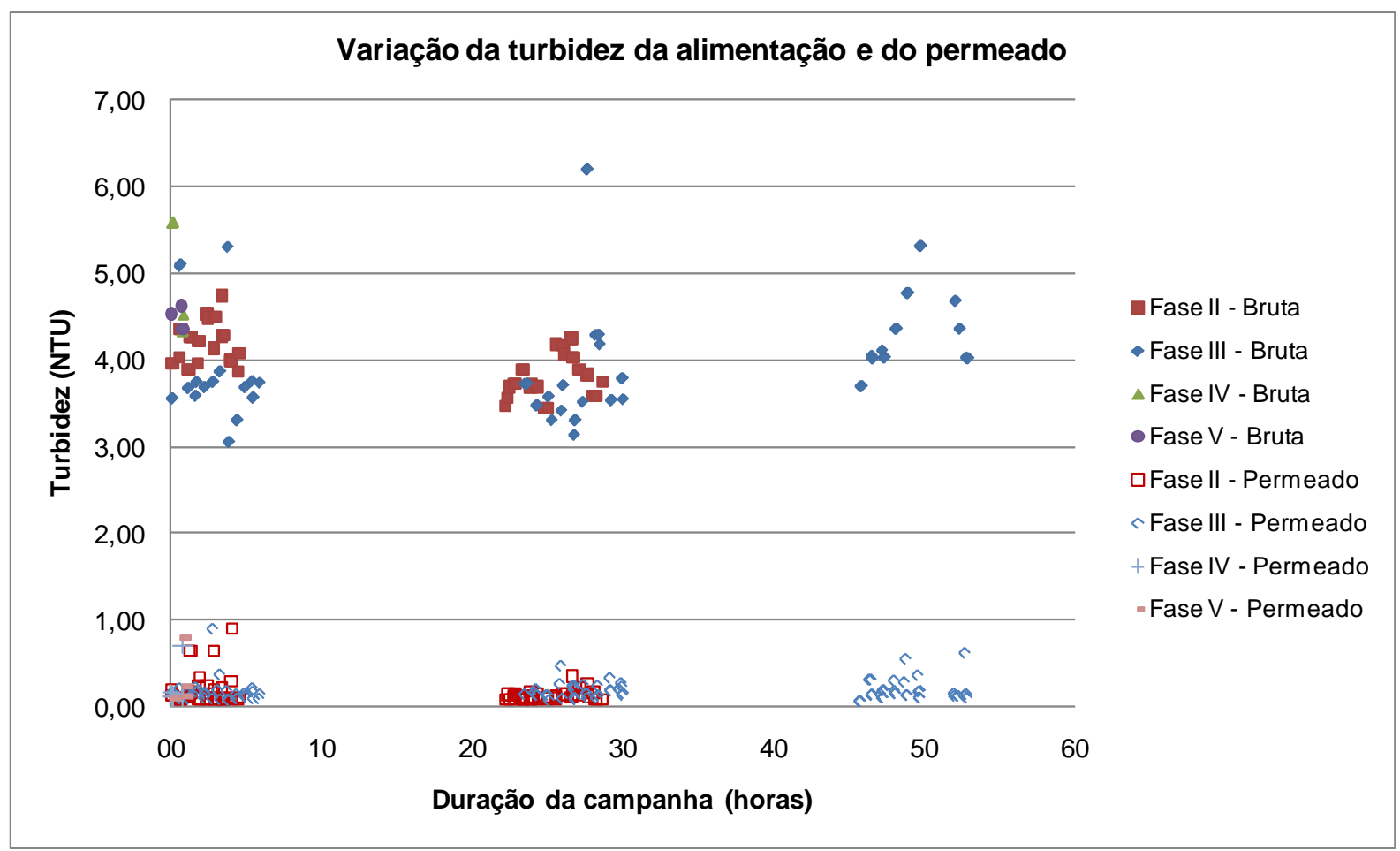

Figura 5.7- Variação da turbidez da alimentação e do permeado ao longo do primeiro período de operação do piloto.

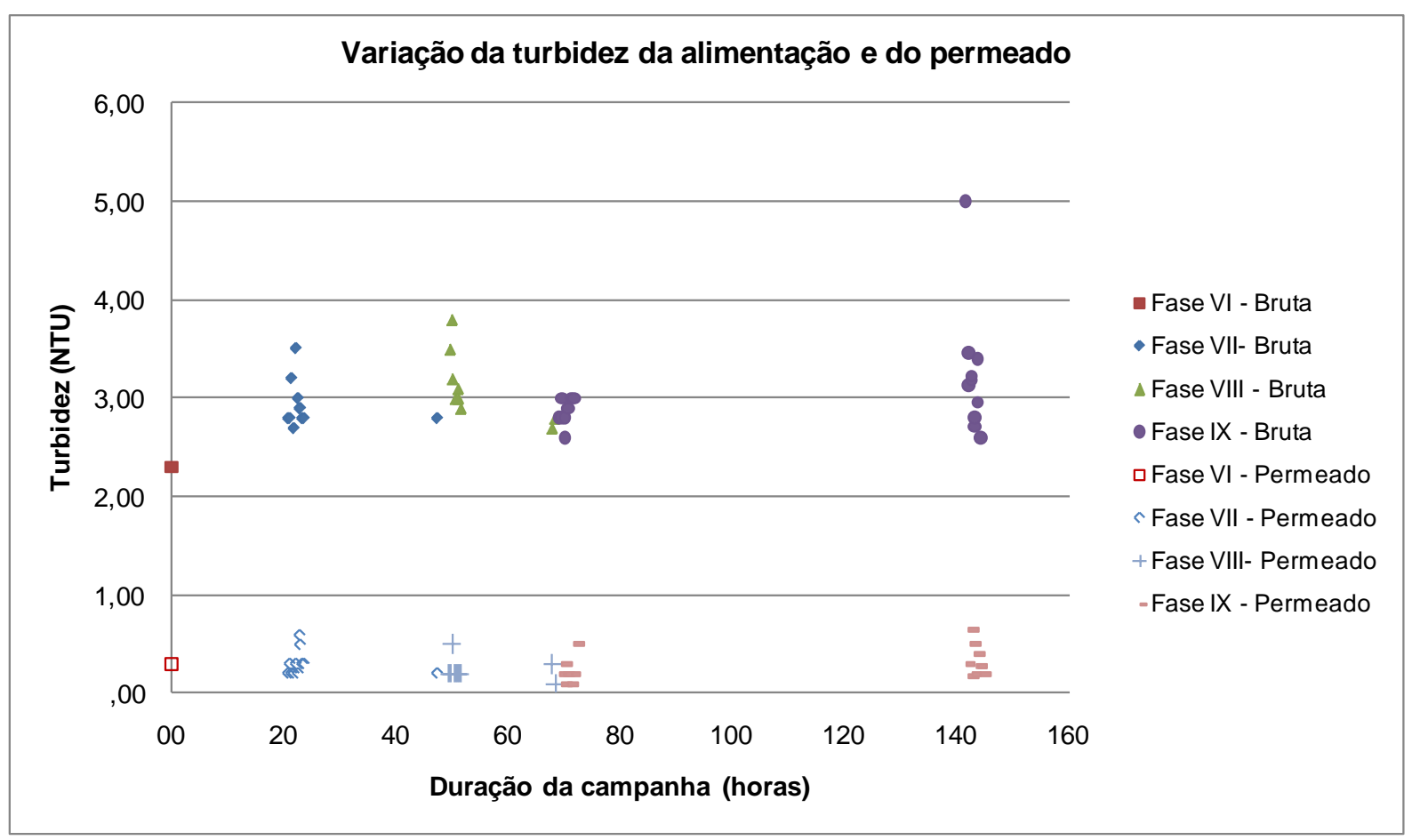

Figura 5.8 - Turbidez da alimentação e do permeado no segundo período de operação do piloto. 
Os dados coletados na fase I, com água isenta de sólidos suspensos, permitiram a determinação da resistência da membrana à água pura, estimada em $2 \times 10^{12} \mathrm{~m}^{-1}$ (desvio padrão de $0,4 \times 10^{12} \mathrm{~m}^{-1}$ ) calculada conforme a metodologia apresentada. $\mathrm{O}$ perfil de variação da resistência de pressão ao longo da primeira fase de operação é indicado no gráfico 5.9. A presença de valores em dois patamares se deve à imprecisão na leitura de pressões e variações nas condições de operação do sistema, todavia, o resultado encontrado possui a mesma ordem de grandeza para membranas de UF $\left(10^{12} \mathrm{~m}^{-1}\right)$ referenciada na literatura (HOWE et al., 2007; CASTAING et al., 2010).

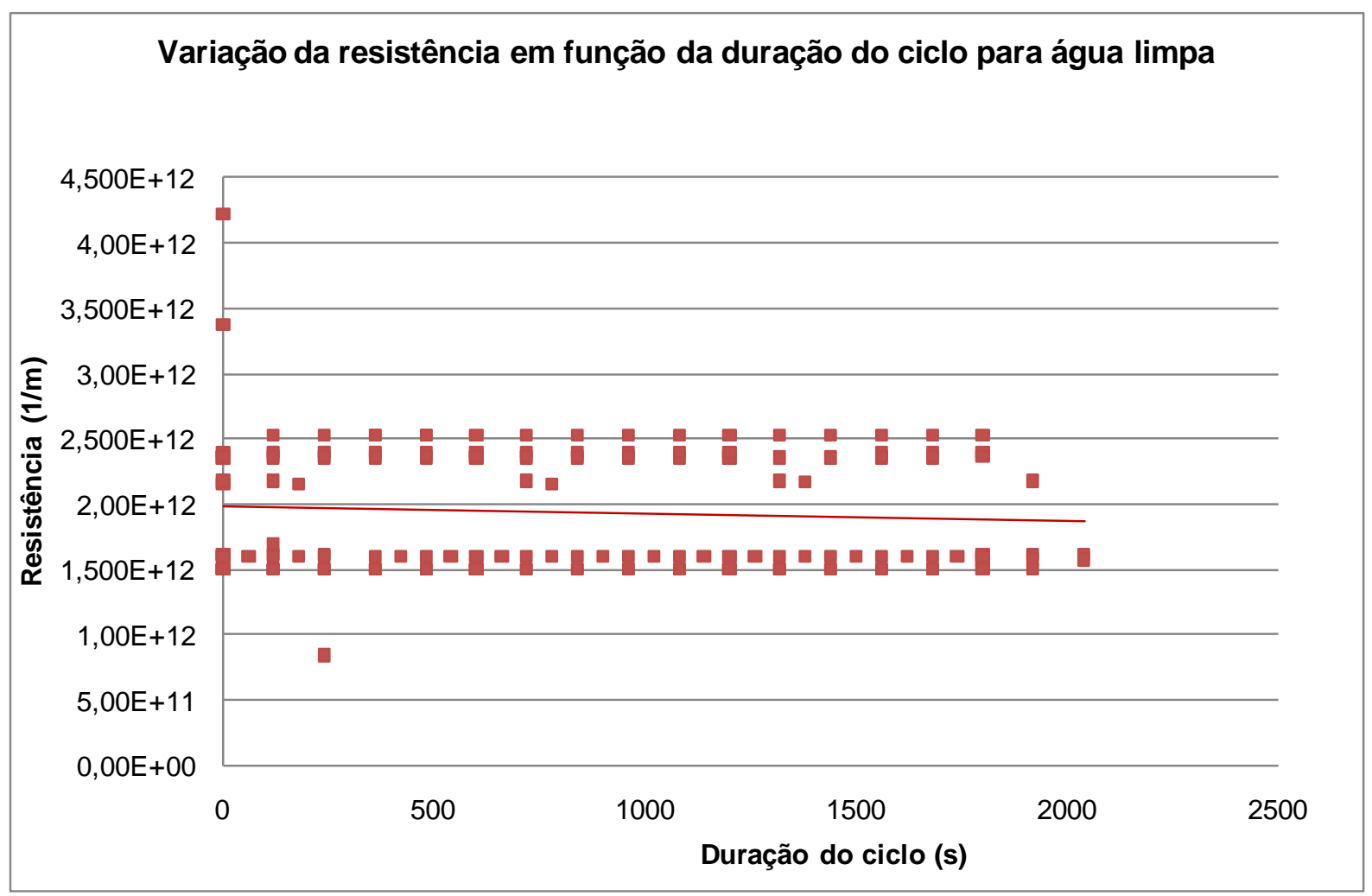

Figura 5.9 - Resistência ao longo da operação do sistema com água pura.

Os dados da fase II, embora tenham sido coletados, não foram aproveitados para a análise em virtude da imprecisão das informações uma vez que o sistema estava em fase de ajustes operando ora com água bruta, ora com água limpa e em regimes de vazão variados. Como as membranas entraram em contato com água bruta, fenômenos de formação de depósitos tiveram início já nesta fase. 
Os dados provenientes da fase III, IV e V (259 pontos) possibilitaram a composição de 26 curvas de obstrução, com um intervalo de 2 minutos entre cada série de parâmetros (gráfico 5.10). Não houve qualquer tipo de tratamento estatístico ou filtragem dos dados coletados. É possível observar nesta trajetória a relação entre as alterações no fluxo e seu impacto nas pressões bem como a escala de variação de pressões em uma membrana nova, entre 0,6 bar e 1,8 bar.

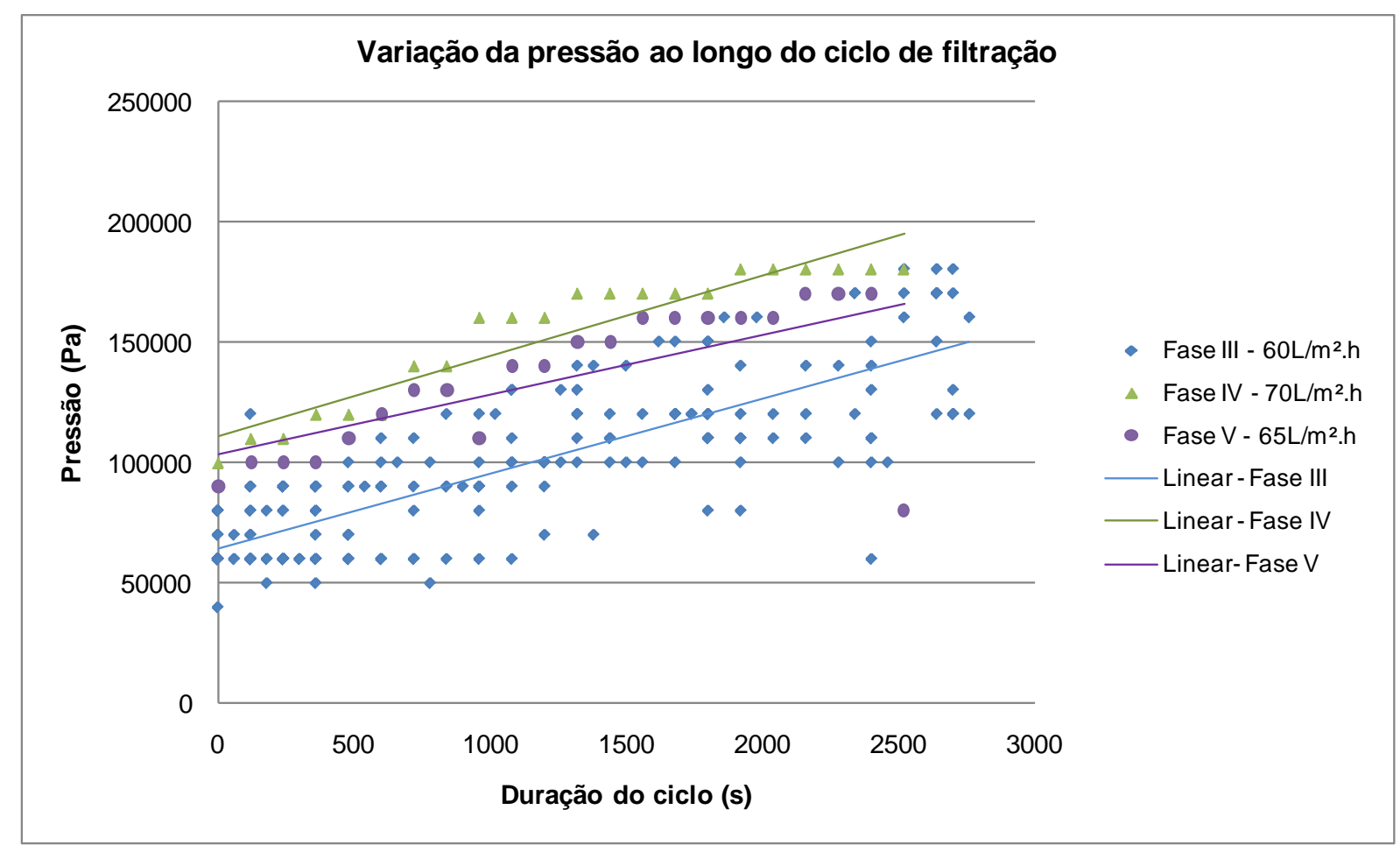

Figura 5.10 - Sobreposição de curvas de pressão em função da duração do ciclo.

O comportamento das pressões é inadequado para a avaliação da obstrução das membranas em virtude das influências da temperatura e das variações de fluxo. Tendo em vista esta consideração, foram elaboradas curvas a partir da resistência, calculada de acordo com a metodologia apresentada previamente (gráfico 5.11). Admitiu-se a pressão de alimentação como pressão efetiva de filtração (o permeado é encaminhado a um tanque atmosférico) e o fluxo foi determinado com base na vazão de permeado e na área nominal da membrana. 


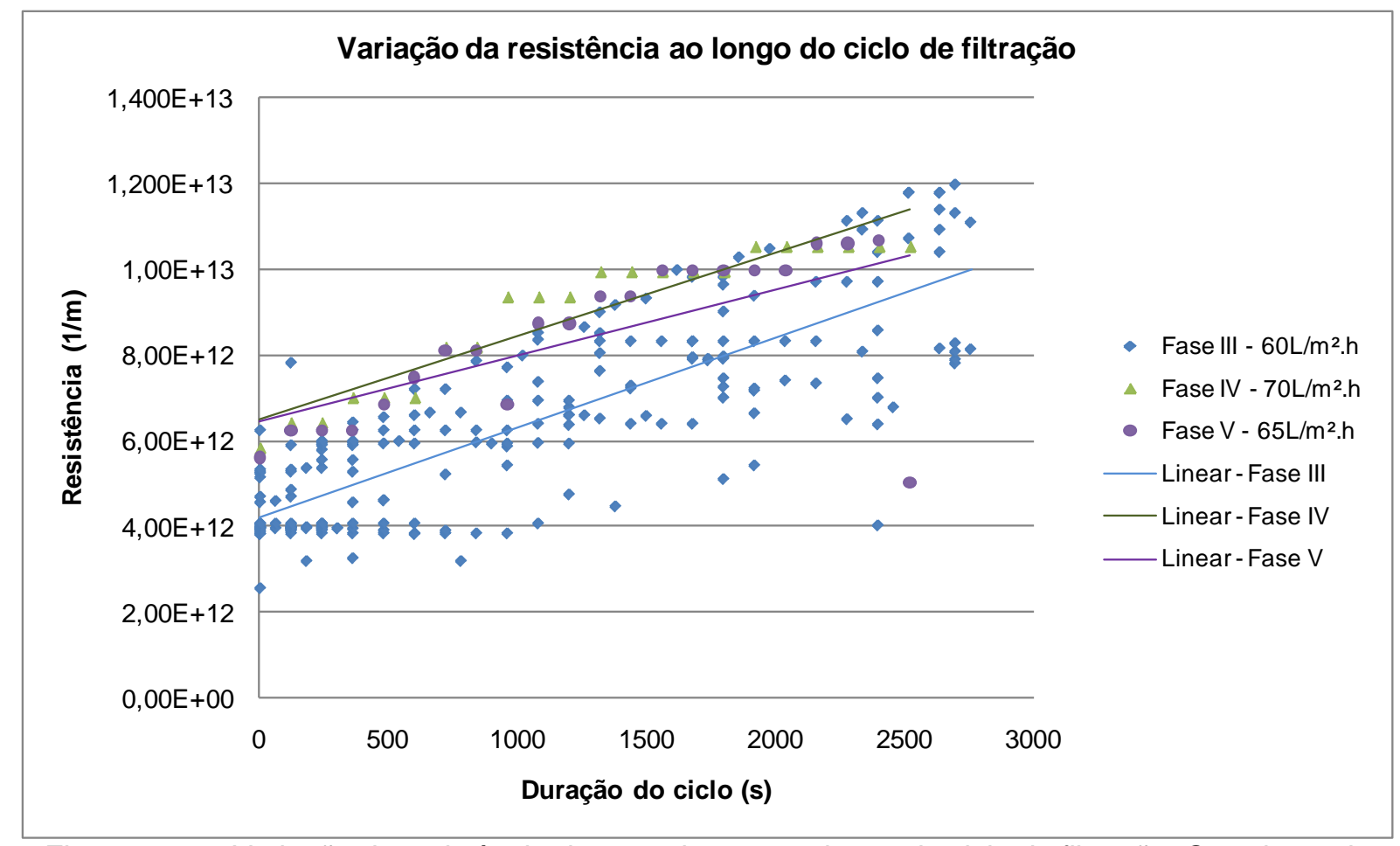

Figura 5.11 - Variação da resistência das membranas ao longo do ciclo de filtração. Os valores da fase III representam a sobreposição de 24 curvas de obstrução. Os valores da fase IV e $V$ foram baseados em apenas uma curva cada.

Através da observação das curvas é possível identificar dois aspectos importantes. O primeiro deles é que a resistência da membrana no instante zero, logo após a contralavagem é cerca de 100\% superior à resistência da membrana à água pura. Reações químicas e adsorção podem explicar este comportamento, outra hipótese é a obstrução rápida da membrana através do mecanismo de bloqueio de poros, difícil de ser detectada através da metodologia de coleta de dados utilizada. Wang et al. (2008) observa em seus estudos este tipo de comportamento e complementa que em membranas de UF, o bloqueio inicial de poros chega a ser o maior responsável pela alteração da permeabilidade no ciclo de filtração.

O segundo ponto observado é a evolução contínua das curvas, apontando para uma tendência de obstrução uniforme ao longo do ciclo como um todo. A resistência antes da contralavagem atinge valores 4 vezes superiores em relação à membrana limpa, a pressão acompanha o mesmo comportamento. Ao longo dos ciclos de filtração, as curvas aumentam em decorrência da formação de depósitos que não são removidos na operação de contralavagem conforme ilustra o gráfico 5.12 , elaborado com base nos resultados da fase III. 


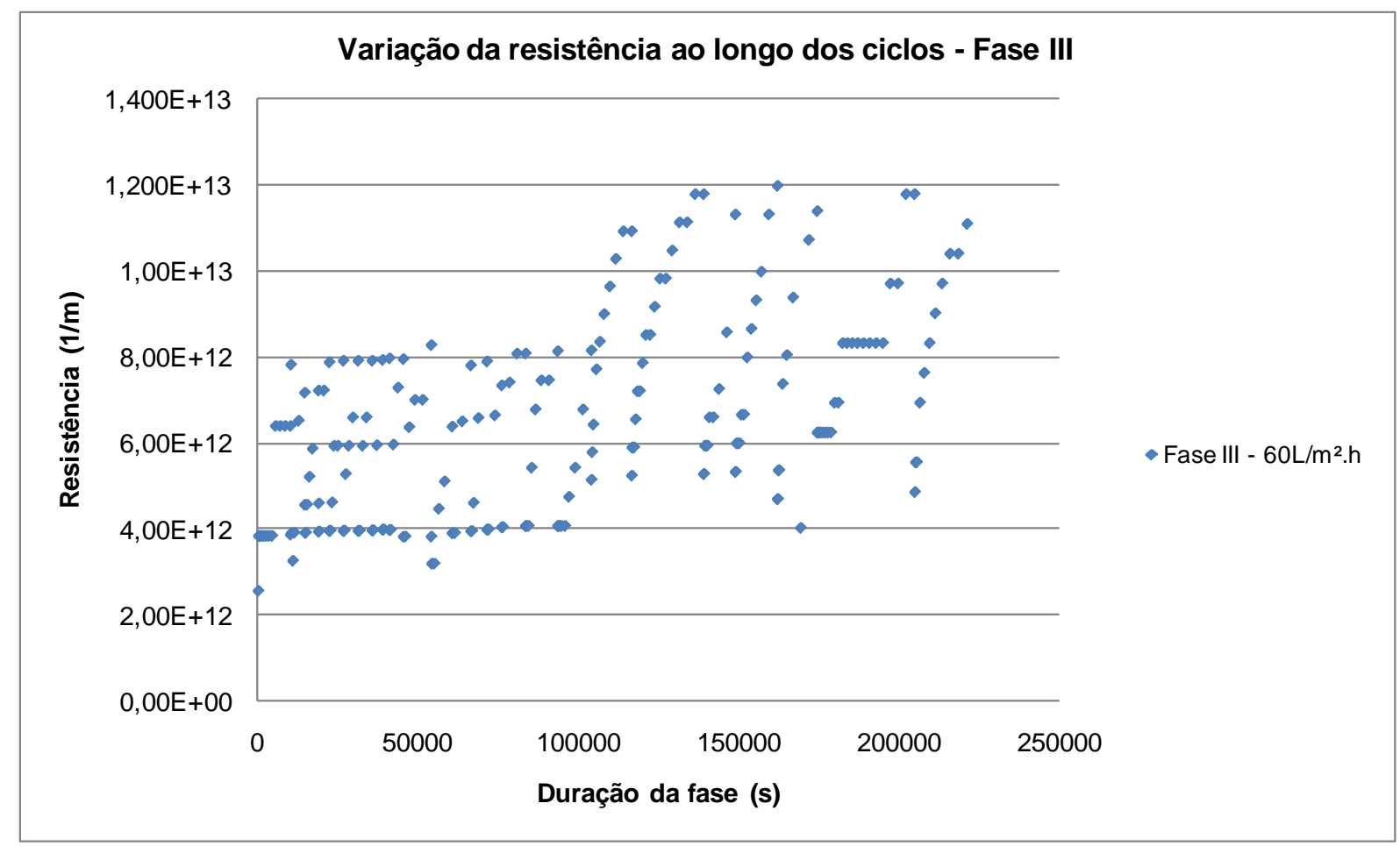

Figura 5.12 - Formação de depósitos ao longo da operação. A descontinuidade refere-se ao período de dois dias em que não houve coleta de dados.

A operação da Ultrafiltração ao longo do segundo período (gráfico 5.13) permitiu a análise do comportamento das membranas em diferentes condições de fouling. $O$ sistema permaneceu parado, com a membrana instalada por dois meses. A fase VI foi iniciada logo após esta parada. A permeabilidade, nesta condição estava seriamente comprometida possivelmente devido à formação de biofilmes, levando à pressões da ordem de 3 bar, superiores aos limites de garantia estabelecidos pelo fabricante das membranas (2,5 bar).

Uma primeira limpeza química, apenas com solução alcalina de hidróxido de sódio foi conduzida levando a uma redução significativa da resistência. Os resultados do ensaio após a limpeza foram representados pela fase VII. De forma a recuperar ainda mais as condições iniciais da membrana, uma nova limpeza química foi realizada, desta vez com solução de hidróxido de sódio e hipoclorito de sódio. A limpeza, muito mais efetiva, levou a resistência a patamares próximos aos obtidos na primeira parte dos ensaios conforme os resultados da fase VIII. 


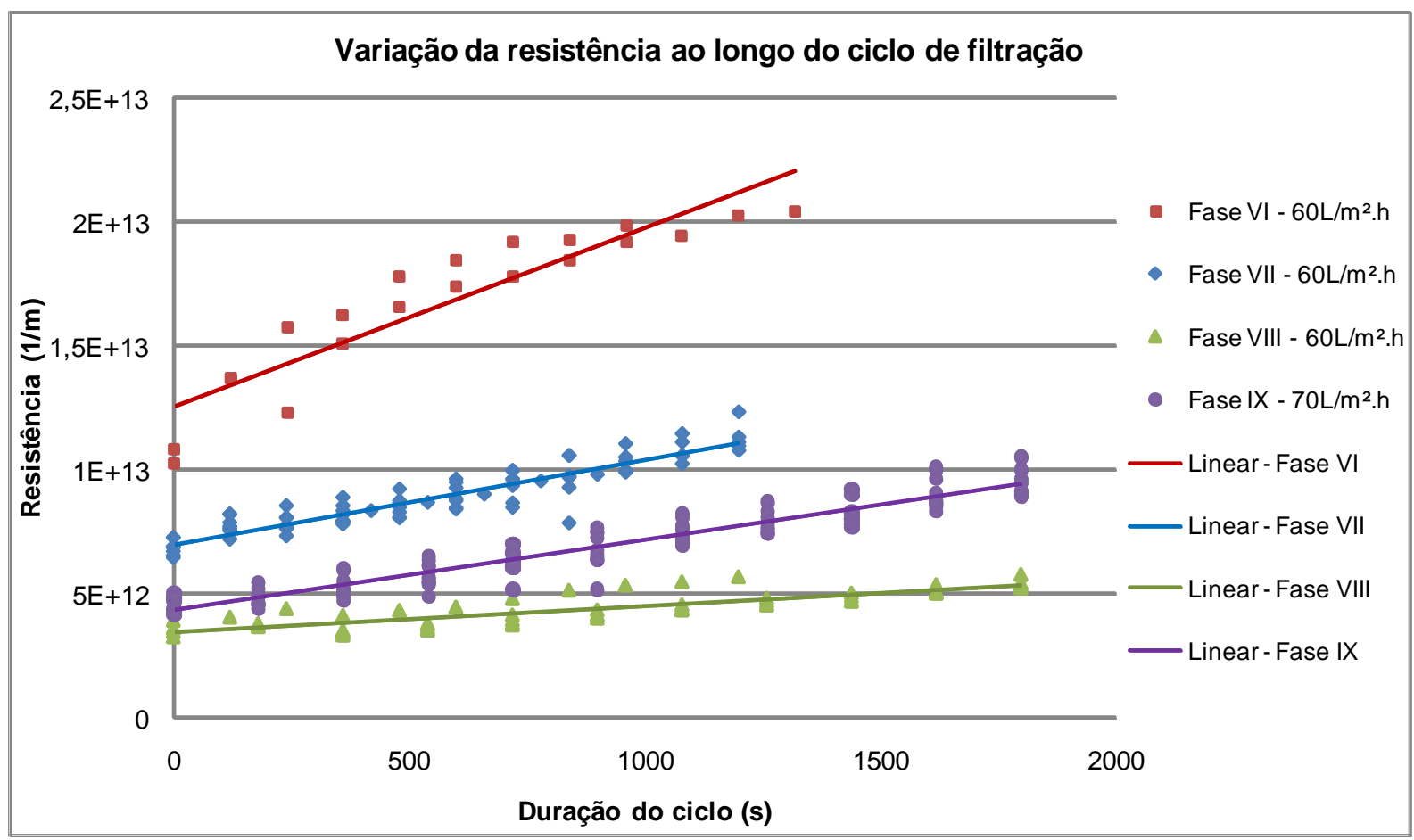

Figura 5.13 - Variação da resistência ao longo das fases do segundo período de operação da planta. Fase VI: Membrana muito colmatada. Fase VII: Resultados após limpeza com hidróxido de sódio. Fase VIII: Resultados da limpeza com hipoclorito e hidróxido de sódio.

De forma a obter os parâmetros C e m conforme a metodologia proposta, foram traçadas curvas do $\ln (d R / d \omega)$ em função do $\ln (R)$. O resultado não foi satisfatório conforme apresentam os gráfico 5.14 e 5.15 em função da elevada dispersão dos pontos, fator que impossibilitou a linearização dos valores. 


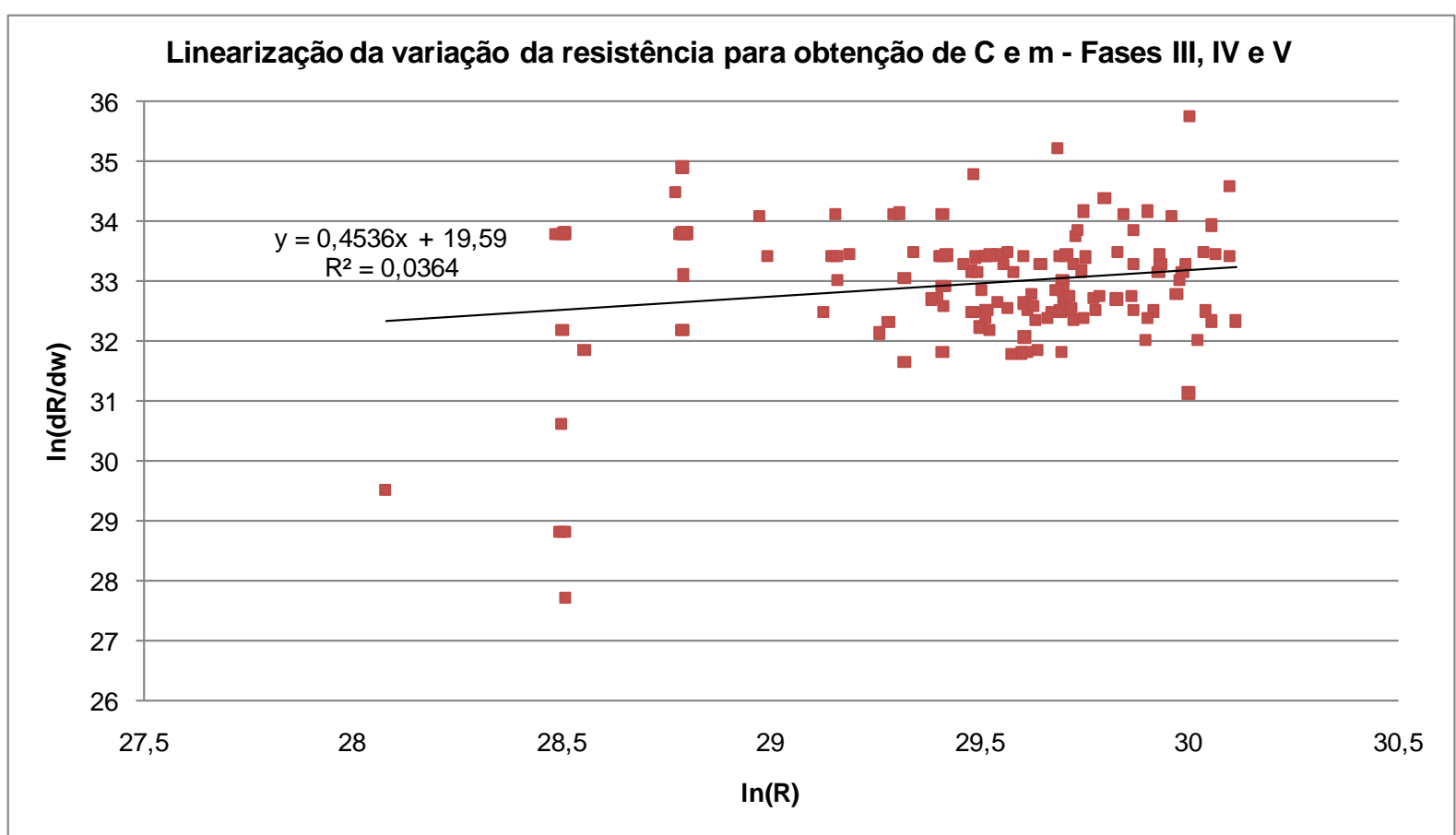

Figura 5.14 - Determinação do coeficiente C e m nas fases III, IV e V (primeira parte dos ensaios).

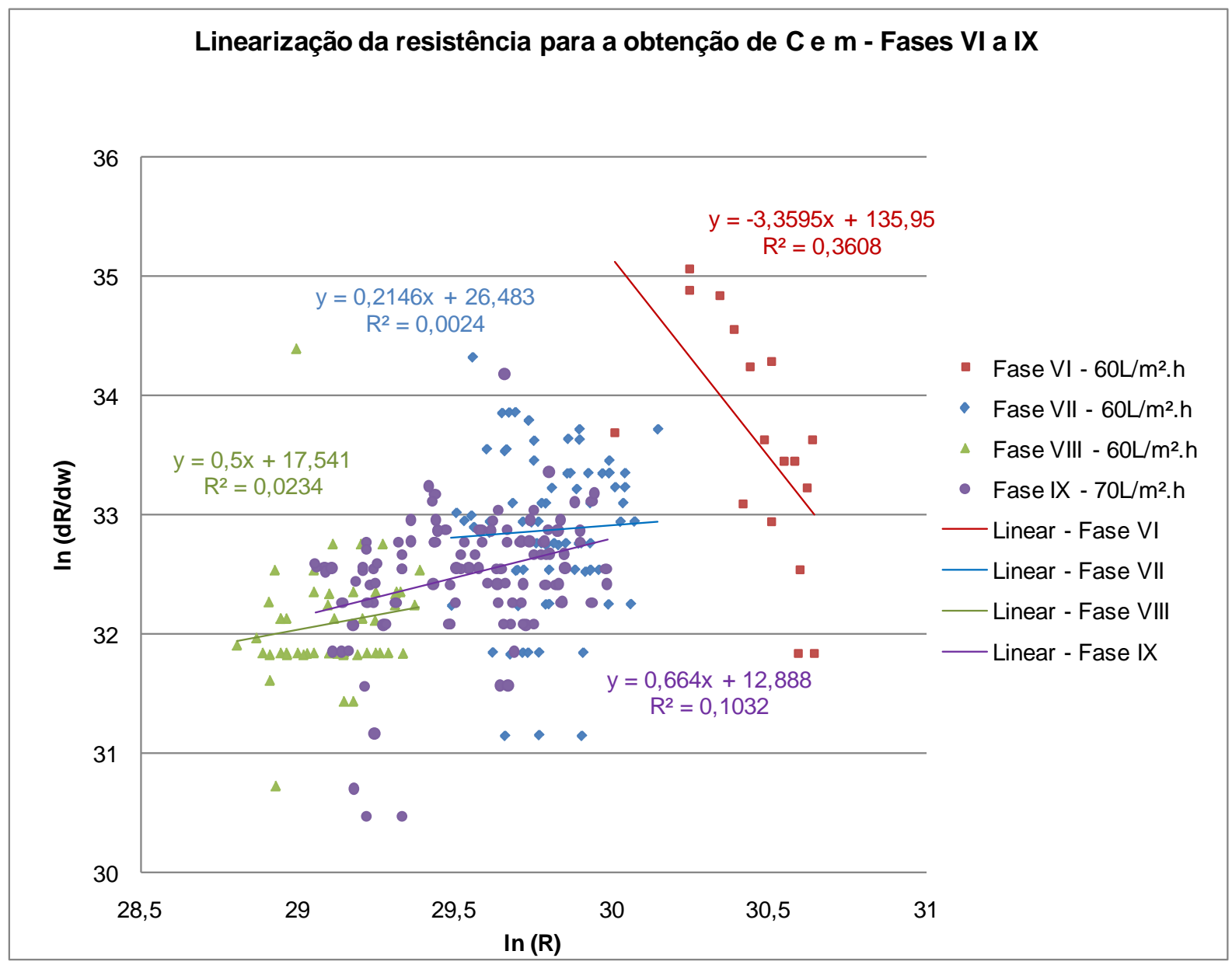

Figura 5.15 - Determinação do coeficiente C e m nas fases VI a IX (segunda parte dos ensaios). 
A variação da resistência pelo volume produzido $(d R / d \omega)$ e a variação da resistência (dR), quando convertidos para escala logarítmica acabam por aproximar os pontos e potencializar a variação natural das pressões, mudanças na qualidade de água e fatores externos, tais como incrustações permanentes. A amplificação dos erros torna a linearização muito imprecisa e de difícil aplicação na determinação dos coeficientes " $\mathrm{C}$ " e "m" baseando-se em dados de uma planta piloto. Esta técnica, contudo, pode apresentar bons resultados em estudos em laboratório, considerando a possibilidade de ensaios com maior amplitude de resistência e volume de água, bem como fatores externos controlados.

Uma alternativa para a determinação dos parâmetros de obstrução das membranas é a análise da curva da resistência em função do volume conforme os gráficos 5.16 e 5.17. Tendo como base o formato da distribuição obtida, foram realizadas duas aproximações, uma exponencial e outra linear para cada fase de operação conforme os resultados da tabela 5.9. Os coeficientes de correlação foram semelhantes ou ligeiramente favoráveis à modelagem linear.

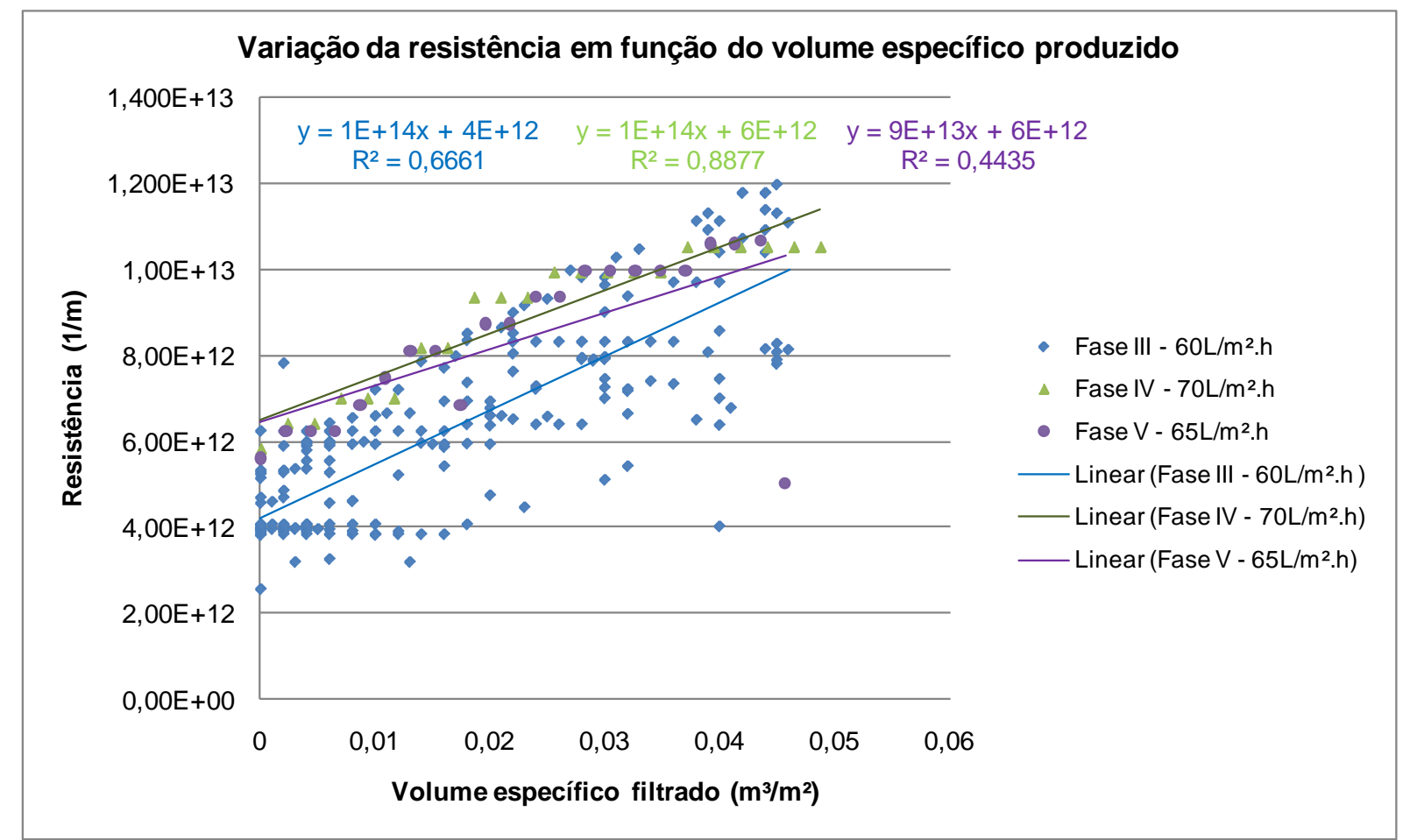

Figura 5.16 - Linearização das curvas da resistência (R) em função do volume filtrado ( $\omega$ ) para as fases III a V. 


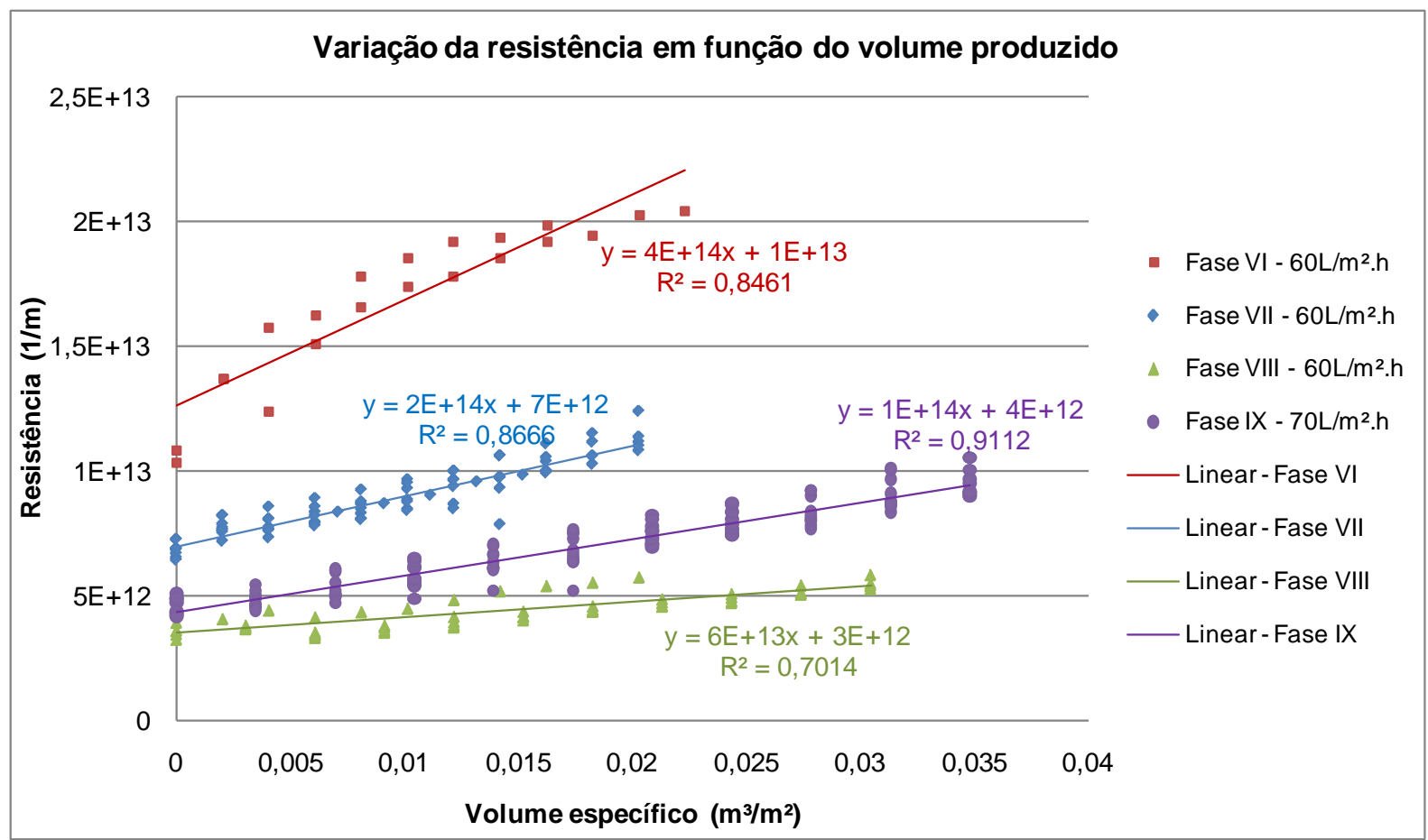

Figura 5.17 - Linearização das curvas da resistência $(R)$ em função do volume filtrado $(\omega)$ para as fases VI a IX.

Tabela 5.9 - Resultados da regressão linear e exponencial dos dados operacionais.

\begin{tabular}{cccc}
\hline & & \multicolumn{2}{c}{ Coeficiente R $\mathbf{R}^{2}$ de Pearson } \\
Fase & Quantidade de dados & Ajuste exponencial & Ajuste linear \\
III & 215 & 0,64 & 0,66 \\
IV & 22 & 0,86 & 0,88 \\
V & 22 & 0,37 & 0,44 \\
VI & 21 & 0,79 & 0,85 \\
VII & 90 & 0,87 & 0,87 \\
VIII & 55 & 0,70 & 0,70 \\
IX & 121 & 0,91 & 0,91 \\
\hline
\end{tabular}

Adotando o comportamento linear como melhor aproximação, o comportamento da membrana passa a acompanhar o modelo ideal de filtração em torta. Outras referências na literatura também verificam a predominância deste mecanismo para 0 tratamento de água (BLANKERT et al. 2007; CASTAING et al. 2010; HOWE et al. 2007; WANG, et al., 2008; YUN YE et al., 2010; KATSOUFIDOU et al., 2010. MENDRET et al. 2009).

Tomando como base no equacionamento proposto na tabela 3.2, o valor de "m" passa a ser zero na filtração em torta. O valor de "C" pode ser obtido através da linearização da relação de "R" (resistência) em função de "dw" (volume de água tratada por $\mathrm{m}^{2}$ de membrana). Na reta resultante, o valor de " $\mathrm{R}_{0}$ " (resistência da 
membrana limpa) representa o ponto de intercepção e o valor de "C", a inclinação conforme indica a equação 5.27, elaborada com base nas equações de Hermia.

$$
R(\omega)=R_{0}+C . \omega
$$

Os valores calculados de "C" e "Ro" são apresentados e comparados na tabela 5.10. A pressão inicial e final para 30 e 40 minutos foi calculada através da trajetória de " $\lambda$ " para a temperatura de $25^{\circ} \mathrm{C}$ e para o mesmo fluxo considerado na fase em questão.

Tabela 5.10 - Coeficientes obtidos nas diferentes fases de operação da unidade piloto. A listagem foi ordenada em ordem crescente da pressão no fim de ciclo.

\begin{tabular}{|c|c|c|c|c|c|}
\hline \multirow[t]{2}{*}{ Fase } & \multirow[t]{2}{*}{$R_{0} \times 10^{12}\left(\mathrm{~m}^{-1}\right)$} & \multirow[t]{2}{*}{$\mathrm{C} \times 10^{13}\left(\mathrm{~m}^{-2}\right)$} & \multicolumn{3}{|c|}{ Pressão calculada (KPa) } \\
\hline & & & $0 \mathrm{~min}$ & $30 \mathrm{~min}$ & $40 \mathrm{~min}$ \\
\hline I (água limpa) & 2 & 0 & 25 & 25 & 25 \\
\hline VIII $\left(60 \mathrm{~L} / \mathrm{m}^{2} . h\right)$ & 3,5 & 6,2 & 52 & 79 & 88 \\
\hline III $\left(60 \mathrm{~L} / \mathrm{m}^{2} / \mathrm{h}\right)$ & 4,2 & 12,5 & 63 & 119 & 137 \\
\hline$V\left(65 \mathrm{~L} / \mathrm{m}^{2} . h\right)$ & 6,5 & 8,5 & 104 & 148 & 163 \\
\hline $\mathrm{IX}\left(70 \mathrm{~L} / \mathrm{m}^{2} . \mathrm{h}\right)$ & 4,3 & 14,7 & 75 & 163 & 193 \\
\hline IV $\left(70 \mathrm{~L} / \mathrm{m}^{2} . \mathrm{h}\right)$ & 6,5 & 10,1 & 112 & 174 & 194 \\
\hline VII $\left(60 \mathrm{~L} / \mathrm{m}^{2} . h\right)$ & 7,0 & 20,3 & 112 & 193 & 224 \\
\hline $\mathrm{VI}\left(60 \mathrm{~L} / \mathrm{m}^{2} . \mathrm{h}\right)$ & 12,6 & 42,5 & 187 & 376 & 439 \\
\hline
\end{tabular}

Ao longo das fases de operação, conforme o esperado, o valor de " $\mathrm{R}_{0}$ " aumentou gradativamente e pôde ser devolvido a patamares próximos à partida após as limpezas químicas de manutenção o que indica a predominância de depósitos reversíveis. As alterações de fluxo não demonstraram impactar de forma significativa no valor de " $\mathrm{R}_{0}$ conforme o previsto na modelagem física.

O coeficiente "C", por outro lado, variou de forma destacada nas fases de fouling severo (VI e VII). O comportamento observado não condiz com a premissa adotada no modelo de Hermia, segundo a qual, idealmente, a taxa de aumento de resistência é proporcional apenas ao volume filtrado, ou seja, para fluxos distintos o valor de " $\mathrm{C}$ " deveria manter-se constante assim como ocorreu com resistência inicial " $\mathrm{R}_{0}$ ". $A$ relação entre o fluxo e o fator de formação de depósitos pode ser explicada por interações químicas que ocorrem em função do aumento ou redução da polarização 
de concentrações. Sutzkover-Gutman et al. (2010), com base em uma extensa revisão de artigos referentes à obstrução de membranas de ultrafiltração por matéria orgânica em águas naturais reconhece a influência da polarização de concentrações e da composição da torta na resistência, todavia, em função da complexidade de todos os mecanismos envolvidos, até o momento não existe um modelo genérico capaz de prever estas interações.

De uma forma geral, o modelo de formação de torta se adequou bem às curvas individuais de resistência obtidas na planta piloto. As curvas sobrepostas apresentam uma faixa de variação da resistência inicial, em função de obstruções que não foram removidas na contralavagem, e pequenas alterações no fator de depósitos "C".

Ao considerar séries mais longas com as membranas mantidas em condições normais de limpeza, como foi o caso das fases III e IX, que equivalem a $60 \%$ dos dados coletados, verifica-se que estas oscilações de " $R_{0}$ " e "C" foram compensadas levando a resultados similares e consistentes para a resistência inicial (diferença de 2\%) e para o fator de formação de depósitos (diferença de 17\%). Evidentemente, o curto período de operação da unidade piloto não permitiu a avaliação do comportamento da curva de obstrução em longo prazo impossibilitando a determinação de um valor para o coeficiente $\mathrm{K}_{1}$.

Os coeficientes de comportamento obtidos com as membranas em condições normais, entretanto, não foram válidos para condições de obstrução severa conforme foi observado nas fases VI e VII. Não houve incremento apenas na resistência como havia sido previsto através do coeficiente " $\mathrm{K}_{1}$ ", mas também na inclinação da reta da formação de depósitos ("C") o que inviabiliza previsões para o comportamento da planta nestas condições. A severidade do fouling obtido neste estudo piloto, com pressões superiores aos limites de garantia das membranas, dificilmente seria atingida em uma planta em escala industrial. Observando-se as recomendações dos fabricantes quanto à limpeza e de dosagem de coagulantes é possível manter a resistência em um patamar estável por meses. 
Como a turbidez da água bruta manteve-se praticamente constante ao longo dos ensaios, também não foi possível estabelecer qualquer tipo de correlação entre a qualidade e água de alimentação e a trajetória de obstrução das membranas. De qualquer forma, tendo como base o comportamento de filtração em torta observado, o uso do índice MFI-UF anteriormente apresentado pode auxiliar na correlação da qualidade da água com o com o comportamento das membranas em futuros aperfeiçoamentos do modelo físico.

\subsection{Otimização do TCO}

Tendo a função de TCO definida para as condições de trabalho estabelecidas, a última etapa necessária ao dimensionamento econômico dos sistemas de ultrafiltração é minimizar esta função garantindo desta forma os menores custos para a configuração estabelecida.

De acordo com as premissas adotadas para a concepção do modelo físico, as equações de comportamento de membranas baseadas no bloqueio de poros permitem a otimização simultânea da duração do ciclo de filtração (t) e da área instalada $(A)$.

Para durações de ciclo de produção de permeado muito pequenas, há um excesso de operações de contralavagem o que leva a uma redução da recuperação levando à necessidade de instalar mais membranas, aumento do consumo de produtos químicos, geração de efluentes e consumo de água de alimentação. Quando a duração do ciclo aumenta, o consumo energético passa a ser superior conforme ilustra o gráfico 5.18, o tempo de ciclo é limitado pela pressão máxima suportada pelas membranas.

Considerando a área de membranas, uma menor quantidade de elementos representa um fluxo superior com velocidade de incremento de pressão mais acentuada levando ao consumo de energia maior e a operações de limpeza mais freqüentes. Áreas maiores influenciam no custo de capital e de reposição de membranas, todavia, permitem operação com pressões mais baixas e limpezas mais 
espaçadas. O resultado da influência da área de membranas é ilustrado no gráfico 5.19, a quantidade mínima de membranas é limitada pela pressão máxima suportada pelas membranas.

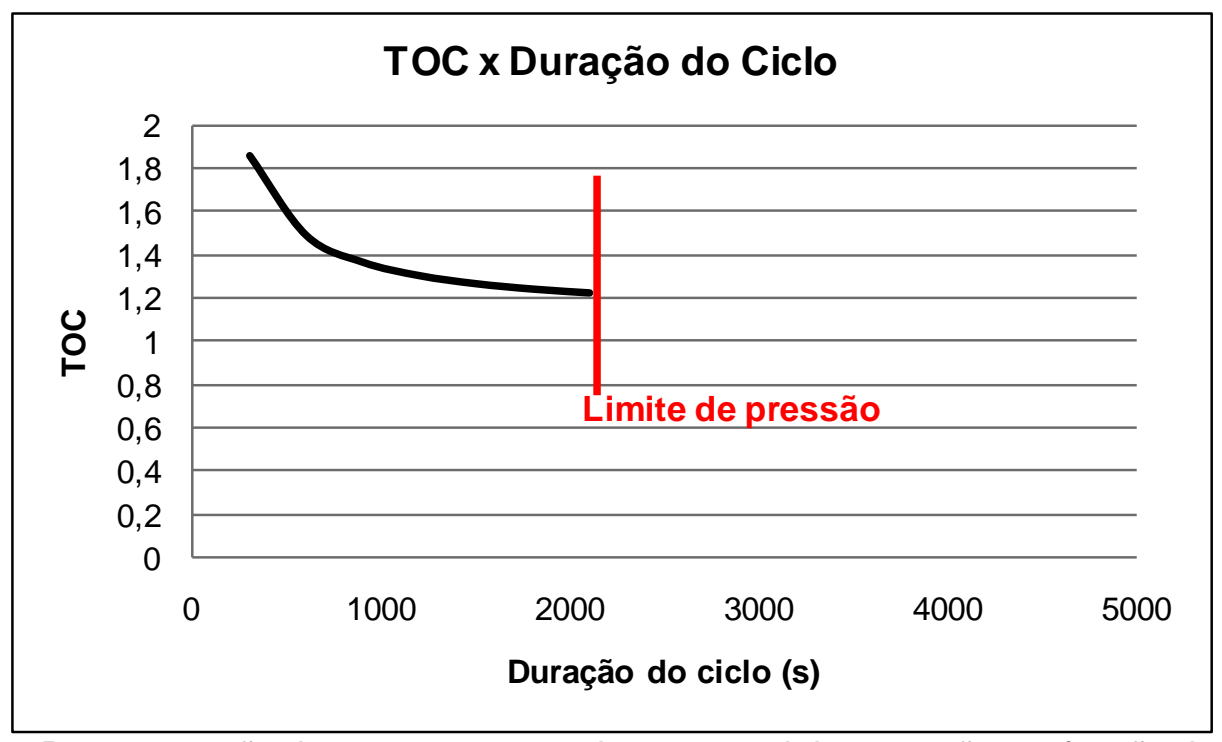

Figura 5.18 - Representação do comportamento do custo total de operação em função da duração do ciclo para um caso genérico a partir do modelo proposto.

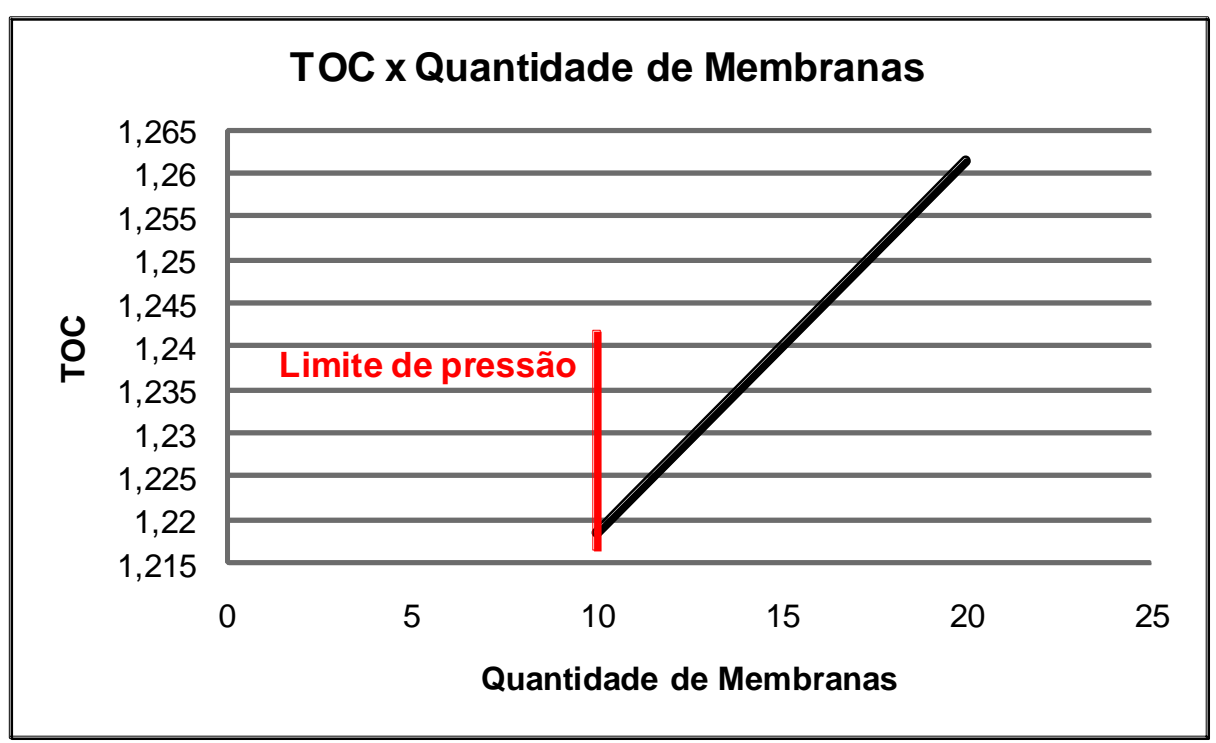

Figura 5.19 - Representação do comportamento do custo total de operação em função da quantidade de membranas para um caso genérico a partir do modelo proposto.

De forma a encontrar o ponto de equilíbrio entre a quantidade de membranas instaladas e a duração do ciclo de filtração foi concebido um modelo numérico discreto ilustrado no diagrama 5.20. O modelo realiza uma busca do valor ótimo dentro de uma região (matriz) limitada pelos seguintes critérios de parada: 
- Pressão ao longo do ciclo menor que a pressão máxima $\left(P_{\text {máx }}\right)$ suportada pelas membranas;

- Tempo de ciclo mínimo;

- Tempo de ciclo máximo;

- Quantidade mínima de membranas;

- Quantidade máxima de membranas.

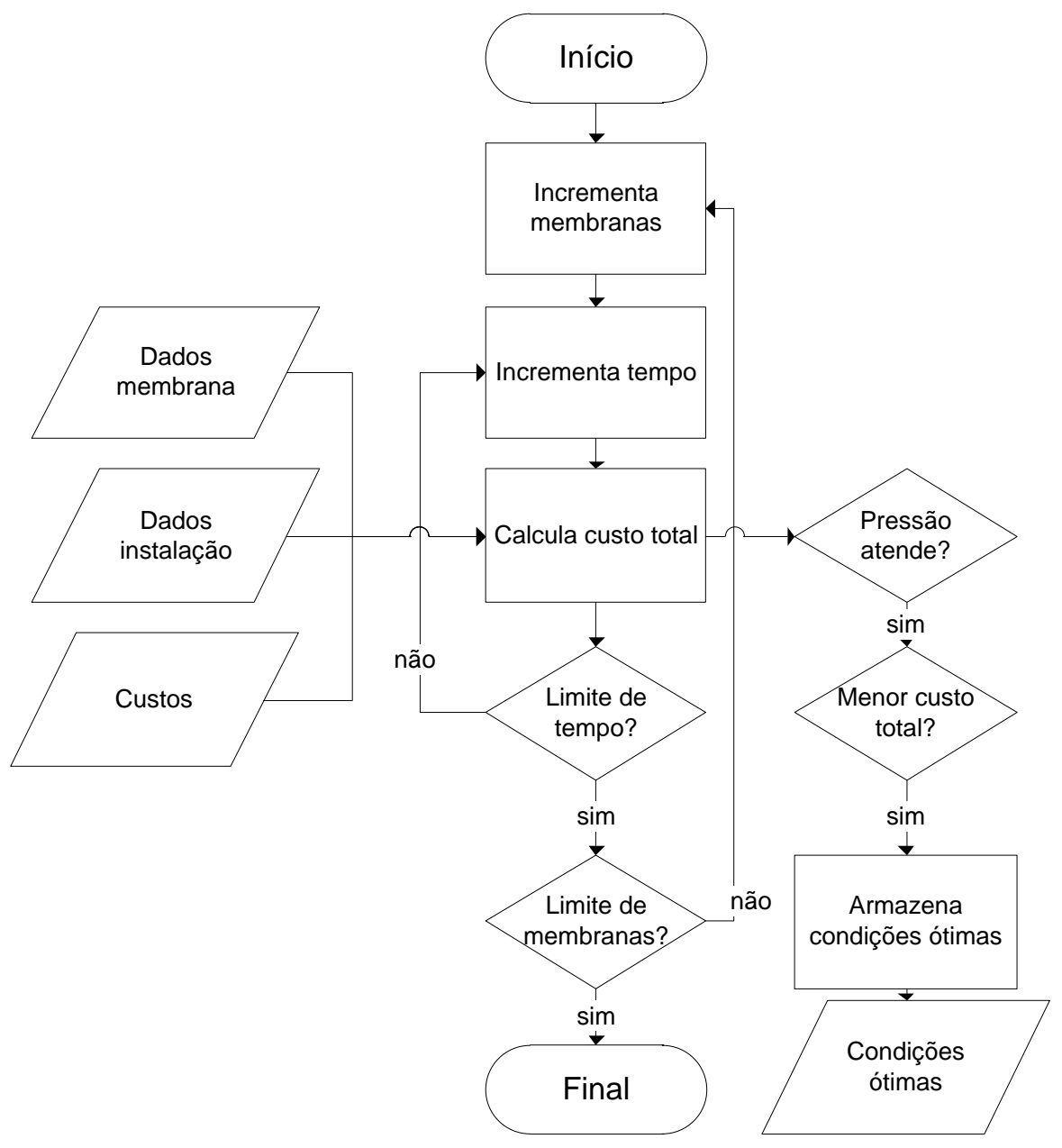

Figura 5.20 - Algoritmo de otimização da quantidade de membranas e duração do ciclo.

O passo de incremento do tempo e da quantidade de elementos ocorre em unidades fixas como, por exemplo, de 10 em 10 segundos e de 1 em 1 elementos de membrana. A discretização da quantidade de membranas e do tempo simplifica o cálculo reduzindo o número de interações numéricas mantendo os resultados dentro dos limites de precisão necessários ao projeto e à operação de um sistema de ultrafiltração. 
O algoritmo proposto também pode ser aplicado na otimização dinâmica de sistemas de ultrafiltração já existentes. Neste caso, são fixadas as características da planta como quantidade de membranas e vazão e a partir da curva de obstrução das membranas passa a ser possível determinar a duração ideal do ciclo de filtração para a situação atual.

Com o intuito de discutir o impacto do algoritmo proposto em um projeto, o mesmo foi executado tendo como valores de entrada as características do sistema definidas na análise de sensibilidade, os custos relativos ao cenário econômico sem cobrança pela água e os parâmetros de comportamento das membranas médios obtidos na fase III do ensaio piloto $\left(R_{0}=4,2 \times 10^{12} \mathrm{~m}^{-1}, C=1,25 \times 10^{14} \mathrm{~m}^{-2}\right)$. É importante ressaltar que os modelos das membranas são diferentes, porém o comportamento será assumido como o mesmo em função das similaridades em diâmetro de corte e permeabilidade dos elementos.

$\mathrm{O}$ coeficiente de aumento de resistência $\mathrm{K}_{1}$ foi alterado de forma a refletir o impacto desta variável no projeto ótimo e o único critério de parada utilizado foi a pressão máxima suportada pelas membranas. Os demais parâmetros não tiveram seus valores restringidos de forma a permitir uma busca pelo valor mínimo global.

O resultado da otimização é apresentado na tabela 5.11. Não foi encontrado mais de um valor ótimo para o TCO em nenhum dos casos, a existência de uma solução única é explicada pelo equacionamento adotado na modelagem. 
Tabela 5.11 - Resultado da otimização com variação do coeficiente K1.

\begin{tabular}{|c|c|c|c|c|c|}
\hline Variável & $\begin{array}{l}\text { Referência } \\
\text { Fornecedor }\end{array}$ & $\begin{array}{l}\text { Variação } \\
\text { Fornecedor }\end{array}$ & $\begin{array}{c}\text { Otimização } \\
K_{1}=1\end{array}$ & $\begin{array}{c}\text { Otimização } \\
\mathrm{K}_{1}=2\end{array}$ & $\begin{array}{c}\text { Otimização } \\
K_{1}=5\end{array}$ \\
\hline Quantidade de membranas & 22 & 15 a 38 & 20 & 26 & 49 \\
\hline $\begin{array}{l}\text { Duração da etapa de } \\
\text { filtração (s) }\end{array}$ & 1800 & $\begin{array}{l}1200 a \\
2400\end{array}$ & 2400 & 2590 & 5230 \\
\hline $\begin{array}{l}\text { Pressão no final da carreira } \\
(\mathrm{kPa})\end{array}$ & 200 & Máx 200 & 200 & 200 & 200 \\
\hline $\mathrm{TCO} \mathrm{R} \$ / \mathrm{m}^{3}$ & 0,13 & - & 0,12 & 0,15 & 0,22 \\
\hline
\end{tabular}

A partir dos resultados da otimização, observa-se que para valores de $K_{1}=1$ (não considera aumento de resistência ao longo da vida útil) e $\mathrm{K}_{1}=2$ (aumento de 100\% na resistência ao final da vida útil) a quantidade de membranas encontrada situa-se dentro da faixa de valores recomendados. O tempo de ciclo, por sua vez, chega a índices mais agressivos. Considerando que as curvas de obstrução foram elaboradas com base em uma água com turbidez relativamente baixa (em torno de 4 NTU), um resultado agressivo como este na duração da carreira de filtração é esperado.

Quando o coeficiente $\mathrm{K}_{1}$ assumiu o valor 5, tanto o valor da duração do ciclo quanto a quantidade de membranas assumiram valores distantes das referências e recomendações do fornecedor. Este resultado indica que a adoção de valores muito conservadores para o coeficiente pode levar à distorção da otimização e a parâmetros de projeto não realistas.

Do ponto de vista prático, a execução de um projeto com parâmetros fora dos limites máximos e mínimos recomendados pelo fornecedor das membranas não é interessante uma vez que a garantia dos módulos só é válida se estas faixas são respeitadas. Desta forma, foram considerados no algoritmo os limites de tempo de ciclo e quantidade mínima e máxima de elementos conforme orientações do fabricante.

Um novo cálculo dos valores ótimos foi realizado, desta vez considerando o impacto da mudança de cenário econômico com ou sem a cobrança pela água e os limites 
de garantia apresentados pelos fabricantes. Os resultados são apresentados na tabela 5.12.

Tabela 5.12 - Resultados da otimização dentro dos limites dos fabricantes para dois cenários econômicos.

\begin{tabular}{|c|c|c|c|c|}
\hline Variável & $\begin{array}{l}\text { Referência } \\
\text { Fornecedor }\end{array}$ & $\begin{array}{c}\text { Variação } \\
\text { Fornecedor }\end{array}$ & $\begin{array}{c}\text { Otimização } \\
\text { com } \\
\text { cobrança }\end{array}$ & $\begin{array}{c}\text { Otimização } \\
\text { sem } \\
\text { cobrança }\end{array}$ \\
\hline Quantidade de membranas & 22 & 15 a 38 & 20 & 17 \\
\hline Duração da etapa de filtração (s) & 1800 & 1200 a 2400 & 2400 & 1240 \\
\hline Pressão no final da carreira $(\mathrm{kPa})$ & 200 & Máx 200 & 200 & 200 \\
\hline $\mathrm{K}_{1}$ & - & & 1 & 1 \\
\hline TCO (com e sem cobrança) R $\$ / m^{3}$ & 0,13 & - & 0,12 & 0,07 \\
\hline
\end{tabular}

O novo resultado, conforme o esperado manteve a quantidade de membranas e a duração no cenário com cobrança uma vez que a recomendação já estava dentro dos limites estabelecidos pelo fornecedor. No caso do cálculo sem a cobrança pelo uso da água, a quantidade de elementos foi mantida próxima ao patamar mínimo e a duração do ciclo de filtração foi reduzida de forma a privilegiar o consumo energético.

A diferença entre os resultados ótimos em função do cenário econômico evidencia o impacto dos custos sobre as variáveis de projeto conforme já havia sido constatado na etapa de análise de sensibilidade.

Os resultados da otimização numérica do TCO como um todo foram promissores, valores compatíveis com as recomendações dos fabricantes foram obtidos no cálculo sem restrições baseado nas características da membrana utilizada no equipamento piloto. Foi observada uma resposta significativa nas variáveis de projeto às mudanças no cenário econômico o que justifica a otimização do projeto de acordo com a região geográfica e condições econômicas. 


\section{CONCLUSÕES}

As similaridades entre as características dos elementos e o modo de operação dos produtos oferecidos por diferentes fabricantes membranas permitiram com sucesso a criação de um modelo genérico único, que contempla os principais aspectos impactantes no dimensionamento de sistemas. Às variáveis de projeto foram atribuídos custos de forma a possibilitar a determinação do custo total de propriedade (TCO) que posteriormente foi utilizado como função objetivo para a otimização.

O valor de TCO determinado através do modelo econômico não contempla todas as parcelas que compõem o custo real da água tratada, essa diferença se deve ao fato que aspectos não relacionados diretamente ao dimensionamento ótimo do processo como obras civis, operadores e impostos foram desconsiderados de forma a manter o modelo de projeto simples, alimentado pela menor quantidade de dados possível.

A análise de sensibilidade permitiu identificar as variáveis passíveis de otimização em projeto mais impactantes na composição do TCO: duração da contralavagem, duração da carreira de filtração e quantidade de membranas. A análise também verificou que o grau de contribuição destes componentes no valor final da água varia em função do cenário econômico influenciando na forma com que o dimensionamento é conduzido e nos próprios resultados do projeto.

O comportamento das membranas adotado no modelo físico considerou a relação entre a qualidade de água e o comportamento da membrana como aderente ao modelo de colmatação proposto por Hermia (1982). A análise dos dados provenientes da operação de uma planta piloto com água bruta confirmou esta relação permitindo identificar o mecanismo predominante com sendo o de filtração em torta. No estudo de caso realizado, foi constatado que os parâmetros de colmatação são válidos até um determinado nível de formação de depósitos, assumindo outros valores em condições de obstrução severa. Infelizmente não foi possível, com a série de dados disponível, confirmar se este comportamento se mantém em longas jornadas de filtração, ao longo da vida útil da membrana. 
O método inicialmente proposto para a determinação dos coeficientes $\mathrm{C}$ e $\mathrm{m}$ baseado na equação geral da formação de depósitos, demonstrou ser ineficaz na análise dos dados obtidos na unidade piloto. Em condições laboratoriais, utilizando células de fluxo, esta metodologia pode levar a resultados mais precisos uma vez que a amplitude de variação de pressões e o volume específico de água podem ser aumentados de forma permitir o traçado de retas em escala logarítmica.

A curva da formação de depósitos, estabelecida no modelo físico, foi utilizada na elaboração de um algoritmo de otimização da quantidade de membranas e da duração do ciclo de filtração, baseado no mínimo valor do custo total de operação. Outras variáveis apontadas como significativas na análise de sensibilidade não puderam ser otimizadas uma vez que não foi estabelecida uma relação entre o seu comportamento e fatores de projeto.

Os resultados da otimização utilizando como valores de entrada as informações obtidas na análise de sensibilidade e as curvas da unidade piloto levaram a resultados dentro da faixa de recomendações dos fabricantes de membranas, usualmente baseadas nos resultados de operações de longo prazo em plantas industriais. A variável de redução de desempenho ao longo da vida útil " $\mathrm{K}_{1}$ " atuou como um fator de segurança tornando o projeto mais conservador. Como o modelo de otimização permite o uso dos limites estabelecidos pelos fabricantes de membranas como condição de parada, o modelo também evita projetos excessivamente arrojados ou conservadores que poderiam invalidar a garantia dos elementos.

De uma forma geral o modelo para projeto ótimo proposto apresentou resultados compatíveis com as recomendações dos fabricantes de membranas. Considerando a ampla faixa de variação da quantidade de membranas e de duração de ciclo especificadas nos manuais, o uso desta ferramenta pode levar a projetos muito menos arbitrários.

Para uso do modelo de projeto ótimo de novos sistemas é recomendável a utilização de séries de dados provenientes de unidades piloto com a duração mínima de um intervalo entre limpezas químicas. A época ideal para o levantamento dos dados na 
unidade piloto deve ser baseada no comportamento do manancial ao longo do ano hidrológico, de forma a contemplar as condições mais adversas de teor de sólidos, atividade microbiológica ou concentração de poluentes. Cabe ressaltar que o modelo de dimensionamento não foi validado para ensaios em células de fluxo em laboratório, o uso deste tipo de dados requer atenção uma vez que características peculiares de operação no campo não são representadas de forma fiel em condições laboratoriais.

No decorrer da elaboração deste trabalho, verificou-se uma segunda aplicação para o modelo de dimensionamento econômico: a otimização dinâmica de plantas já existentes. A maioria das variáveis de projeto consideradas no modelo também são variáveis operacionais (duração dos ciclos, fluxos de operação e contralavagem, etc..). As curvas de obstrução das membranas bem como as variações dos custos das commodities (energia elétrica, produtos químicos, etc..) permitem ajustar as variáveis operacionais de forma a obter o mínimo custo total em uma janela operacional de curto prazo (dias ou semanas) baseada nas leituras mais recentes de desempenho. 


\section{RECOMENDAÇÕES PARA ESTUDOS FUTUROS}

- Incorporação, no modelo físico, de uma relação entre a eficiência da contralavagem e os parâmetros de projeto;

- Incorporação, no modelo físico, de uma relação entre a dosagem de produtos químicos e a eficiência da operação e da contralavagem;

- Investigação sobre o comportamento do parâmetro "C" em membranas muito colmatadas ou obstruídas por biofilmes ou matéria orgânica.

- Determinação da faixa de variação real esperada para o coeficiente $K_{1}$ no final da vida útil das membranas.

- Estudo da possibilidade de uso do coeficiente $\mathrm{K}_{1}$ linearmente variável ao longo da vida útil do sistema.

- Análise de sensibilidade considerando variações do custo da energia elétrica;

- Estudo de resultados econômicos obtidos da aplicação do modelo no projeto de plantas reais e na otimização dinâmica de sistemas já existentes.

- Adaptação do modelo para otimização no modo de pressão constante (s=1). 


\section{REFERÊNCIAS BIBLIOGRÁFICAS}

AWWA, American Water Works Association. Microfiltration and ultrafiltration membranes for drinking water. $1^{\text {st }}$ ed. Denver: 2005 (AWWA manual; M53).

AWWA, American Water Works Association. Water Quality and Treatment: A handbook of community water supplies. $5^{\text {th }}$ ed., Revisão de Raymond D. Letterman. EUA: 1999

AWWA, APHA, WEF, Standard Methods for the Examination of Water and Wastewater. $20^{\text {th }}$ edition, Washington, 1998.

BAKER, RICHARD W. Membrane Technology and Applications. 2 ed. England: John Willey \& Sons, 2004.

BERSTAD, D.A. et al. Accurate measurements of the viscosity of water in the temperature range $19.5-25.5^{\circ} \mathrm{C}$. Physica A: Statistical and Theoretical Physics, Netherlands, ed. 151, p. 246-280, 1988.

BLANKERT, B.; BETLEM, B.H.L.; ROFFEL, B. Dynamic optimization of a dead end filtration trajectory: Blocking filtration laws. Journal of Membrane Science, ASCE, Netherlands, ed. 285, p. 90-95, 2006.

BLANKERT, B.; KATTENBELT, C.; BETLEM, B. Dynamic optimization of a dead end filtration trajectory: Non-ideal cake filtration. Journal of Membrane Science, Netherlands, ed. 290, p. 114-124, 2007.

BOERLAGE S.F.et al. The modified fouling index using ultrafiltration membranes (MFI-UF): characterisation, filtration mechanisms and proposed reference membrane Journal of Membrane Science, Netherlands, ed. 197, p. 1-22, 2002.

BOERLAGE S.F.et al. Development of the MFI-UF in constant flux filtration Desalination, Netherlands, ed. 161, p. 103-113, 2004.

CASTAING, J.B et al. Investigating submerged ultrafiltration (UF) and microfiltration (MF) membranes for seawater pre-treatment dedicated to total removal of undesired micro-algae. Desalination, Netherlands, ed. 253, p.71-77, 2009.

CHERYAN, MUNIR. Ultrafiltration and Microfiltration Handbook. $2^{\circ}$ ed. USA: CRC Press, 1998. 
DARAMOLA, M.O; KEESMAN, K.J.. Modelling and Economic Analysis of Ultrafiltration Units: Case Study of a Full-Scale UF Plant. European Journal of Scientific Research, Vol 20, n³, o 544-557, 2008.

DESSOUKY, H.T; ETTOUNEY, H.M. Fundamentals of Salt Water Desalination. Netherlands, Elsevier, 2002

DOW Water Solutions. FILMTEC Reverse Osmosis Membranes Technical Manual, 2004 (609-00071-0309).

DOW Water Solutions. Ultrafiltration Product Manual. Version 1. Midland: 2009 (795-00022-0309).

EPA, Environmental Protection Agency. Low pressure membrane filtration for pathogen removal. Cincinnati: 2001 (EPA 815-C-01-001).

GUADIX, A. et al. Optimal design and operation of continuous ultrafiltration plants. Journal of Membrane Science, Netherlands, ed. 235, p. 131-138, 2004.

HERMIA, J. Constant pressure blocking filtration laws - application to powerl tonion fluids. Transactions of the Institution of Chemical Engineers. [s.I.]: 1982, p. 183-187.

HOWE, K.J.. et al. Effect of membrane configuration on bench-scale MF and UF fouling experiments. Water Research, Netherlands, ed. 41, p.3842-3849, 2007.

HYDRANAUTICS, Nitto Denko. Backwash Optimization for HYDRAcap Systems by Qualitative Analysis. Hydranautics Membranes Technical Service Bulletin. Oceanside, EUA: 2006 (TSB135.02).

HYFLUX, Cingapura, KRISTAL K600ET Design and Operation Manual. Version 1.1, 2010.

IUPAC, Reino Unido. Terminology for membranes and membrane processes. International Union of Pure \& Applied Chemistry, Vol. 68, No. 7, p. 1479-1489, 1996

JUDD, SIMON; JEFFERSON, BRUCE. Membranes for Industrial Wastewater Recovery and Reuse. $1^{\circ}$ ed. United Kingdom: Elsevier, 2003. 
JUDD, SIMON; JUDD, CLAIRE. The MBR Book. $2^{\circ}$ ed. United Kingdom: Elsevier, 2011.

KATSOUFIDOU, K.S. et al. UF membrane fouling by mixtures of humic acids and sodium alginate: Fouling mechanisms and reversibility. Desalination, Netherlands, ed. 264, p.220-227, 2010.

LAUTENSCHLAGER, S.R. Otimização do processo de Ultrafiltração no tratamento avançado de efluentes e águas superficiais, 2006. 226 p. Tese (Doutorado). Escola Politécnica da Universidade de São Paulo, 2006.

MENDRET, J. et al. In situ dynamic characterization of fouling under different pressure conditions during dead-end filtration: Compressibility properties of particle cakes. Journal of Membrane Science, Netherlands, ed. 333, p.20-29, 2009.

METCALF \& EDDY. Wastewater Engineering: Treatment and reuse. $4^{\text {th }}$ ed. Revisão de George Tchobanoglous, Franklin Burton e David Stensel. New York: Mc Graw-Hill, 2003.

MIERZWA, J. C. Desafios para o tratamento de água de abastecimento e o potencial de aplicação do processo de ultrafiltração. 2009. Tese (Livre Docência) - Escola Politécnica, Universidade de São Paulo, São Paulo: 2009.

MIERZWA, J.C; et al. Tratamento de água para abastecimento público por ultrafiltração: avaliação comparativa através dos custos diretos de implantação e operação com os sistemas convencional e convencional com carvão ativado.

Engenharia Sanitária e Ambiental, Brasil, Vol. 13, n¹, 2008.

MILLIPORE. História da empresa. Disponível em:

<http://www.millipore.com/company/cp3/millipore_history>. Acesso em 11 nov/2010

MWH. Water treatment principals and design. $2^{\text {nd }}$ ed. Revisão de John Crittenden [et al.]. New Jersey: John Wiley \& Sons, Inc., 2004.

NIST Handbook $n^{\circ}$ 135, Fuller, S.K.; Petersen, S.R. Life-Cycle Costing Manual for the Federal Energy Management Program, Washington: US Governament Printing Office, 1996

NORIT Co., Holanda, The XIGATM Concept and Operation Manual Técnico. [s.I.]: 2007 (CAPF-XIGA-0143). 
OWEN, G.; BANDI, M., HOWELL, J.A.; CHURCHOUSE, S.J., Economic assessment of membrane processes for water and waste water treatment. Journal of Membrane Science, Netherlands, ed. 102, p. 77-91, 1995.

PANNEL, D. J.; Sensitivity analysis: strategies, methods, concepts, examples. http://cyllene.uwa.edu.au/ dpannell/dpap971f.htm, 1997

PEARCE, G. K. UF/MF pre-treatment to RO in seawater and wastewater reuse applications: a comparison of energy costs. Desalination, Netherlands, ed. 222, p. 66-73, 2007.

PICKERING, K.; WIESNER, M. Cost model for low-pressure membrane filtration. National Science Foundation Journal (ASCE), Texas, p. 772-797, 1992.

RENKIN, E. M. Filtration, diffusion, and molecular sieving through porous cellulose membranes. Journal of General Physiology. 38:1, 1955

RUNDA, China, Ultrafiltration Operation Manual; Zhejiang Runda Environment Protetion Tech Co.,Ltd, 2008

SCHIPPERS, J.C.; VERDOUWS. The Modified Fouling Index, a method of determining the fouling characteristics of water. Desalination, Netherlands, ed. 32, p.137-148, 1980.

SCHNEIDER, R. P.; TSUTIYA, M. T. Membranas filtrantes para o tratamento de água, esgoto e água de reuso, Brasil: Associação Brasileira de Engenharia Sanitária e Ambiental, 2001.

SUTZKOVER-GUTMAN. Humic substances fouling in ultrafiltration processes. Desalination, Netherlands. ed. 261, p.218-231, 2010.

TORAY Industries, Inc., Japão Toray Membrane Module Instructions Manual Model: Pressured Type PVDF Hollow Fiber Membrane Module "HFU Series": 2008 (BJJHJEBG).

WANG, F.; TARABARA, V. V. Pore blocking mechanisms during early stages of membrane fouling by colloids. Journal of Colloid and Interface Science, Netherlands, ed. 328, p.464-469, 2008. 
YUN YE. et al. Effects of operating conditions on submerged hollow fibre membrane systems used as pre-treatment for seawater reverse osmosis. Journal of Membrane Science, Netherlands, ed. 365, p.78-88, 2010.

ZONDERVAN, E. et al. Modeling and optimization of a sequence of chemical cleaning cycles in dead-end ultrafiltration. Journal of Membrane Science, Netherlands, ed. 308, p. 207-217, 2007.

ZONDERVAN, E.; ROFFEL, B. Modeling and optimization of membrane lifetime in dead-end ultra filtration. Journal of Membrane Science, Netherlands, ed. 322, p. 46-51, 2008. 